\title{
ANÁLISE DA ESTRUTURA E DINÂMICA DE UMA COMUNIDADE DE ESPÉCIES ARBÓREAS EM UM FRAGMENTO DE FLORESTA RIBEIRINHA, IPEÚNA, SP
}

\author{
DANIELA FESSEL BERTANI \\ Bióloga
}

Orientador: PROF. DR. JOÃO LUIZ FERREIRA BATISTA

Dissertação apresentada à Escola Superior de Agricultura "Luiz de Queiroz", Universidade de São Paulo, para obtenção do título de Mestre em Ciências, Área de Concentração: Ciências Florestais.

PIRACICABA

Estado de São Paulo - Brasil

Fevereiro - 2000 


\title{
Dados Internacionais de Catalogação na Publicação (CIP) DIVISÃO DE BIBLIOTECA E DOCUMENTAÇÃO - Campus "Luiz de Queiroz"/USP
}

\author{
Bertani, Daniela Fessel \\ Análise da estrutura e dinâmica de uma comunidade de espécies arbóreas em um \\ fragmento de floresta ribeirinha, Ipeúna, SP / Daniela Fessel Bertani. - - Piracicaba, \\ 2000. \\ 70 p. : il.
}

Dissertaçāo (mestrado) - Escola Superior de Agricultura Luiz de Queiroz, 2000. Bibliografia.

1. Composiçāo floristica 2. Dinâmica. 3.Distribuiçāo espacial 4. Fragmento florestal 5. Mata ciliar I. Título

CDD 634.9224

"Permitida a cópia total ou parcial deste documento, desde que citada a fonte - $\mathrm{O}$ autor" 
Com muita saudade, dedico este trabalho ao meu pai

À minha mãe, por tudo 
"Como eu preciso de campo,

De folhas, brisas, vertentes, Encosto-me a ti, que és árvore, De onde vão caindo flores Sobre os meus olhos dormentes"

Cecilia Meireles 


\section{SUMÁRIO}

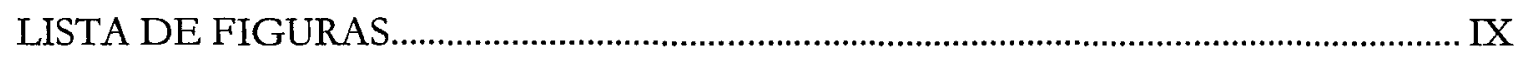

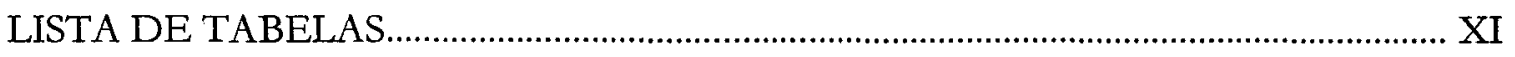

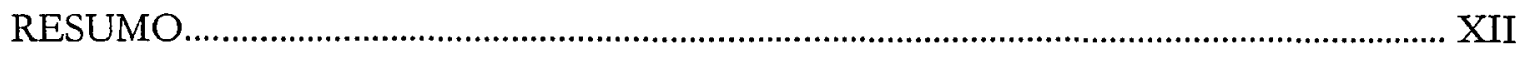

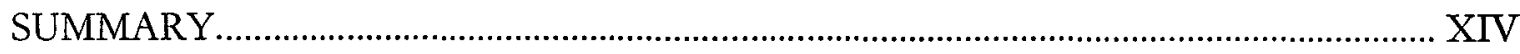

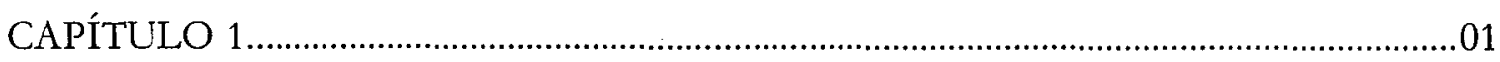

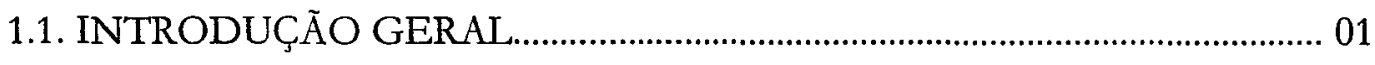

1.2. REFERÊNCIAS BIBLIOGRÁFICAS.............................................................. 03

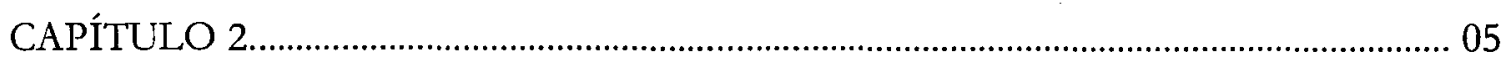

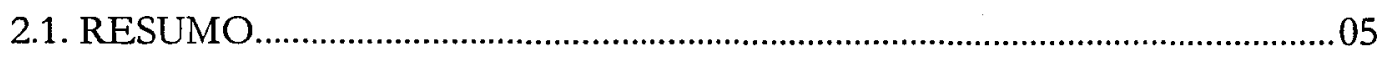

2.2. INTRODUÇÃO

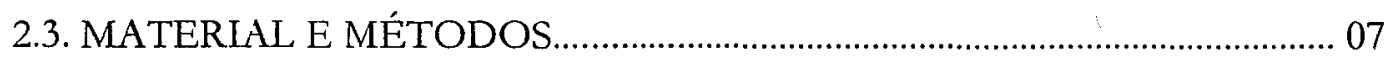

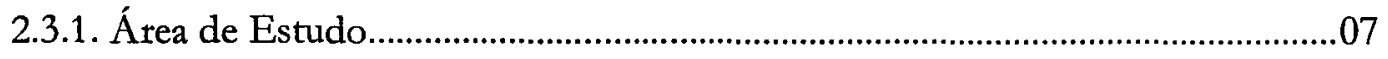

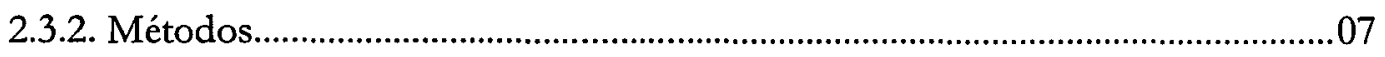

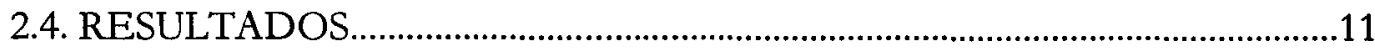

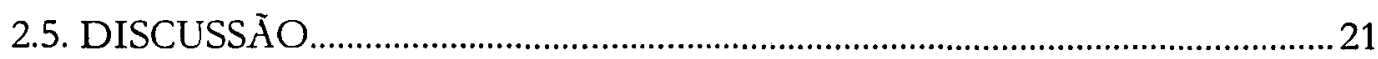

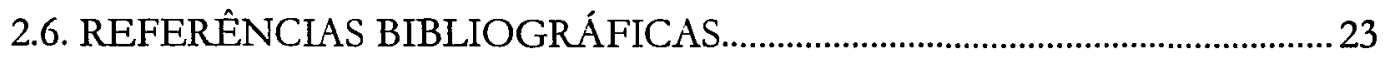

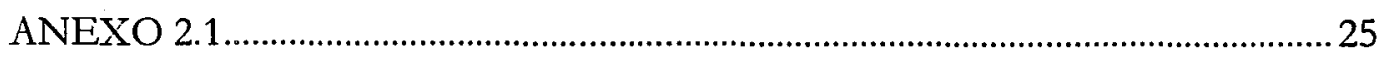

ANEXO 2.2 
CAPÍTULO 3

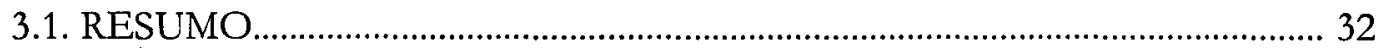

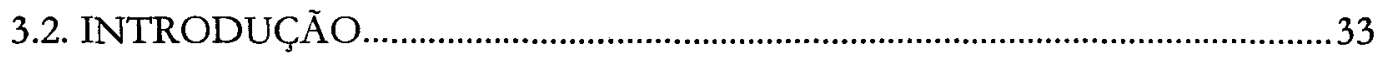

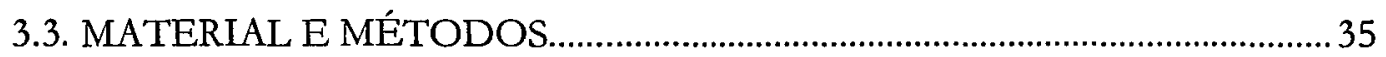

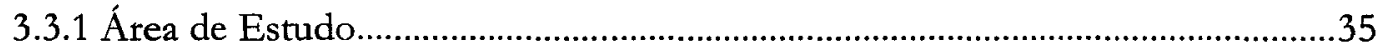

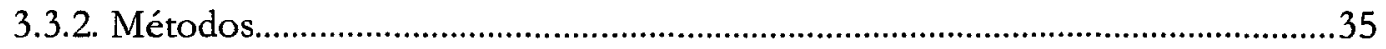

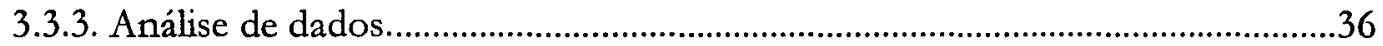

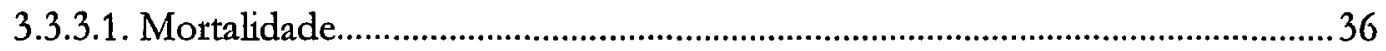

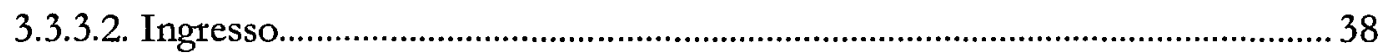

3.3.3.3. Crescimento .................................................................................................

3.3.3.4. Distribuição Espacial..........................................................................................39

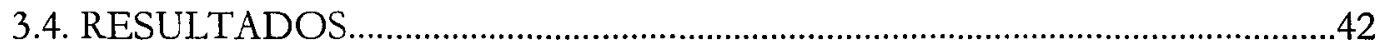

3.4.1. Mortalidade

3.4.2. Ingresso

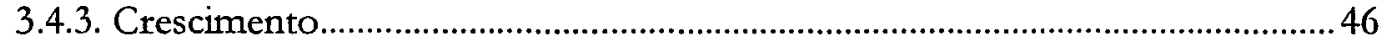

3.4.4. Distribuição Espacial......................................................................................

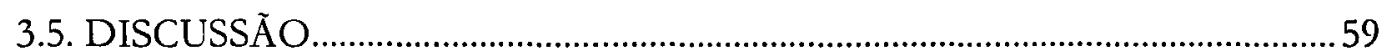

3.5.1. Mortalidade

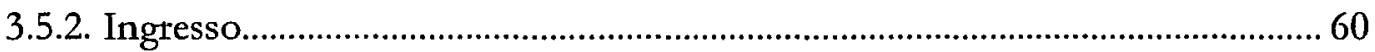

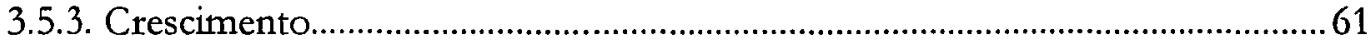

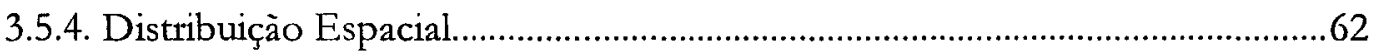

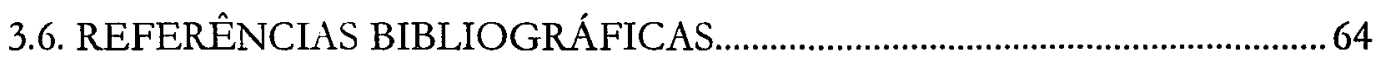

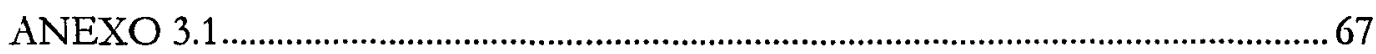

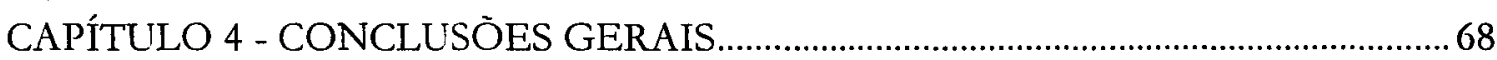




\section{LISTA DE FIGURAS}

2.1 - Rio Passa Cinco

2.2 - Mapa topográfico e dos principais tipos de solo da área amostrada em um trecho de floresta ribeirinha do rio Passa Cinco Ipeúna,SP

2.3 - Dendrograma de classificação dos dados de vegetação, da floresta ribeirinha do Rio Passa Cinco, Ipeúna, SP, pelo método de Ward

2.4 - Representação gráfica dos resultados da análise de correspondência (CA) para os dados da vegetaçào amostrada na floresta ribeirinha do rio Passa Cinco, Ipeúna,SP.

2.5 - Densidade relativa por espécies encontradas nos levantamentos feitos em 1989 e 1998, na floresta ribeirinha do Rio Passa Cinco, Ipeúna,SP.

2.6 - Dominância relativa por espécies encontradas nos levantamentos feitos em 1989 e 1998, na floresta ribeirinha do Rio Passa Cinco, Ipeúna, SP.

2.7 - Porcentagem de IVI (indice de valor de importância) por espécie encontrada em 1989 e 1998, na floresta ribeirinha do Rio Passa Cinco, Ipeúna, SP.

2.8 - Porcentagem do número de indivíduos por família botânica encontrada em 1989 e 1998, na floresta ribeirinha do Rio Passa Cinco, Ipeúna, SP

2.9 - Porcentagem do número de espécies por familia botânica encontrada em 1989 e 1998, na floresta ribeirinha do Rio Passa Cinco, Ipeúna, SP

2.10 - Densidade por classes de diâmetro em cada vegetação sobre os três diferentes tipos de solo.

3.1 - Mapa topográfico e dos principais tipos de solo da área amostrada em um trecho de floresta ribeirinha do tio Passa Cinco Ipeúna, SP

3.2 - Mapa da distribuição espacial dos individuos amostrados por Rodrigues (1992) em 1989, representando a área utilizada para o estudo da distribuição espacial, na floresta ribeirinha do Rio Passa Cinco, Ipeúna, SP

3.3 - Distribuição das taxas de mortalidade por classes de diâmetró na comunidade e nas três sub-áreas. 
3.5 - Distribuição das taxas de crescimento médio por classes de diâmetro na comunidade e nos três sub-grupos vegetacionais.

3.6 - Representação gráfica dos resultados da função K-Ripley para análise do padrão espacial, para os individuos arbustivo-arbóreos amostrados em 1989 e 1998.

3.7 - Mapa da distribuição da árvores que morreram no período de 1989 à 1998, na área amostrada para análise espacial da floresta ribeirinha do Rio Passa Cinco, Ipeúna.

3.8 - Representação gráfica dos resultados das análises do padrão espacial das árvores que morreram entre 1989 e 1998, através da função K-Ripley.

3.9 - Mapa da distribuição da árvores ingressantes no período de 1989 à 1998, na área amostrada para análise espacial da floresta ribeirinha do rio Passa Cinco, Ipeúna... 53

3.10 - Representação gráfica dos resultados das análises do padrão espacial das árvores ingressantes entre 1989 e 1998, através da função K-Ripley.

3.11 - Representação gráfica dos resultados das análises do padrão espacial das árvores em 1989 e 1998, através da função K-Ripley, para os três sub-grupos vegetacionais 


\section{LISTA DE TABELAS}

2.1- Comparação dos parâmetros fitossociológicos da comunidade de árvores com DAP $\geq 5$ cm encontradas nos levantamentos feitos em 1989 e 1998, na floresta ribeirinha do Rio Passa Cinco, Ipeúna, SP.

3.1 - Taxas anuais de mortalidade e meia vida calculadas para a comunidade como um todo e para cada sub-grupo vegetacional identificado no mosaico ribeirinho... 42

3.2 - Taxa de mortalidade (me) por classes de diâmetro (d) para a comunidade como um todo e para cada sub-grupo vegetacional identificado no mosaico ribeirinho..... 43

3.3 - Taxas anuais de ingresso para a comunidade

e para os três sub-grupos vegetacionais do mosaico tibeirinho...................................... 45

3.4 - Taxa anual de crescimento para a comunidade

e para os três sub-grupos vegetacionais do mosaico ribeirinho.

3.5 - Taxas de crescimento médio ( $\mathrm{cm} /$ ano) por classes de diâmetro para

a comunidade e para os três sub-grupos vegetacionais do mosaico ribeirinho. 48 


\title{
ANÁLISE DA ESTRUTURA E DINÂMICA DE UMA COMUNIDADE DE ESPÉCIES ARBÓREAS EM UM FRAGMENTO DE FLORESTA RIBEIRINHA, IPEÚNA, SP
}

\author{
Autora: DANIELA FESSEL BERTANI \\ Orientador: Prof. Dr. JOÃO LUIZ FERREIRA BATISTA
}

\section{RESUMO}

No presente estudo foi feita a análise temporal da heterogeneidade florística e estrutural em um trecho de floresta ribeirinha. $O$ trecho é caracterizado por um mosaico florestal constituído por três grupos vegetacionais correlacionados com as características edáficas da área. Em 1989 e1998 foram medidos e mapeados todos os indivíduos com DAP $\geq 5 \mathrm{~cm}$, em 157 parcelas de $5 \times 10 \mathrm{~m}$ ao longo do Rio Passa Cinco, Ipeúna, SP, totalizando uma área de 0,785 ha em um trecho da floresta ribeirinha. Foram analisadas as alterações florísticas e fitossociológicas, além dos padrões de dinâmica para a comunidade como um todo e para cada grupo vegetacional.

Poucas alterações ocorreram na comunidade em 9 anos, o que indica estabilidade para a vegetação no periodo estudado. As diferenças florísticas e estruturais entre os grupos vegetacionais se mantiveram com o tempo.

O grupo vegetacional localizado imediatamente paralelo ao curso d'água apresentou características peculiares, como maior diversidade, densidade, e distribuição espacial agrupada de seus indivíduos. Foi a área com maiores taxas de crescimento e mortalidade. 
Estas características devem estar estritamente relacionadas com a dinâmica das cheias do rio, o que condiciona características ambientais diferenciadas no tempo e no espaço.

Em relação aos outros grupos vegetacionais encontrados, na área fora da interferência do curso dá água, percebe-se que tanto a topografia como as características edáficas são fatores determinantes do padrão de distribuição espacial, da estrutura e da dinâmica de seus indivíduos.

O rio, considerado como um fator de perturbação nas faixas ribeirinhas, deve ser entendido como um elemento de manutenção da diversidade e heterogeneidade nestas áreas. 


\title{
STRUCTURE AND DYNAMICS ANALYSIS OF A TREE COMMUNITY IN A RIVERINE FOREST FRAGMENT, IPEÚNA, SP
}

\author{
Author: DANIELA FESSEL BERTANI \\ Adviser: Prof. Dr. JOÃO LUIZ FERREIRA BATISTA
}

\section{SUMMARY}

The floristic and structural heterogeneity change of a stream-side forest along the Passa Cinco River (Ipeuna, SP) is analyzed over a 9-year time period. Three forest types were identified in the forest and were related to differences in soil conditions. All trees with DBH greater or equal to $5 \mathrm{~cm}$ were measured and mapped in two occasion (1989 and 1998) in 157 contiguous plots of $5 \times 10 \mathrm{~m}(0.785 \mathrm{ha})$.

The plant community was very stable over the 9-year period. Little change was observed on the forest as a hole and the floristic and structural differences among the forest types remained strong.

The forest type immediately along the river showed higher species diversity and tree density, while the spatial pattern of individual trees were clustered. This forest had the larger growth and mortality rates. These characteristics may be related to the annual river dynamics of overflow that creates particular environmental conditions in this forest type.

The other two forest types, that are away from the river overflow area, had their floristic and structural characteristics related to topography and soil fertility, which affect the spatial pattern and the dynamics of individual trees. 
The river dynamics, that is usually considered a disturbing factor of stream-side forests, should be understood as an element for the maintenance of forest diversity and heterogeneity. 


\section{CAPÍtULLO 1}

\subsection{INTRODUÇÃO GERAL}

A problemática gerada em torno da conservação de espécies e ecossistemas, principalmente em regiões tropicais, tem sido enfatizada nas últimas décadas. $O$ conhecimento da distribuiçào geográfica da fauna e flora, assim como suas propriedades biológicas e vulnerabilidade às mudanças ambientais, ainda é batante limitado (Lovejoy, 1997; Wilson, 1997).

A alta diversidade de espécies de plantas em florestas tropicais tem sido relativamente bem documentada (e.g. Gentry, 1990; Morellato, 1992; Wilson \& Sandoval 1996; Rodrigues, no prelo; Metzer et al., 1997). Porém, os processos que contribuem para a origem e manutenção desta alta diversidade, dentro e entre áreas, ainda não são totalmente compreendidos. Várias teorias tem sido propostas para explicar a alta diversidade em florestas tropicais, como a teoria da estabilidade climática, da heterogeneidade espacial, da competição, de perturbaçòes severas ou frequentes (Pianka, 1994; Crawley, 1997), diferenças na fenologia de floração das espécies, etc. (Gentry, 1974). A hipótese da dinâmica de clareiras é um exemplo de perturbação frequente que pode contribuir para o aumento de diversidade. Os processos de abertura de clareiras, que podem variar quanto à frequência e tamanho, são perturbações naturais que permitem a coexistência de diferentes grupos sucessionais de espécies, em diferentes fases do ciclo de crescimento (Whitmore, 1978). Outro modelo seria a alta mortalidade de sementes e plântulas próximas à planta mãe, em função da maior herbivoria e incidência de patógenos dependentes da densidade destas, resultando em populações hiperdispersas (Janzen, 1970; Connel, 1971). Estes processos 
muitas vezes estão relacionados, em pequena ou larga escala, à heterogeneidade espacial e temporal (Greig-Smith, 1979; Mazer, 1996).

As florestas ribeirinhas são caracterizadas pela grande heterogeneidade ambiental, que contribui para a existência de um mosaico vegetacional com diferenças florísticas pronunciadas e elevada diversidade (Rodrigues, no prelo). Os componentes desta heterogeneidade são a frequência ou natureza de distúrbios físicos, a frequência e duração de inundações, condições ambientais específicas, como topografia, qualidade da luz, qualidade do solo e a variação da camada de serrapilheira, entre outros. Estes componentes podem gerar regimes que resultam na seletividade de espécies ou na evolução de taxons à uma especialização à determinado habitat (Mazer, 1996).

A presença do rio é um fator gerador de uma dinâmica própria, e segundo modelo proposto por Rodrigues (1992), a faixa de vegetação sob influência direta deste tem como características físicas o solo ser um aluvião recente, ocorrer erosão laminar intensa, deposição de areia fina, apresentar camada de serapilheira e banco de sementes temporários e radiação solar sazonal na superfície do solo (Rodrigues 1992). Nestas florestas ocorrem também áreas que não sofrem a interferência direta do curso d'água, que apresentam variações quanto às origens do solo, erosão laminar pouco intensa, camada de serrapilheira e banco de sementes permanentes, e eventual radiação solar na superfície do solo (Rodrigues, 1992).

O objetivo do presente estudo foi caracterizar o mosaico vegetacional presente em uma floresta ribeirinha, quanto à estrutura e dinâmica, relacionando estas características com a heterogeneidade ambiental própria desta formação.

Este trabalho foi dividido em duas partes. A primeira, Capítulo 2, apresenta as diferenças florísticas e estruturais da floresta ribeirinha do Rio Passa Cinco em diferentes substratos, e as alterações na comunidade nove anos após o estudo realizado por Rodrigues (1992). A segunda parte, Capítulo 3, apresenta dados de crescimento, mortalidade, ingresso e distribuiçào espacial para a comunidade como um todo e para os diferentes grupos vegetacionais encontrados na área. 


\subsection{REFERÊNCIAS BIBLIOGRÁFICAS}

CONNEL, J.H. Diversity in tropical rain forests and coral reefs. Science, v.199, p.1302$1310,1978$.

CRAWLEY, M.J. Plant Ecology. Oxford: Blackwell Science, 1997.

GENTRY, A.H. Flowering phenology and diversity in a tropical Bignoniaceae. Biotropica, v.6, p.64-68, 1974.

GENTRY, A.H. Four Neotropical Rainforests. New Haven: Yale University Press, 1990.

GREIG-SMITH, P. Pattern in vegetation. Journal of Ecology, v.67, p.755-779, 1979.

JANZEN, D.H. Herbivores and the number of tree species in the tropical forests. American Naturalist, v.104, p.501-528, 1970.

LOVEJOY, T.E. Considerações diversas. In: WILSON, E.O. (Ed.). Biodiversidade. Rio de Janeiro: Editora Nova Fronteira, 1997. p.537-545.

MAZER, S.J. Floristic composition, soil quality, litter accumulation, and decomposition in terra firme and floodplain habitats near Pakitza, Peru. In: WILSON, D.E. \& SANDOVAL, A. (Ed.). Manu/ The biodiversity of southeastern Peru. Washington, D.C.: Smithsonian Institution, 1996. p.89-125.

METZER, J.P., Bernacci, L.C. \& Goldenberg, R. Pattern of tree species diversity in riparian forest fragments of different widths (SE Brazil). Plant Ecology, v.133, p.135-152, 1997.

MORELLATO, L.P.C. História natural da Serra do Japi: ecologia e preservação de uma área florestal no sudeste do Brasil. Campinas: Editora da Unicamp/FAPESP, 1992.

PIANKA, E.R. Evolucionary ecology. New York: HarperCollins College Publishers, 1994.

RODRIGUES, R.R. Matas Ciliares: uma abordagem multidiciplinar. Piracicaba: FAPESP, no prelo.

RODRIGUES, R.R.. Análise de um remanescente de vegetação natural as margens do Rio Passa Cinco, Ipeúna. SP. Campinas, 1992. Tese de Doutorado. Universidade Estadual de Campinas.

WHITMORE, T.C. Gaps in the forest canopy. In: TOMLINSON, P.B. \& ZIMMERMANN, M.H. (Ed.). Tropical trees as a living systems. Cambridge: Cambridge Univ. Press, 1978. p. 639-655. 
WILSON, D.E. \& SANDOVAL, A. Manu/ The biodiversity of southeastern Peru. Washington D.C.: Smithsonian Institution, 1996.

WILSON, E.O. Biodiversidade. Rio de Janeiro: Editora Nova Fronteira, 1997. 


\section{CAPÍTULO 2}

\section{ANÁLISE TEMPORAL DA HETEROGENEIDADE FLORÍSTICA E ESTRUTURAL EM UMA FLORESTA RIBEIRINHA}

\subsection{RESUMO}

Neste trabalho foi constatada a presença de um mosaico vegetacional em um trecho de floresta ribeirinha, e discutidos os possíveis fatores que definem este mosaico. Foram também verificadas as alterações florísticas e fitossociológicas na área em nove anos. Foram amostradas 157 parcelas contínuas de $5 \times 10 \mathrm{~m}$, em uma área de 0,785 ha ao longo do Rio Passa Cinco, Ipeúna, SP. Foram feitas medidas de diâmetro e mapeados todos os indivíduos com DAP maior ou igual a $5 \mathrm{~cm}$, em 1989 e 1998. As análises multivariadas da vegetação indicaram a presença de três grupos vegetacionais relacionados aos três tipos de solo identificados na área. As análises quantitativas da estrutura da comunidade demostraram diferenças em cada um destes grupos, que se mantiveram ao longo do tempo, indicando associações florísticas próprias correlacionadas a cada tipo de solo. O grupo vegetacional sobre solo Aluvial, na faixa imediatamente paralela ao curso d'água, apresentou diferenças florísticas mais pronunciadas, e maior diversidade de espécies, área basal e densidade de indivíduos. Em nove anos poucas alterações na estrutura fitossociológica foram observadas 
para as espécies de maior valor de importância na área, com um aumento de 2,01\% do número total de indivíduos e $2,80 \%$ na área basal total.

\subsection{INTRODUÇÃO}

As florestas ribeirinhas são caracterizadas pela grande heterogeneidade ambiental, gerada por fatores físicos e bióticos. Como fatores físicos podemos citar as variações topográficas, edáficas e a influência do regime de cheias do rio, resultando na deposição e retirada de sedimentos e a retirada da camada de serapilheira (Rodrigues, 1992; Mazer, 1996; Oliveira Filho et al., 1997). Os fatores bióticos seriam a influência das áreas florestais adjacentes e a função de corredor de vegetação destas áreas, que poderia proporcionar um trânsito maior de polinizadores e dispersores, além de uma maior possibilidade de fluxo gênico com áreas mais remotas.

Esta complexidade de fatores resulta em um mosaico vegetacional, com grande heterogeneidade florística e alta diversidade (Rodrigues, no prelo). Alguns estudos tem demonstrado que o mosaico vegetacional de fragmentos florestais tem grande correlação com as características físico-químicas do solo e com o gradiente topográfico (Lescue \& Boulet, 1985; Rodrigues, 1992; Oliveira Filho et al., 1994; Mazer, 1996; Sabatier, 1997). Porém poucos estudos identificam as características vegetacionais nestes diferentes sítios ou unidades do mosaico, e abordam as possíveis alterações temporais (Mazer, 1996).

A proposta deste estudo foi identificar o mosaico vegetacional encontrado num trecho de floresta ribeirinha do Rio Passa Cinco, discutindo as possíveis características do ambiente definidoras da heterogeneidade espacial da vegetação, e verificar as alterações temporais (florísticas e fitossociológicas) da composição deste mosaico vegetacional. 


\subsection{MATERIAL E MÉTODOS}

\subsection{1 Área de Estudo}

Este estudo foi realizado em um fragmento de floresta ribeirinha do Rio Passa Cinco, localizado no município de Ipeúna ( $22^{\circ} 26^{\prime} 08^{\prime \prime}$ S e $47^{\circ} 43^{\prime} 05^{\prime \prime}$ O), Estado de São Paulo, que faz parte da APA de Corumbataí. Apresentando uma área de aproximadamente 60 ha, tem como atividade principal do entorno a cultura de cana de açúcar. Apesar da bacia do Rio Passa Cinco se caracterizar como altamente perturbada, tendo como principal causa práticas agrícolas inadequadas, restaram alguns fragmentos florestais remanescentes, como a área de estudo, que foi mantida em bom estado de conservação por estar confinada em um fundo de vale. Ainda assim, podem ser observados alguns sinais de degradação neste trecho de floresta ribeirinha, principalmente nas bordas, pela extração seletiva de madeira e pelo fogo originado da cultura de cana-de-açúcar. Os limites deste fragmento florestal estão definidos por encostas íngremes, com declividade superior a $30^{\circ}$. Nesta região, o rio tem cerca de $12 \mathrm{~m}$ de largura média, o fundo é irregular com grandes depósitos de material oriundo de assoreamento à montante, e alcança profundidade média de 1,5 m em época de chuvas (Figura 2.1).

O clima da região de Ipeúna caracteriza-se como quente úmido, com inverno seco (maio a setembro) e verão chuvoso (outubro a fevereiro) (Rodrigues, 1992).

\subsubsection{Métodos}

Este estudo foi feito em uma área de $7850 \mathrm{~m}^{2}$, em um trecho de floresta ribeirinha do Rio Passa Cinco. Foi demarcada uma parcela de $200 \mathrm{~m}$ ao longo do rio e $40 \mathrm{~m}$ perpendicular à este, subdividida em 157 parcelas menores, de $5 \times 10 \mathrm{~m}$ (Figura 2.2). $\mathrm{O}$ levantamento de solos indicou a existência de três tipos principais de solo neste trecho de floresta de aproximadamente 0,8 ha, sendo estes (Rodrigues 1992): solo Aluvial (AL), solo Podzólico Vermelho Amarelo (PV) e solo Areia Quartzosa Intermediário para Cambissolo, de textura fina/franco arenosa ( $\mathrm{AQ} / \mathrm{Cb}$ ), conforme Figura 2.2. A descrição destes solos e as características físico-químicas estão apresentadas em Rodrigues (1992). 


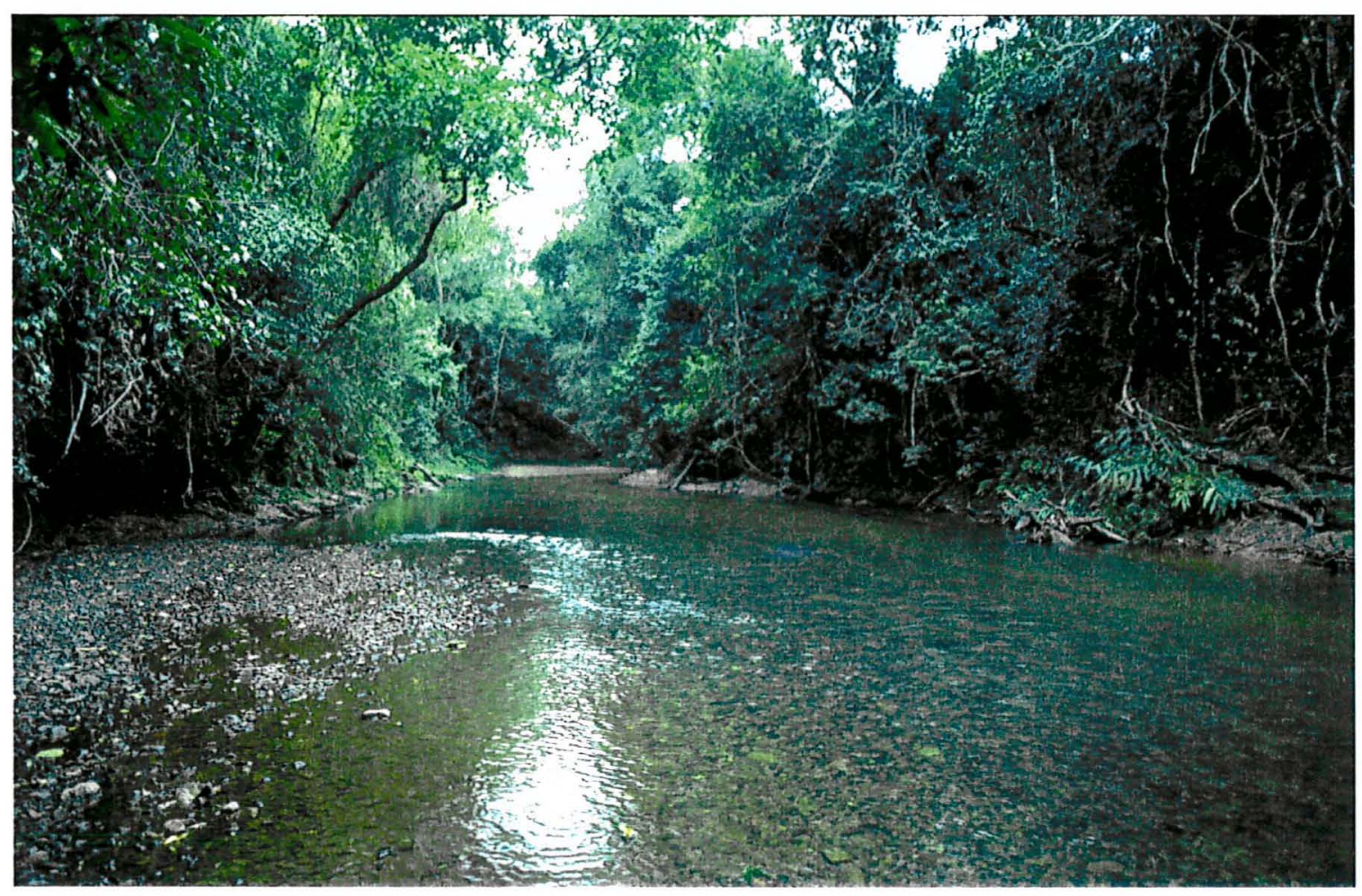

Figura 2.1 - Aspecto da vegetação às margens do Rio Passa Cinco. A área de estudo localiza-se na margem direita do rio. 


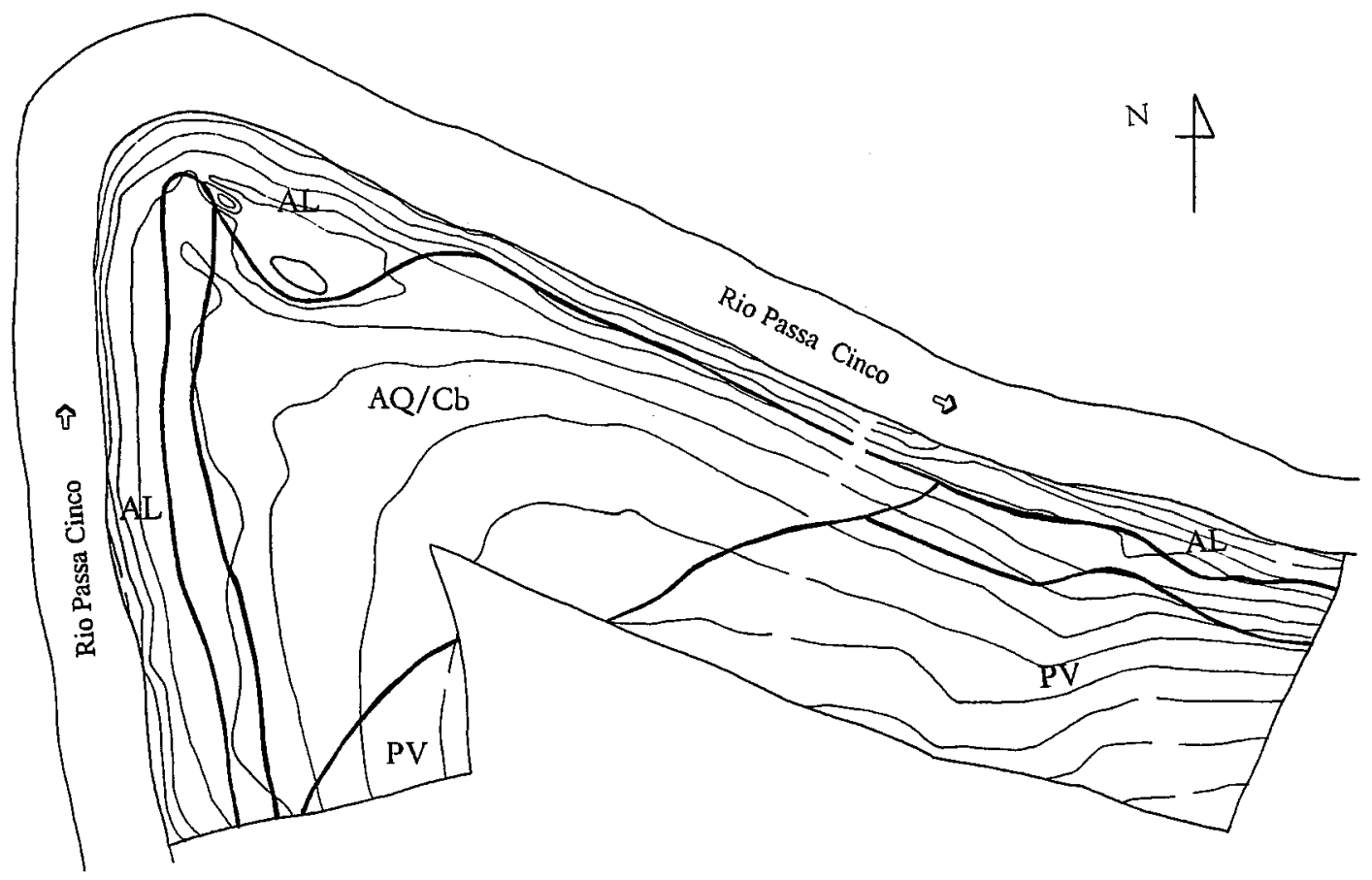

esc. aprox. : 1:1000

Figura 2.2 - Mapa topográfico e dos principais tipos de solo da área amostrada num trecho de floresta ribeirinha do rio Passa Cinco Ipeúna, SP. AQ/Cb - areia Quartzosa intermediário para cambissolo; $\mathrm{Al}$ - solo aluvial distrófico; $\mathrm{PV}$ - podzólico vermelho amarelo. 
Em 1989 foram amostrados e mapeados todos os indivíduos arbustivo-arbóreos com diâmetro à altura do peito (DAP) maior ou igual a $5 \mathrm{~cm}$, em cada sub-parcela $(5 \times 10 \mathrm{~m})$. Em 1998, foram repetidas as medições, e os indivíduos ingressantes, que atingiram DAP maior ou igual à $5 \mathrm{~cm}$, foram mapeados e tomadas suas medidas de diâmetro.

Todos os individuos amostrados foram numerados com plaquetas de alumínio galvanizado e coletados para posterior identificação.

O material coletado foi identificado através de observações de campo, com auxilio de especialistas, e quando possível por comparações com material do Herbário ESA (ESALQ/USP).

Os parâmetros fitossociológicos calculados para a vegetação da área de estudo foram os normalmente utilizados em trabalhos desta natureza (cf. Martins, 1993).

Para verificar a existência de um mosaico vegetacional na floresta ribeirinha, em função das características fisiográficas do ambiente, foram feitas análises multivariadas tendo como unidade amostral as sub-parcelas de $5 \times 10 \mathrm{~m}$. A análise de classificação foi feita pelo método de Ward (Gauch, 1982), no programa FITOPAC (Shepherd, 1988), e a ordenação foi feita pelo método de média recíproca (RA), ou análise de correspondência (CA), utilizando o programa Canoco (Hill, 1973 e 1974; Ter Braak, 1985 e 1988). Para estas análises foram consideradas as espécies que apresentaram mais de 5 individuos, para os dados do levantamento de 1989, segundo recomendação de Gauch (1982).

Para as comparações florísticas entre os três grupos vegetacionais identificados na análise multivariada foi utilizado o coeficiente de similaridade de Jaccard (Krebs, 1989). Foram utilizados os índices de Shannon ( $\left.\mathrm{H}^{\prime}\right)$ e equidade (J') como medida de diversidade de espécies (Krebs, 1989). 


\subsection{RESULTADOS}

Em 1989 foram amostrados 1395 indivíduos vivos com DAP maior ou igual a $5 \mathrm{~cm}$, distribuídos 'em 35 famílias, 73 gêneros e 105 espécies. O Anexo 2.1 lista os parâmetros fitossociológicos calculados para as espécies encontradas na floresta ribeirinha do Rio Passa Cinco, no levantamento feito em 1989, em ordem crescente de IVI. A densidade total foi de 1788,93 indivíduos/ha.

A Figura 2.3 apresenta um dendrograma da classificação dos dados de vegetação pelo método de Ward. De acordo com a figura, este método separou dois grandes grupos de parcelas, que apresentaram entre si valor alto de dissimilaridade $(745,40)$. O grupo A, foi constituído por parcelas da faixa sobre interferência direta do curso d'água, às margens do rio. O grupo $\mathrm{B}$ foi constituído por vários subgrupos com diferentes graus de dissimilaridade.

A Figura 2.4 apresenta o resultado da análise de correspondência (CA). O eixo 1 separou dois grupos principais de parcelas. À direita no diagrama, com maiores valores no eixo 1, estão ordenadas as espécies que foram mais abundantes nas parcelas imediatamente paralelas ao curso d'água. À esquerda no diagrama, com menores valores no eixo 1, foram agrupadas o restante das espécies. Estas espécies, mais abundantes em parcelas não ribeirinhas, foram agrupadas no eixo 2. Na porção inferior do diagrama estão ordenadas principalmente as espécies mais comuns das parcelas do canto sudeste, e algumas do canto sudoeste da área de amostragem. Ainda em relação ao eixo 2 , na parte superior do diagrama, com valores mais altos, foram agrupadas as espécies mais comuns das parcelas da porção central da área de estudo, e as restantes do canto sudoeste. Comparando estes dados com o mapa de solos da área (Figura 2.2), as parcelas imediatamente paralelas ao curso d'água estavam sobre o solo Aluvial (AL), enquanto as parcelas do canto sudeste estavam sobre o solo Podzólico Vermelho Amarelo (PV). As parcelas da porção central e canto sudoeste da área estavam sobre o solo transicional entre areia Quartzosa (AQ) e Cambissolo (Cb).

Os agrupamentos obtidos pelo método de ordenação foram muito parecidos com àqueles obtidos pelo método de classificaçào, reforçando a presença de três grupos vegetacionais: vegetação do canto sudeste; vegetação da beira do rio $(0-5 \mathrm{~m})$ e vegetação da 


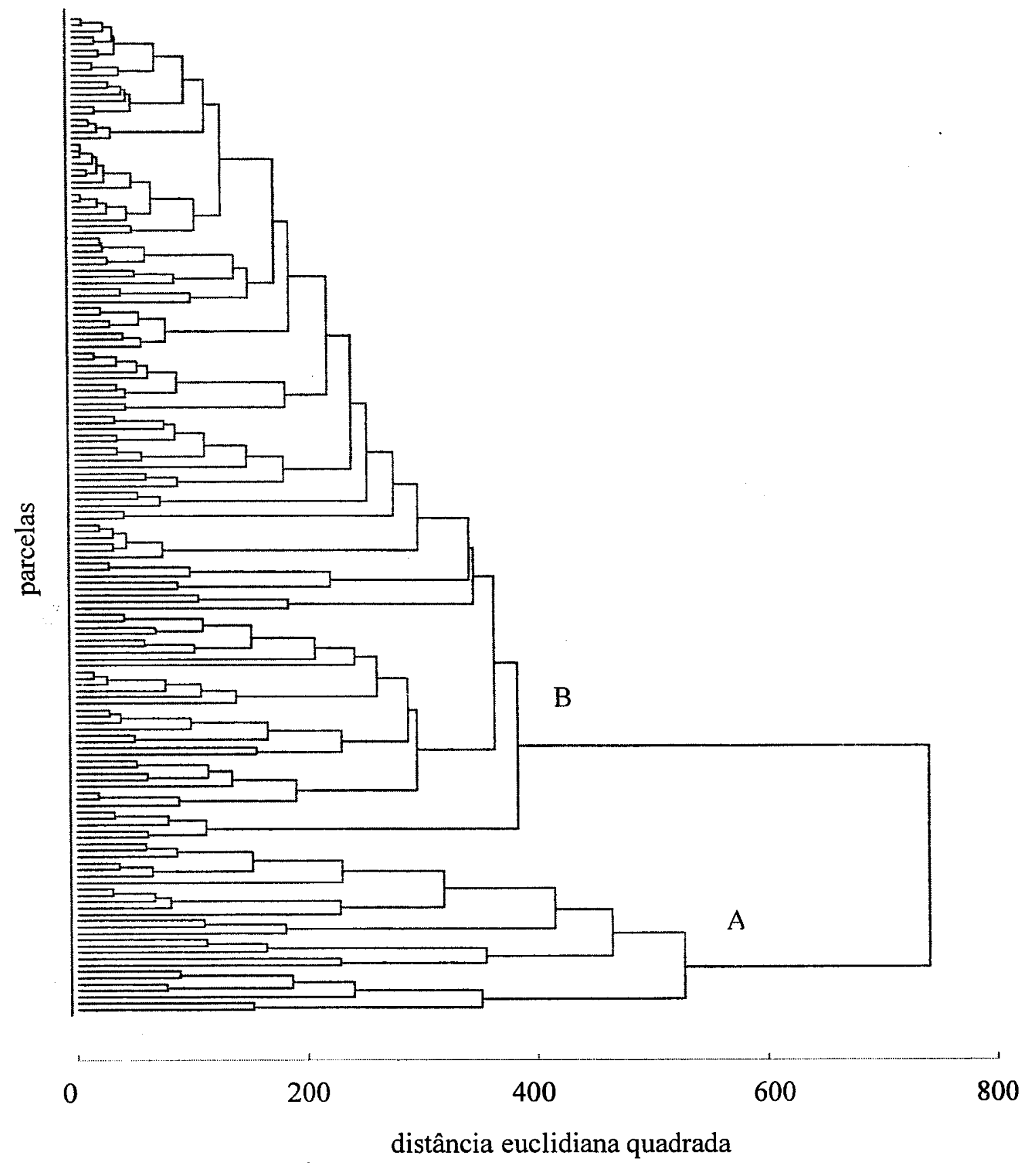

Figura 2.3 - Dendrograma de classificação dos dados de vegetação, da floresta ribeirinha do Rio Passa Cinco, Ipeúna, SP, pelo método de Ward. 


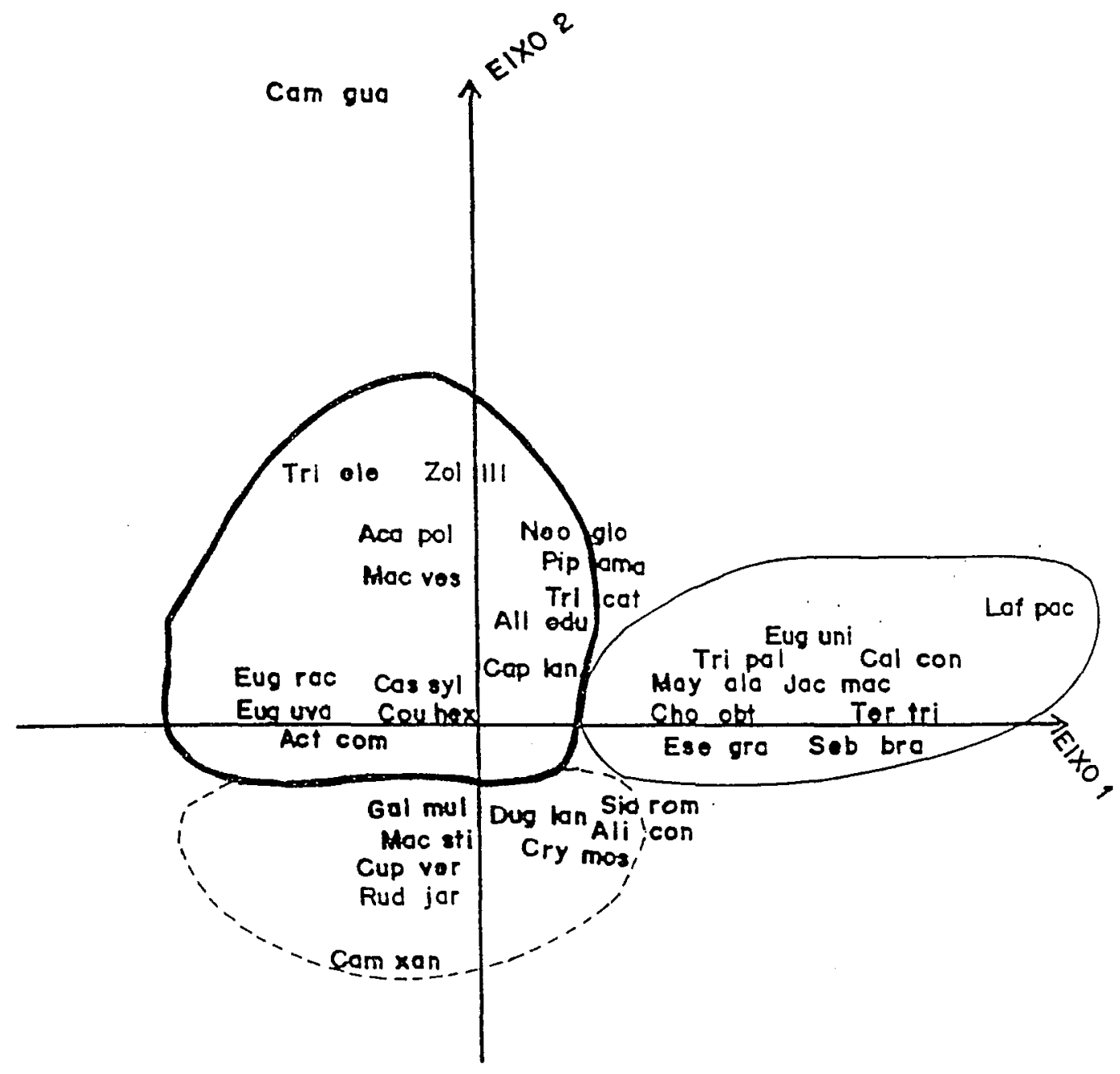

Figura 2.4 - Representação gráfica dos resultados da análise de correspondência (CA) para os dados da vegetação amostrada na floresta ribeirinha do rio Passa Cinco, Ipeúna, SP. 
porção central e do canto sudoeste da área de estudo.

O Anexo 2.2 apresenta a lista das espécies que ocorreram em cada um desses grupos vegetacionais, nos levantamentos de 1989 e 1998. Em relação à similaridade entre estas áreas, a vegetação sobre solo Aluvial se mostrou menos similar em relação às outras duas áreas. A vegetação sobre o solo Aluvial apresentou $47 \%$ de similaridade em relação à vegetação sobre o solo $\mathrm{AQ} / \mathrm{Cb}$ e $46 \%$ em relação à vegetação sobre o solo PV. Entre os grupos vegetacionais sobre os solos $\mathrm{AQ} / \mathrm{Cb}$ e $\mathrm{PV}$ os valores foram mais elevados (61\%). Porém, estes valores são relativamente altos, e o que provavelmente irá diferenciar as três sub-áreas será a análise quantitativa dos dados estruturais da comunidade, apresentados a seguir.

No levantamento feito em 1998, foram encontrados 1423 indivíduos vivos, distribuídos em 34 famílias, 74 gêneros e 107 espécies (Anexo 2.1). A densidade total foi de 1812,82 individuos/ha.

Após um período de nove anos, entre 1989 e 1998, pode-se observar um aumento de 2,01\% no número total de indivíduos e um aumento de 2,80\% na área basal por hectare (Tabela 2.1).

Em relação aos dados obtidos em 1989, no levantamento de 1998 houve um aumento da densidade relativa de Actinostemon klotzchii (figura 2.5), promovendo um aumento do número total de individuos na comunidade, já que as demais espécies não apresentaram grandes variaçōes para este parâmetro. Em alguns casos houve até uma diminuição da densidade relativa, como ocorreu com Callisthene minor e Matayba elaeagnoides entre outras.

Nota-se um aumento da dominância relativa, para as espécies Callisthene minor, Cariniana estrellensis, Diatenopteryx sorbifolia, Copaifera langsdorfii, Actinostemon klotzchii Centrolobium tomentosum e Syagrus romanzoffiana (Figura 2.6). Neste periodo, A. klotzchii passou de $10^{\circ}$ para $6^{\circ}$ posição na ordenação da dominância, em função do aumento do número de indivíduos nesta população. Para Matayba elaeagnoides, Luebea divaricata, Acacia polyphylla ocorreu uma redução dos valores de dominância, sendo que Acacia polyphylla passou de $6^{\circ}$ para $10^{\circ}$ na ordenação, em função da redução do número de indivíduos amostrados.

Neste intervalo de tempo houve um aumento nos valores de importância para Actinostemon klotzchii que passou de $2^{\circ}$ lugar em 1989 para $1^{\circ}$ lugar em 1998 (Anexo 2.1), em 


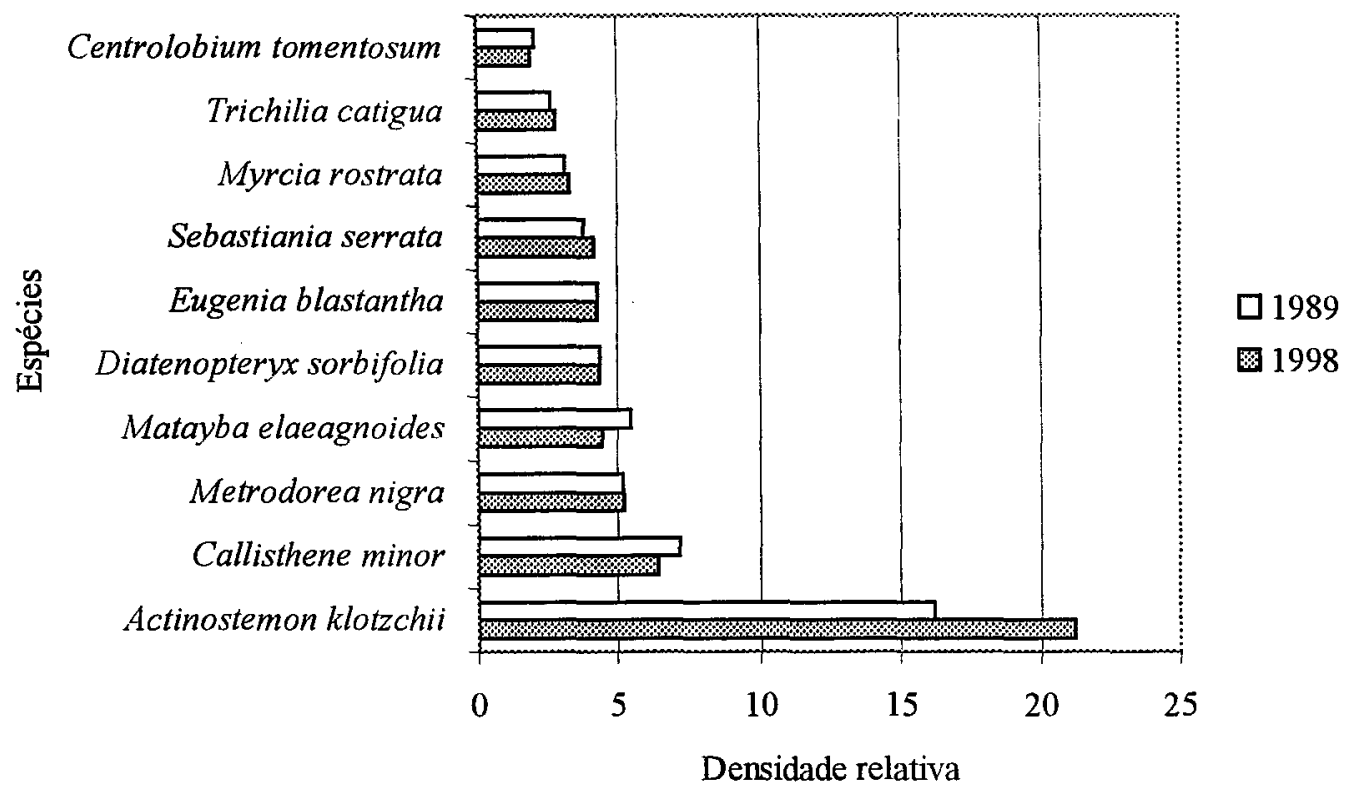

Figura 2.5 - Densidade relativa por espécies encontradas nos levantamentos feitos em 1989 e 1998, na floresta ribeirinha do Rio Passa Cinco, Ipeúna, SP

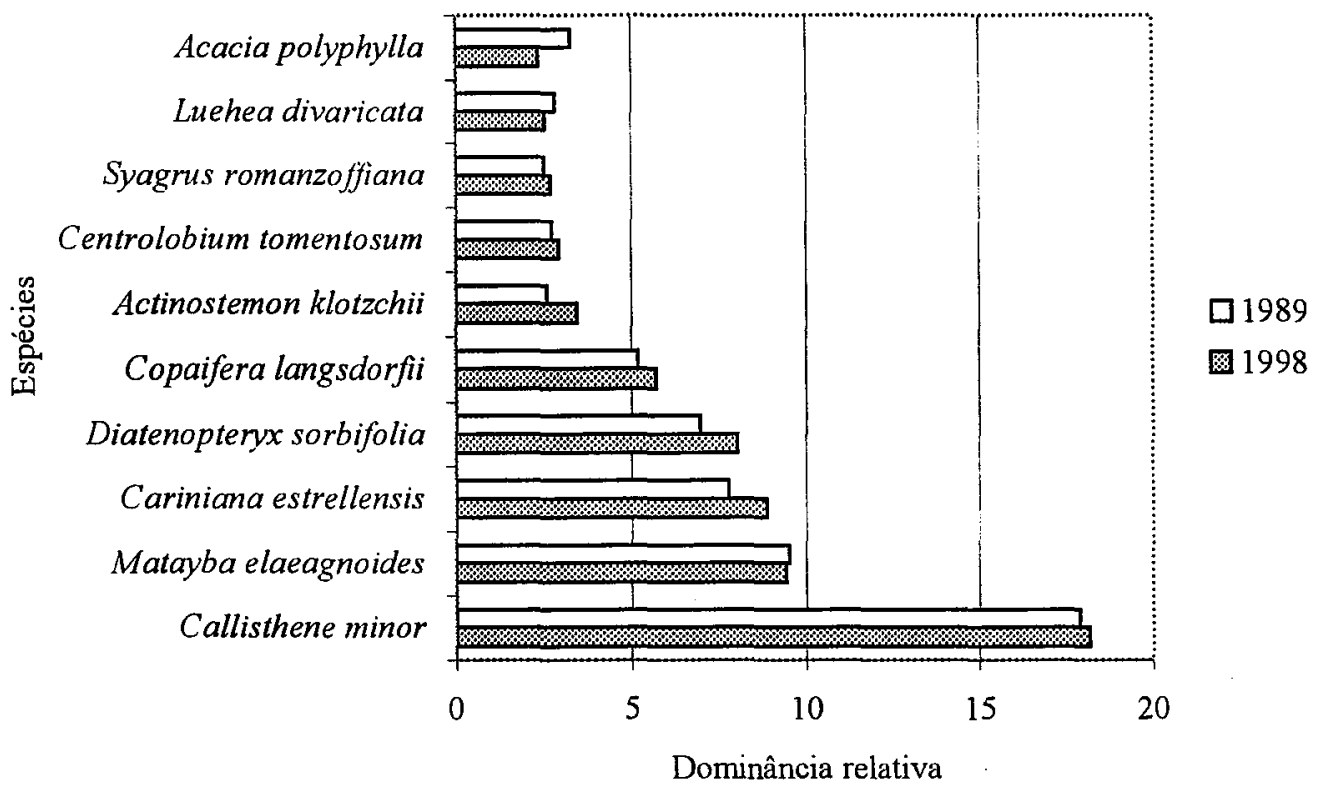

Figura 2.6 - Dominância relativa por espécies encontradas nos levantamentos feitos em 1989 e 1998, na floresta ribeirinha do Rio Passa Cinco, Ipeúna, SP 
função do aumento de densidade e frequência relativas. A Figura 2.7 ilustra o aumento da porcentagem de IVI para esta espécie. O pequeno acréscimo nos valores de importância para Callisthene minor, Cariniana estrellensis, Diatenopteryx sorbifolia e Metrodorea nigra (Figura 2.7) ocorreu em função do crescimento de área basal destas espécies neste período. Matayba elaeagnoides e Eugenia blastantha apresentaram diminuição nos seus valores de importância, devido principalmente à redução do número de individuos destas populações

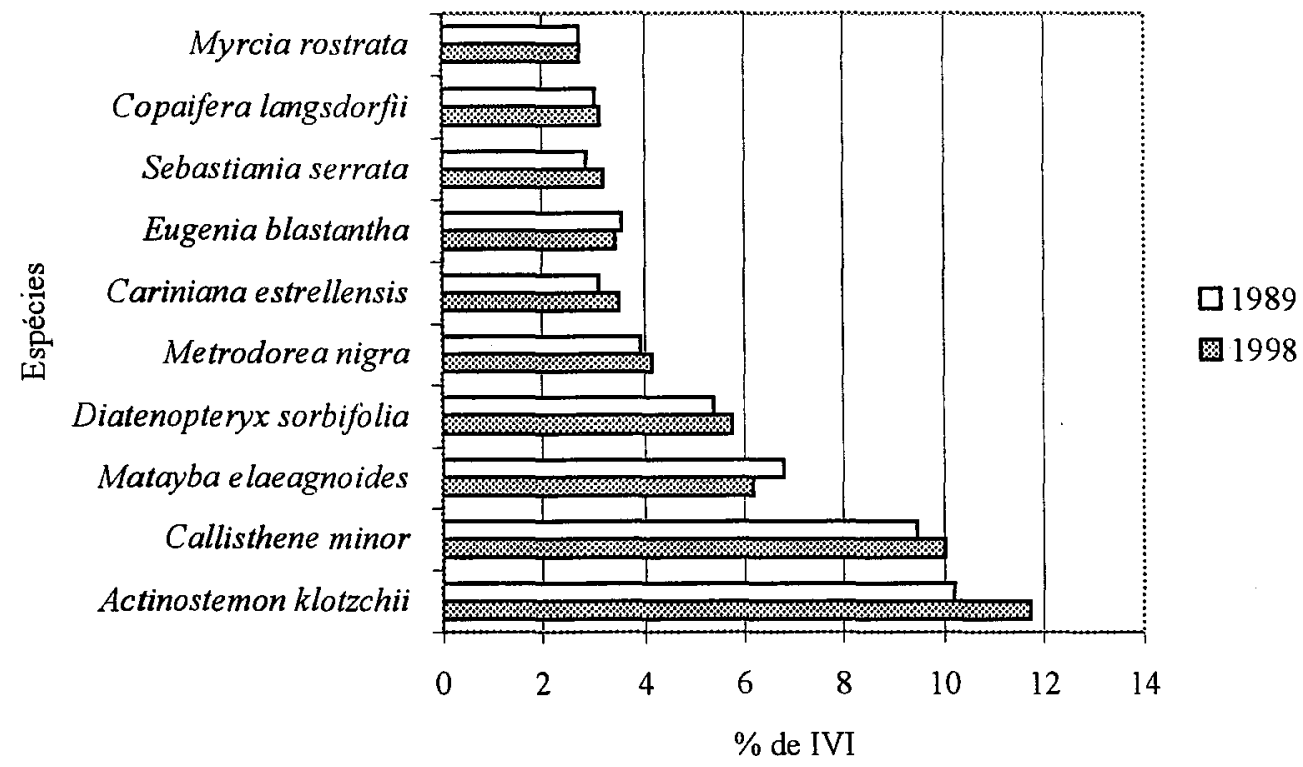

Figura 2.7 - Porcentagem de IVI (índice de valor de importância) por espécie encontrada em 1989 e 1998, na floresta ribeirinha do Rio Passa Cinco, Ipeúna, SP.

Algumas espécies representadas por apenas um indivíduo, definidas por alguns autores como raras (Martins, 1993), que foram amostradas no levantamento de 1989, não foram encontradas neste levantamento. Foi o caso de Erythrina crista-galli (Fabaceae), Patagonula americana (Boraginaceae), Ocotea sp (Lauraceae) e Eugenia aff. pluriflora (Myrtaceae). No entanto foram amostradas algumas espécies novas, isto é, que não foram amostradas em 
1989 mas foram em 1998, como: Albiria polycephala (Mimosaceae), Myriaria floribunda (Myrtaceae), Ixora venulosa (Rubiaceae) e Prockia crucis (Flacourtiaceae).

A Figura 2.8 ilustra uma diminuição do número de indivíduos na maioria das famílias botânicas entre 1989 e 1998. Porém, para as famílias Euphorbiaceae, Fabaceae e Meliaceae houve um aumento do número de indivíduos, reflexo da contribuição de algumas espécies como Actinostemon klotzchii e Sebastiania serrata entre outras.

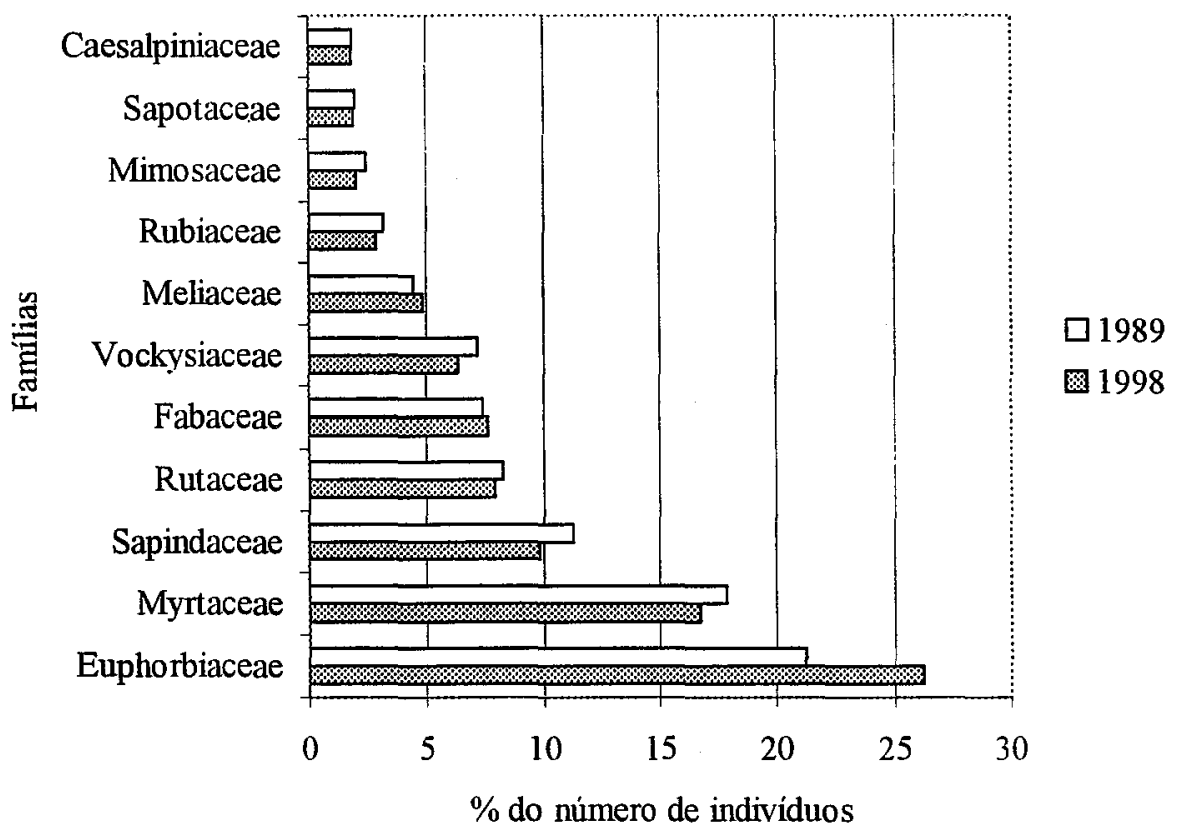

Figura 2.8 - Porcentagem do número de individuos por família botânica encontrada na floresta ribeirinha do Rio Passa Cinco, Ipeúna, SP.

Ocorreu também uma oscilação do número de espécies por família, observando-se um aumento para Myrtaceae, Rubiaceae, Flacourtiaceae e Mimosaceae, e uma diminuição para as outras familias como Fabaceae, Rutaceae, Euphorbiaceae, Meliaceae, Lauraceae e Sapindaceae (Figura 2.9). 


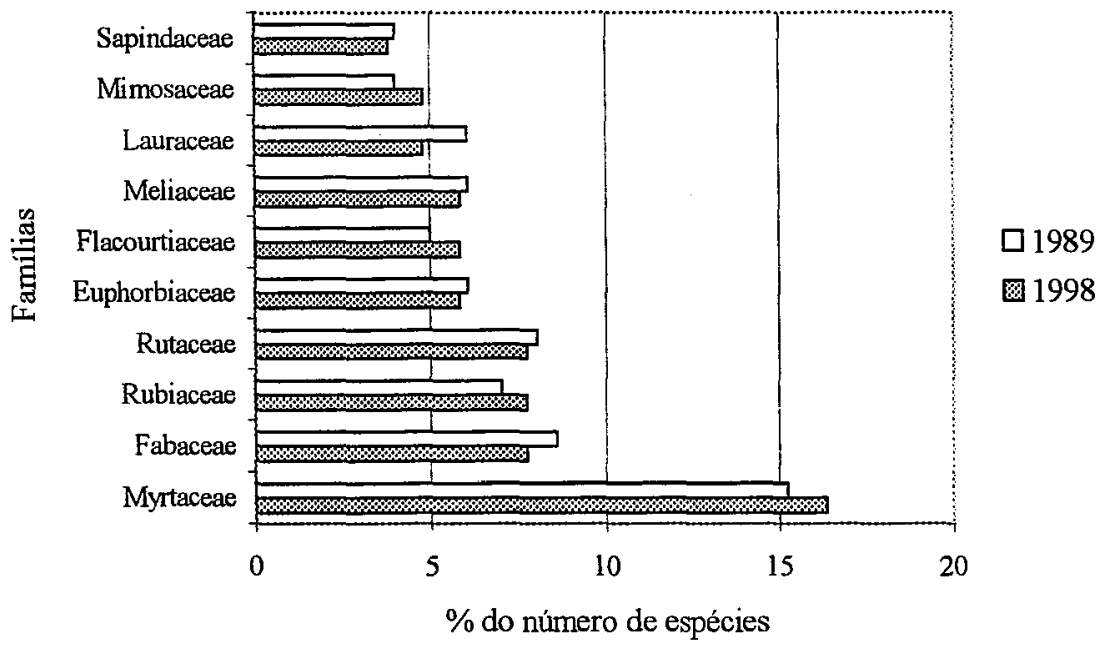

Figura 2.9 - Porcentagem do número de espécies por familia botânica encontrada em 1989 e 1998, na floresta ribeirinha do Rio Passa Cinco, Ipeúna, SP.

A Tabela 2.1 mostra uma comparação dos dados fitossociológicos observados em 1989 e 1998, para a comunidade como um todo, e considerando os três grupos vegetacionais.

Em relação à comunidade, houve um aumento da densidade, área basal e riqueza entre 1989 e 1998 (Tabela 2.1). A diversidade diminuiu em função da diminuição da equidade.

Entre os três grupos vegetacionais, o grupo que ocorreu imediatamente paralelo ao curso d'água, sobre solo Aluvial, apresentou os maiores valores para todos os parâmetros analisados na Tabela 2.1. Entre 1989 e 1998 houve uma diminuição da densidade e diversidade, em função da diminuição da riqueza. A área basal apresentou aumento considerável.

O grupo vegetacional localizado no canto sudoeste e na porção central da área de estudo, sobre solo $\mathrm{AQ} / \mathrm{Cb}$, apresentou os menores valores de diversidade, acompanhada pelos valores baixos de riqueza e equidade, quando comparado aos outros grupos vegetacionais. No período estudado, ocorreu aumento considerável na densidade e área 
Tabela 2.1- Comparação dos parâmetros fitossociológicos da comunidade de árvores com DAP $\geq 5 \mathrm{~cm}$ encontradas nos levantamentos feitos em 1989 e 1998, na floresta ribeirinha do Rio Passa Cinco, Ipeúna, SP. $\mathrm{n}=$ número de indivíduos; dens. $=$ densidade $\left(\mathrm{n} \times \mathrm{ha}^{-1}\right) ; \mathrm{ab}=$ área basal $\left(\mathrm{m}^{2} \times \mathrm{xa}^{-1}\right) ; \mathrm{n}^{\mathrm{o}}$ de $\mathrm{sp}=$ número de espécies; $\mathrm{H}^{\prime}=$ índice de Shannon (nits $\mathrm{x} \mathrm{n}^{-1}$ ) e $\mathrm{J}^{\prime}=$ equidade.

\begin{tabular}{|c|c|c|c|c|c|c|c|c|}
\hline \multirow{2}{*}{$\begin{array}{c}\text { área } \\
\left(\mathrm{m}^{2}\right) \\
\text { ano - \%* }\end{array}$} & \multicolumn{2}{|c|}{$\begin{array}{l}\text { total } \\
(7850)\end{array}$} & \multicolumn{2}{|c|}{$\begin{array}{l}\text { solo aluvial } \\
(1550)\end{array}$} & \multicolumn{2}{|c|}{$\begin{array}{c}\text { solo } \mathrm{AQ} / \mathrm{Cb} \\
(2600)\end{array}$} & \multicolumn{2}{|c|}{$\begin{array}{l}\text { solo PV } \\
(1900)\end{array}$} \\
\hline & $1989 / 1998$ & $\%$ & $1989 / 1998$ & $\%$ & $1989 / 1998$ & $\%$ & $1989 / 1998$ & $\%$ \\
\hline $\bar{n}$ & $1395 / 1423$ & 2,01 & $391 / 378$ & $-3,32$ & $434 / 478$ & 10,14 & $301 / 293$ & $-2,66$ \\
\hline dens. & $1788,9 / 1812,8$ & 1,34 & $2522,3 / 2438,7$ & $-3,31$ & $1670,6 / 1839,2$ & 10,09 & $1584 / 1542$ & $-2,66$ \\
\hline$a b$ & $33,55 / 34,49$ & 2,80 & $58,23 / 63,18$ & 8,50 & $30,82 / 33,25$ & 7,88 & $26,45 / 23,01$ & -13 \\
\hline $\mathrm{n}^{\underline{Q}}$ de $\mathrm{sp}$ & $105 / 107$ & 1,90 & $72 / 67$ & $-6,94$ & $60 / 61$ & 1,67 & $65 / 69$ & 6,15 \\
\hline$H^{\prime}$ & $3,694 / 3,578$ & $-3,14$ & $3,674 / 3,616$ & $-1,58$ & $3,213 / 3,019$ & $-6,04$ & $3,523 / 3,489$ & $-0,97$ \\
\hline $\mathrm{J}^{\prime}$ & $0,55 / 0,53$ & $-3,64$ & $0,59 / 0,59$ & 0,00 & $0,54 / 0,51$ & $-5,56$ & $0,58 / 0,57$ & $-1,72$ \\
\hline
\end{tabular}

* estas colunas representam a porcentagem de aumento ou diminuição em nove anos, para cada parâmetro.

basal. A diversidade diminuiu em função da diminuição da equidade. Neste caso, nota-se que a diminuição da equidade está relacionada com o aumento da dominância de $A$. klotzçbii nesta área.

O grupo vegetacional do canto sudeste da área de estudo, sobre solo $\mathrm{PV}$, apresentou os menores valores de densidade e área basal. Entre 1989 e 1998 houve uma grande diminuição na área basal. Também ocorreram diminuições nos valores da densidade $e$ equidade, levando a uma pequena diminuição da diversidade. A riqueza aumentou nesta área.

A Figura 2.10 apresenta a densidade de individuos por classes de diâmetro em cada grupo vegetacional. Nota-se um maior número de indivíduos de menor diâmetro no grupo vegetacional sobre o solo $\mathrm{PV}$, o que está relacionado a um número maior de espécies com menores diâmetros. Da mesma forma a vegetação sobre o solo $\mathrm{AQ} / \mathrm{Cb}$, pelo grande 
número de indivíduos de Actinostemon klotzchii, uma espécie típica de subbosque e altamente ramificada. No grupo vegetacional sobre solo Aluvial, existe um maior número de indivíduos de maior diâmetro, acima de $45 \mathrm{~cm}$, devido à presença das espécies Cariniana estrellensis, Calisthene minor, Luebea divaricata, Terminalia triflora, Copaifera langsdorffii e Lonchocarpus cultratus.

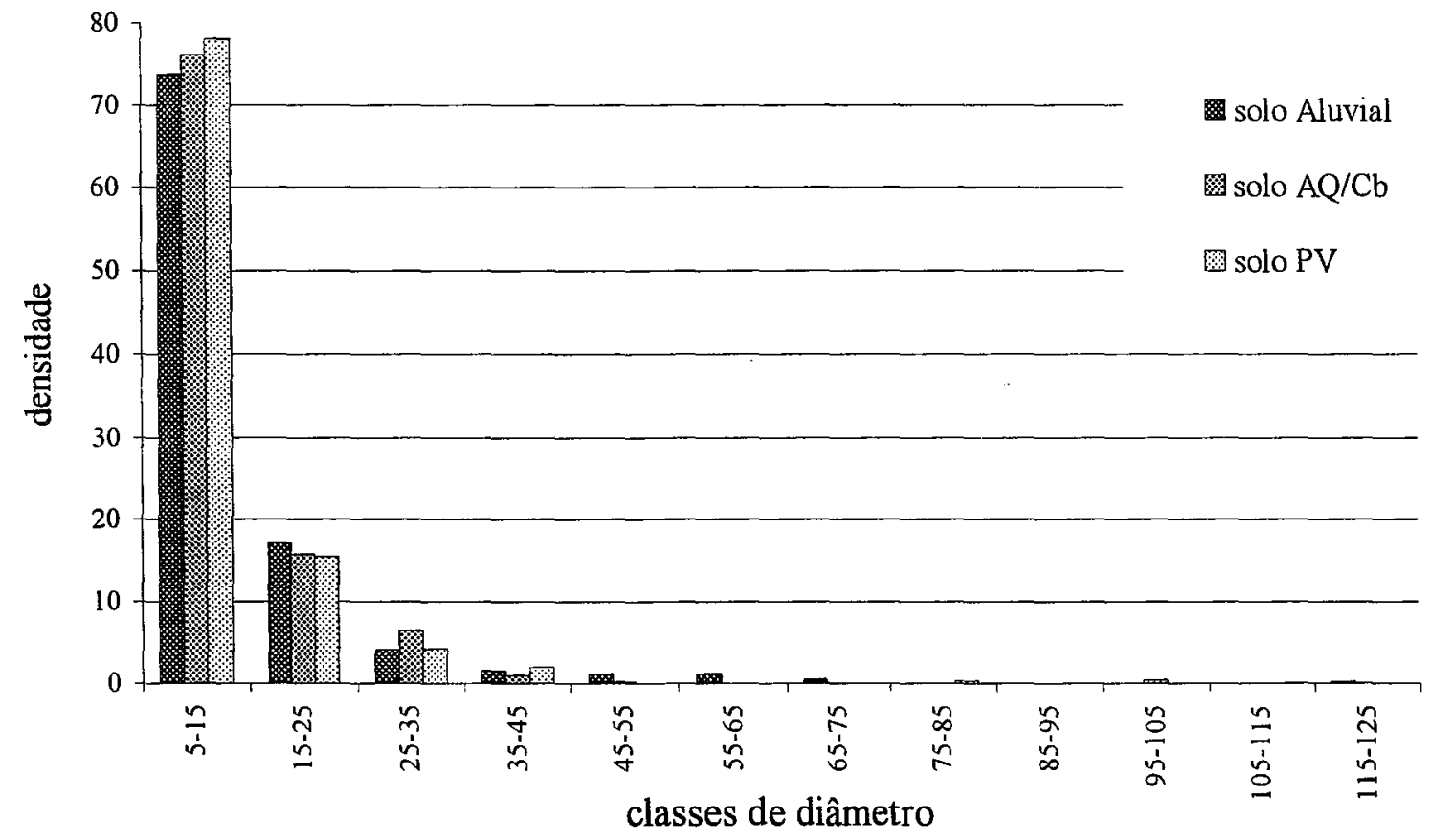

Figura 2.10 - Densidade por classes de diâmetro em cada vegetação sobre os três diferentes tipos de solo. 


\subsection{DISCUSSÃO}

Poucas mudanças florísticas e estruturais ocorreram em nove anos na floresta ripária do Rio Passa Cinco. Em estudo de quatro anos em uma mata de galeria no Distrito Federal, Felfili (1994) encontrou mudanças na densidade de algumas espécies mais abundantes, sugerindo que a estrutura fitossociológica é dinâmica, e que as espécies dominantes podem mudar com o tempo. Alguns estudos em florestas tropicais sugeriram que em áreas sem a ocorrência de distúrbios severos, ocorrem poucas mudanças na densidade e composição de espécies, indicando uma aparente estabilidade (Swaine et al., 1987). Porém estes trabalhos foram desenvolvidos em pequena escala de tempo, sendo ainda inadequadas estas conclusões.

Santos et al. (1996), em um fragmento de floresta mesófila semidecídua, encontrou $23 \%$ de mudanças na riqueza de espécies em 11 anos, e redução na densidade de duas espécies mais abundantes, relacionando isto ao isolamento e ao pequeno tamanho do fragmento. A floresta ribeirinha do presente estudo está dentro de um fragmento de aproximadamente $60 \mathrm{ha}$, bem menor do que o fragmento estudado por Santos et al. (1996), de aproximadamente 250 ha, e poucas alterações ocorreram na área. Isto pode indicar que a presença do rio é um fator da manutenção da vegetação, em relação à tiqueza de espécies e densidade de indivíduos, reforçando a idéia da função de corredor de vegetação de áreas ribeirinhas.

Outro fator que provavelmente contribui para a diversidade da área é a heterogeneidade ambiental, não gerada apenas pelo rio, mas pelos diferentes tipos de solo e topografia encontrados neste local. Apesar da elevada similaridade florística entre os três grupos vegetacionais, as análises multivariadas e quantitativas permitiram diferenciar clatamente que os três grupos vegetacionais são associações bem definidas e distintas.

O grupo que ocorreu imediatamente paralelo ao curso d'água, sobre o solo Aluvial, se diferenciou dos demais por apresentar menor valor de similaridade, maior diversidade, densidade e área basal total. A presença do curso d'água pode causar uma maior seletividade, com a ocorrência de espécies típicas de formações ribeirinhas, como as espécies do gênero Inga (Gibbs \& Leitão Filho, 1978), Tapirira guianensis (Torres et. al., 1994; Salis et al., 1994; Toniato et al., 1998), Lafoensia pacari (Durigan, 1994) e Terminalia triflora 
(Torres et. al., 1994; Toniato et al., 1998), entre outras. As inundações periódicas, apesar de restritivas em relação à diversidade, tem atuação diferenciada no espaço, provocando grande heterogeneidade ambiental. Este seria o fator principal da elevada diversidade encontrada na área. Os maiores valores de densidade e área basal poderiam estar relacionados com a maior luminosidade pela presença do rio, pois no período de estudo houve um grande aumento da área basal total. A diminuição, após nove anos, da densidade e diversidade podem estar ocorrendo em função da perturbação gerada pelas cheias do rio e a seletividade de algumas espécies a este tipo de ambiente. As inundações nesta faixa são rápidas, retirando a camada de serapilheira e eliminando alguns indivíduos mais jovens, de espécies menos agressivas, que não apresentaram crescimento rápido da parte radicular desde as cheias anteriores. As inundações mais duradouras estào restritas à apenas alguns trechos.

O grupo vegetacional localizado no canto sudoeste e porção central da área de estudo, sobre solo $\mathrm{AQ} / \mathrm{Cb}$, apresentou menor densidade e diversidade, o que pode estar relacionado ao fato de tratar-se de um solo recente, tendo sido um antigo leito de rio. Em nove anos houve aumento da densidade, e conseqüente aumento de área basal. A diversidade diminuiu em funçào da diminuição da equitatividade, causada pelo aumento na dominância da A. klotŗchii.

O grupo vegetacional do canto sudeste da área de estudo, sobre solo PV, apresentou os menores valores de densidade. A área basal total foi baixa, o que se deve a um número maior de espécies com menores diâmetros. Em nove anos, houve uma pequena diminuição dos valores de densidade e diversidade, porém um aumento do número de espécies. $\mathrm{A}$ área basal diminuiu bastante, o que poderia ser um indício de que a declividade pode estar atuando como um fator restritivo nesta área.

Assim, nesta condição ribeirinha existe um mosaico vegetacional relacionado às características fisiográficas, principalmente à presença do rio e dinâmica de suas cheias, topografia e solo. 


\subsection{REFERÊNCIAS BIBLIOGRÁFICAS}

DURIGAN, G. Florística, Fitossociologia e produção de folhedo em matas ciliares da região oeste do estado de São Paulo. Campinas, 1994. Tese de doutorado. Universidade Estadual de Campinas.

FELFILI, J.M.. Floristc composition and phytossociology of the gallery forest alongside the Gama stream in Brasilia, DF, Brazil. Revta. Brasil. Bot, v.17, p.1-11, 1994.

GAUCH, Jr.H.G. Multivariate analysis in community ecology. Cambridge: Cambridge University Press, 1982.

GIBBS , P.E. \& LEITÃO FILHO, H.F. Floristic composition of an area of gallery forest near Mogi Guaçu, State of São Paulo, S.E. Brazil. Revta. Brasil. Bot, v.1, p.151-156, 1978.

HILL, M.O. Reciprocal averaging: an eigenvector method of ordination. Journal of Ecology, v.61, p.237-49, 1973.

HILL, M.O. Correspondence analysis: a negleted multivariate methods. J.R. Statist. Soc., ser C., v.23, p.340-354, 1974.

KREBS, C.J. Ecologycal methodology. New York: Harper Collins Publishers, 1989.

LESCURE, J.P. \& BOULET, R. Relationships between soil and vegetation in a tropical rain forest in French Guiana. Biotropica , v.17, n.2, p.155-164, 1985.

MARTINS, F.R. Estrutura de uma floresta mesófila. Campinas: Ed. Universidade Estadual de Campinas, 1993.

MAZER, S.J. Floristic composition, soil quality, litter accumulation, and decomposition in terra firme and floodplain habitats near Pakitza, Peru. In: WILSON, D.E. \& SANDOVAL, A. (Ed.). Manu/ The biodiversity of southeastern Peru. Washington, D.C.: Smithsonian Institution, 1996. p.89-125.

OLIVEIRA FILHO, A.T., VILELA, E.A., GAVILANES, M.L. \& CARVALHO, D.A. Effect os flooting regime and understorey bamboos on the physionomy and tree species composition of a tropical semideciduous forest in southeastern Brazil. Vegetatio, v.113, p.99-124, 1994.

OLIVEIRA FILHO, A.T., CURI, N., VILELA, E.A. \& CARVALHO, D.A.. Tree species distribution along soil catenas in a riverside semideciduous forest in southeastern Brazil. Flora, v.192, p.47-64, 1997. 
RODRIGUES, R.R.. Análise de um remanescente de vegetação natural as margens do Rio Passa Cinco, Ipeúna. SP. Campinas, 1992. Tese de Doutorado. Universidade Estadual de Campinas.

RODRIGUES, R.R. Matas Ciliares: uma abordagem multidiciplinar. Piracicaba: no prelo.

SHEPHERD, G.J. FITOPAC-versão preliminar. Manual do usuário. Campinas:

Departamento de Botânica, Instituto de Biologia, Universidade Estadual de Campinas, 1988.

SABATIER, D., GRIMALDI, M., PRÉVOST, M.F., GUILLAUME, J., GODRON, M., DOSSO, M. \& CURMI, P. The influence of soil cover organization on the floristc and structural heterogeneity of a Guianan rain forest. Plant Ecology, v.131, p.81-108, 1997.

SALIS, S.M., TAMASHIRO, J.Y. \& JOLY, C.A. Florística e fitossociologia do estrato arbóreo de um remanescente de mata ciliar do Rio Jacaré-Pepira, Brotas, SP. Revta. Brasil. Bot., v.17, n.2, p.93-103, 1994.

SANTOS, F.A.M., TAMASHIRO, J.Y., RODRIGUES, R.R. \& SHEPHERD, G.J. The dynamics of tree population in a semideciduous forest at Santa Genebra reserve, Campinas, Se, Brazil. Supplement to Bulletin of the Ecology Society America. Providence, Rhode Island, 1996.

SWAINE, M.D., LIEBERMAN, D.\& PUTZ, E.F. The dynamics of tree populations in tropical forests: a review. Journal of Tropical Ecology, v.3, p.359-366, 1987.

TER BRAAK, C.J.F. Correspondence analysis of incidence and abundance data: properties properties in terms of a unimodal responce model. Biometrics, v.41, p.859-873, 1985.

TER BRAAK, C.J.F. Canoco a Fortran: program for canonical community ordination by partial detrended canonical correspondence analysis, principal analysis and redudancy analysis (Version 2.1). Wageningen: TNO - Institute of Applied Computer Science, 1988.

TORRES, R.B., MATTHES, L.A.F. \& RODRIGUES, R.R.. Florística e estrutura do componente arbóreo de mata de brejo em Campinas, SP. Revta. Brasil. Bot., v.17, n.2. p.189-194, 1994.

TONIATO, M.T.Z.. LEITÃO FILHO, H.F. \& RODRIGUES, R.R. Fitossociologia de um remanescente de floresta higrófila (mata de brejo) em Campinas, SP. Revta. Brasil. Bot., v.21, n.2, p.197-210, 1998. 
Anexo 2.1 - Resultado dos parâmetros fotossociológicos de 1989 e 1998 calculados para as espécies amostradas em um trecho de floresta ribeirinha do Rio Passa Cinco, Ipeúna, SP, em ordem decrescente de IVI para 1998. $\mathrm{n}^{\mathrm{0}}$ - número de indivíduos; dens. r.- densidade relativa; dom. r. - dominância relativa; freq. $r$ - freqüência relativa; IVI índice de valor de importância.

\begin{tabular}{|c|c|c|c|c|c|c|c|c|c|c|}
\hline \multirow{2}{*}{$\begin{array}{l}\text { espécie } \\
\text { ano }\end{array}$} & \multicolumn{2}{|c|}{$\mathrm{n}^{\mathrm{a}}$} & \multicolumn{2}{|c|}{ dens .r } & \multicolumn{2}{|c|}{$\operatorname{dom} \cdot r$} & \multicolumn{2}{|c|}{ freq .I } & \multicolumn{2}{|c|}{ ivi } \\
\hline & 1989 & 1998 & 1989 & 1998 & 1989 & 1998 & 1989 & 1998 & 1989 & 1998 \\
\hline Actinostemon klotzchii (Didr.) Pax. & 226 & 302 & 16,22 & 21,22 & 2,65 & 3,48 & 9,55 & 10,46 & 28,42 & 35,15 \\
\hline Callisthene minor Mart. & 100 & 91 & 7,14 & 6,36 & 17,88 & 18,17 & 5,59 & 5,48 & 30,6 & 30,02 \\
\hline Matayba elaeagnoides Radlk. & 76 & 63 & 5,48 & 4,46 & 9,53 & 9,44 & 5,39 & 4,67 & 20,39 & 18,57 \\
\hline Diatenopteryx sorbifolia Radlk. & 61 & 62 & 4,4 & 4,38 & 6,93 & 8,04 & 4,78 & 4,87 & 16,11 & 17,3 \\
\hline Metrodorea nigra St. Hil. : & 72 & 74 & 5,19 & 5,23 & 1,8 & 2,2 & 4,78 & 4,97 & 11,77 & 12,41 \\
\hline Cariniana estrellensis (Raddi) O. Kuntze & 10 & 10 & 0,72 & 0,71 & 7,78 & 8,88 & 0,81 & 0,91 & 9,31 & 10,5 \\
\hline Eugenia blastantha (Berg.) Legr. & 60 & 60 & 4,33 & 4,24 & 1,83 & 1,76 & 4,47 & 4,26 & 10,63 & 10,27 \\
\hline Sebastiania serrata Muell. Arg. & 53 & 59 & 3,82 & 4,17 & 1,08 & 1,01 & 3,76 & 4,37 & 8,66 & 9,55 \\
\hline Copaifera langsdorffii Desf. & 24 & 22 & 1,73 & 1,56 & 5,17 & 5,7 & 2,23 & 2,13 & 9,14 & 9,38 \\
\hline Myrcia rostrata $\mathrm{DC}$. & 44 & 47 & 3,17 & 3,32 & 1,69 & 1,41 & 3,35 & 3,55 & 8,22 & 8,29 \\
\hline $\begin{array}{l}\text { Centrolobium tomentosum Guill. ex } \\
\text { Benth }\end{array}$ & 29 & 27 & 2,09 & 1,91 & 2,77 & 2,99 & 2,44 & 2,34 & 7,31 & 7,23 \\
\hline Trichilia catigua A. Juss. & 37 & 40 & 2,67 & 2,83 & 1,01 & 1,1 & 2,95 & 3,15 & 6,62 & 7,08 \\
\hline Syagrus romanzoffiana (Cham.) Glassm. & 24 & 24 & 1,73 & 1,7 & 2,59 & 2,74 & 2,03 & 2,03 & 6,35 & 6,47 \\
\hline $\begin{array}{l}\text { Chrysophyllum gonocarpum (Mart. \& } \\
\text { Einchl.) Engl. }\end{array}$ & 26 & 27 & 1,88 & 1,91 & 1,02 & 1,16 & 2,03 & 2,23 & 4,93 & 5,31 \\
\hline Dalbergia brasiliensis Vogel. & 26 & 26 & 1,88 & 1,84 & 1,29 & 1,3 & 2,03 & 2,03 & 5,2 & 5,17 \\
\hline Acacia pobppbylla DC. & 14 & 10 & 1,01 & 0,71 & 3,32 & 2,4 & 1,32 & 0,91 & 5,65 & 4,03 \\
\hline Machaerium nictitans (Vell.) Benth. & 18 & 16 & 1,3 & 1,13 & 1,22 & 1,28 & 1,52 & 1,42 & 4,05 & 3,83 \\
\hline Luehea divaricata Mart. & 9 & 7 & 0,65 & 0,5 & 2,87 & 2,6 & 0,92 & 0,71 & 4,43 & 3,81 \\
\hline Neomitranthes glomerata Legr. & 21 & 23 & 1,51 & 1,63 & 0,42 & 0,44 & 1,73 & 1,73 & 3,66 & 3,79 \\
\hline Machaerium stipitatum Vog. & 22 & 19 & 1,59 & 1,34 & 0,66 & 0,74 & 1,73 & 1,52 & 3,97 & 3,6 \\
\hline Eugenia uniflora L. & 25 & 17 & 1,8 & 1,2 & 0,77 & 1,07 & 1,52 & 1,12 & 4,1 & 3,39 \\
\hline Terminalia triflora (Griseb.) Lillo & 9 & 8 & 0,65 & 0,57 & 2,06 & 1,98 & 0,81 & 0,81 & 3,52 & 3,36 \\
\hline Campomanesia xanthocarpa Berg. & 20 & 15 & 1,44 & 1,06 & 1,95 & 1,55 & 0,92 & 0,71 & 4,31 & 3,33 \\
\hline Calyptranthes concinna DC. & 20 & 21 & 1,44 & 1,49 & 0,61 & 0,7 & 1,02 & 1,02 & 3,06 & 3,2 \\
\hline Tricbilia pallida Sw. & 12 & 14 & 0,87 & 0,99 & 0,55 & 0,73 & 1,22 & 1,42 & 2,63 & 3,14 \\
\hline Eugenia racemulosa Berg. & 17 & 15 & 1,23 & 1,06 & 0,39 & 0,3 & 1,52 & 1,52 & 3,14 & 2,88 \\
\hline Rudgea jasminoides (Cham.) Muel. Arg. & 14 & 15 & 1,01 & 1,06 & 0,24 & 0,27 & 1,12 & 1,42 & 2,37 & 2,75 \\
\hline Calliandra tweediei Benth. & 18 & 15 & 1,3 & 1,06 & 0,2 & 0,19 & 1,52 & 1,42 & 3,02 & 2,67 \\
\hline Casearia syluestris Sw. & 13 & 12 & 0,94 & 0,85 & 0,51 & 0,56 & 1,32 & 1,22 & 2,77 & 2,63 \\
\hline Eugenia pyriformis Camb: & 10 & 11 & 0,72 & 0,78 & 0,6 & 0,65 & 0,92 & 1,02 & 2,24 & 2,45 \\
\hline Couratea bexandra (Jacq.) K.Schum. & 14 & 9 & 1,01 & 0,64 & 0,98 & 0,76 & 1,22 & 0,91 & 3,21 & 2,31 \\
\hline Galipea multiflora Schult. & 10 & 12 & 0,72 & 0,85 & 0,29 & 0,34 & 0,92 & 1,12 & 1,92 & 2,31 \\
\hline Balfourodendron riedelianum Engl. & 7 & 6 & 0,51 & 0,42 & 1,81 & 1,11 & 0,71 & 0,61 & 3,02 & 2,15 \\
\hline $\begin{array}{l}\text { Campomanesia guazumifolia (Camb.) } \\
\text { Berg. }\end{array}$ & 13 & 12 & 0,94 & 0,85 & 0,43 & 0,43 & 0,81 & 0,81 & 2,18 & 2,09 \\
\hline
\end{tabular}


(Cont.) Anexo 2.1 - Resultado dos parâmetros fotossociológicos de 1989 e 1998 calculados para as espécies amostradas em um trecho de floresta ribeirinha do Rio Passa Cinco, Ipeúna, SP, em ordem decrescente de IVI para 1998. $\mathrm{n}^{\circ}$ - número de indivíduos; dens. r.- densidade relativa; dom. r. - dominância relativa; freq. $r$ - freqüência relativa; IVI - índice de valor de importância.

\begin{tabular}{|c|c|c|c|c|c|c|c|c|c|c|}
\hline \multirow{2}{*}{$\begin{array}{l}\text { espécie } \\
\text { ano }\end{array}$} & \multicolumn{2}{|c|}{$\mathrm{n}^{2}$} & \multicolumn{2}{|c|}{ dens. $\mathbf{r}$} & \multicolumn{2}{|c|}{ dom. I } & \multicolumn{2}{|c|}{ freq. I } & \multicolumn{2}{|c|}{ ivi } \\
\hline & 1989 & 1998 & 1989 & 1998 & 1989 & 1998 & 1989 & 1998 & 1989 & 1998 \\
\hline Lafoensia pacari St. Hil. & 13 & 8 & 0,94 & 0,57 & 1,82 & 0,97 & 0,71 & 0,51 & 3,47 & 2,04 \\
\hline $\begin{array}{l}\text { Lonchocarpus cultratus (Vell.) Az.-Tozzi } \\
\text { et H.C. Lima }\end{array}$ & 3 & 3 & 0,21 & 0,21 & 1,58 & 1,58 & 0,2 & 0,2 & 1,99 & 1,99 \\
\hline Maytenus rabusta Reiss. & 10 & 10 & 0,71 & 0,71 & 0,31 & 0,31 & 0,91 & 0,91 & 1,93 & 1,93 \\
\hline Dyospirus sp. & 7 & 6 & 0,51 & 0,42 & 0,83 & 0,83 & 0,61 & 0,51 & 1,94 & 1,76 \\
\hline Allophylus edulis (St. Hil.) Hadlk. & 14 & 9 & 1,01 & 0,64 & 0,27 & 0,16 & 1,32 & 0,91 & 2,56 & 1,71 \\
\hline Cryptocaria aschersoniana $\mathrm{Mez}$ & 9 & 9 & 0,64 & 0,64 & 0,26 & 0,4 & 0,61 & 0,61 & 1,51 & 1,65 \\
\hline Machaerium vestitum Vog. & 9 & 9 & 0,64 & 0,64 & 0,26 & 0,27 & 0,61 & 0,71 & 1,52 & 1,62 \\
\hline Trichilia elegans A. Juss. & 6 & 8 & 0,43 & 0,57 & 0,19 & 0,21 & 0,61 & 0,81 & 1,23 & 1,59 \\
\hline $\begin{array}{l}\text { Esenbeckia frebifuga (St. Hil.) A.Juss. ex. } \\
\text { Mart. }\end{array}$ & 6 & 8 & 0,43 & 0,57 & 0,06 & 0,1 & 0,61 & 0,81 & 1,1 & 1,48 \\
\hline Zollernia ilicifolia (Brongn.) Vog. & 6 & 7 & 0,43 & 0,5 & 0,19 & 0,28 & 0,51 & 0,61 & 1,13 & 1,39 \\
\hline Cbomelia obtusa Cham. \& Schltdl. & 6 & 7 & 0,43 & 0,5 & 0,12 & 0,15 & 0,61 & 0,71 & 1,16 & 1,36 \\
\hline Eugenia florida DC. & 9 & 6 & 0,65 & 0,42 & 0,19 & 0,16 & 0,81 & 0,61 & 1,66 & 1,2 \\
\hline Sebastiania brasiliensis & 9 & 6 & 0,65 & 0,42 & 0,37 & 0,24 & 0,51 & 0,51 & 1,53 & 1,17 \\
\hline Esenbeckia grandiflora Mart. & 4 & 7 & 0,29 & 0,5 & 0,05 & 0,11 & 0,31 & 0,51 & 0,64 & 1,11 \\
\hline Cedrela fissilis Vell. & 3 & 3 & 0,21 & 0,21 & 2,26 & 0,58 & 0,3 & 0,3 & 2,78 & 1,1 \\
\hline Solanum pseudoquina St. Hil. & 4 & 4 & 0,28 & 0,28 & 0,41 & 0,46 & 0,3 & 0,3 & 1,01 & 1,05 \\
\hline Cupania vernalis Camb. & 5 & 5 & 0,35 & 0,35 & 0,58 & 0,27 & 0,41 & 0,41 & 1,35 & 1,03 \\
\hline Jacaranda macrantha Cham. & 5 & 4 & 0,36 & 0,28 & 0,25 & 0,27 & 0,51 & 0,41 & 1,12 & 0,96 \\
\hline Chomelia ribesioides Benth. & 6 & 5 & 0,43 & 0,35 & 0,1 & 0,08 & 0,61 & 0,51 & 1,14 & 0,94 \\
\hline Roupala brasiliensis Klotzsch & 5 & 4 & 0,36 & 0,28 & 0,2 & 0,19 & 0,51 & 0,41 & 1,07 & 0,88 \\
\hline Citronella paniculata Howard. & 4 & 4 & 0,28 & 0,28 & 0,16 & 0,17 & 0,41 & 0,41 & 0,85 & 0,86 \\
\hline Rollinia syluatica (St. Hil.) Mart. & 5 & 4 & 0,36 & 0,28 & 0,23 & 0,24 & 0,41 & 0,3 & 1 & 0,83 \\
\hline Ocotea lanata (Nees) Mez & 3 & 3 & 0,21 & 0,21 & 0,28 & 0,29 & 0,31 & 0,3 & 0,8 & 0,81 \\
\hline Prunus sellowii Koehne & 7 & 4 & 0,51 & 0,28 & 0,13 & 0,12 & 0,71 & 0,41 & 1,35 & 0,81 \\
\hline Aspidosperma polyneuron Muell. Arg. & 2 & 4 & 0,14 & 0,28 & 0,05 & 0,1 & 0,2 & 0,41 & 0,4 & 0,79 \\
\hline Casearia gossypiosperma Briq. & 4 & 3 & 0,29 & 0,21 & 0,19 & 0,24 & 0,41 & 0,3 & 0,89 & 0,76 \\
\hline Duguetia lanceolata St. Hil. & 3 & 4 & 0,22 & 0,28 & 0,03 & 0,05 & 0,31 & 0,41 & 0,55 & 0,73 \\
\hline Eugenia moraviana Berg. & 2 & 3 & 0,14 & 0,21 & 0,18 & 0,19 & 0,2 & 0,3 & 0,52 & 0,71 \\
\hline Securinega guaraiuva Kuhlm. & 4 & 3 & 0,29 & 0,21 & 0,19 & 0,16 & 0,31 & 0,3 & 0,78 & 0,68 \\
\hline Myrcia ramulosa DC. & 2 & 2 & 0,14 & 0,14 & 0,33 & 0,33 & 0,2 & 0,2 & 0,67 & 0,67 \\
\hline Zanthoxylum rhoifolium Lam. & 2 & 2 & 0,14 & 0,14 & 0,21 & 0,28 & 0,2 & 0,2 & 0,56 & 0,63 \\
\hline Astronium graveolens Jacq. & 3 & 3 & 0,21 & 0,21 & 0,07 & 0,09 & 0,3 & 0,3 & 0,59 & 0,61 \\
\hline Rapanea umbellata (Mart.) Mez & 3 & 3 & 0,21 & 0,21 & 0,05 & 0,06 & 0,3 & 0,3 & 0,57 & 0,58 \\
\hline Hymenaea courbaril L. & 2 & 2 & 0,14 & 0,14 & 0,22 & 0,22 & 0,2 & 0,2 & 0,57 & 0,57 \\
\hline Holocalyx balansae Mich. & 2 & 2 & 0,14 & 0,14 & 0,2 & 0,21 & 0,2 & 0,2 & 0,54 & 0,56 \\
\hline Piper amalago L. & 2 & 3 & 0,14 & 0,21 & 0,03 & 0,04 & 0,2 & 0,3 & 0,37 & 0,56 \\
\hline
\end{tabular}


(Cont.) Anexo 2.1 - Resultado dos parâmetros fotossociológicos de 1989 e 1998 calculados para as espécies amostradas em um trecho de floresta ribeirinha do Rio Passa Cinco, Ipeúna, SP, em ordem decrescente de IVI para 1998. $\mathrm{n}^{\mathrm{0}}$ - número de indivíduos; dens. r.- densidade relativa; dom. $r$. - dominância relativa; freq. $r$ - freqüência relativa; IVI - índice de valor de importância.

\begin{tabular}{|c|c|c|c|c|c|c|c|c|c|c|}
\hline \multirow{2}{*}{$\begin{array}{l}\text { espécie } \\
\text { ano }\end{array}$} & \multicolumn{2}{|c|}{$\mathrm{n}^{2}$} & \multicolumn{2}{|c|}{ dens. $r$} & \multicolumn{2}{|c|}{ dom. $\mathbf{r}$} & \multicolumn{2}{|c|}{ freq. $r$} & \multicolumn{2}{|c|}{ ivi } \\
\hline & 1989 & 1998 & 1989 & 1998 & 1989 & 1998 & 1989 & 1998 & 1989 & 1998 \\
\hline Trichilia clausseni DC. & 3 & 3 & 0,21 & 0,21 & 0,04 & 0,04 & 0,3 & 0,3 & 0,56 & 0,56 \\
\hline Croton floribundus (L.) Spreng. & 2 & 2 & 0,14 & 0,14 & 0,18 & 0,18 & 0,1 & 0,2 & 0,42 & 0,52 \\
\hline Guapira opposita (Vell.) Reitz. & 2 & 2 & 0,14 & 0,14 & 0,14 & 0,17 & 0,2 & 0,2 & 0,49 & 0,52 \\
\hline Amaioua guianensis Aubl. & 2 & 2 & 0,14 & 0,14 & 0,13 & 0,14 & 0,2 & 0,2 & 0,47 & 0,48 \\
\hline Casearia obliqua Spreng. & 1 & 1 & 0,07 & 0,07 & 0,3 & 0,29 & 0,1 & 0,1 & 0,47 & 0,46 \\
\hline Zanthoxylum chiloperone (Mart.) Engl. & 1 & 2 & 0,07 & 0,14 & 0,06 & 0,08 & 0,1 & 0,2 & 0,24 & 0,43 \\
\hline Indeterminada 1 & 3 & 2 & 0,22 & 0,14 & 0,28 & 0,08 & 0,31 & 0,2 & 0,8 & 0,42 \\
\hline Xylosma pseudosalzmanii Sleum. & 2 & 2 & 0,14 & 0,14 & 0,06 & 0,06 & 0,2 & 0,2 & 0,04 & 0,4 . \\
\hline Agonandra englerii Hoehne & 2 & 2 & 0,14 & 0,14 & 0,04 & 0,04 & 0,2 & 0,2 & 0,39 & $0,39^{\circ}$ \\
\hline Casearia decandra Jacq. & 2 & 2 & 0,14 & 0,14 & 0,08 & 0,04 & 0,2 & 0,2 & 0,43 & 0,38 \\
\hline Albizia polychephala & 0 & 2 & 0 & 0,14 & 0 & 0,03 & 0 & 0,2 & 0 & 0,37 \\
\hline Nectandra megapotamica (Spreng.) Mez & 1 & 2 & 0,07 & 0,14 & 0,01 & 0,02 & 0,1 & 0,2 & 0,18 & 0,37 \\
\hline Lonchocarpus muehlbergianus Hassl. & 1 & 1 & 0,07 & 0,07 & 0,1 & 0,13 & 0,1 & 0,1 & 0,27 & 0,31 \\
\hline Cecropia pachystachya Trec. & 1 & 1 & 0,07 & 0,07 & 0,1 & 0,12 & 0,1 & 0,1 & 0,27 & 0,3 \\
\hline $\begin{array}{l}\text { Nectandra mollis var oppositifolia (Nees) } \\
\text { Pohwer }\end{array}$ & 1 & 1 & 0,07 & 0,07 & 0,1 & 0,11 & 0,1 & 0,1 & 0,28 & 0,28 \\
\hline Syagrus oleracea & 1 & 1 & 0,07 & 0,07 & 0,07 & 0,07 & 0,1 & 0,1 & 0,24 & 0,24 \\
\hline Sysygium jambos (L.) Alston & 1 & 1 & 0,07 & 0,07 & 0,05 & 0,06 & 0,1 & 0,1 & 0,22 & 0,23 \\
\hline Tapirira guianensis Aubl. & 1 & 1 & 0,07 & 0,07 & 0,03 & 0,06 & 0,1 & 0,1 & 0,21 & 0,23 \\
\hline $\begin{array}{l}\text { Actinostemon concolor (Spreng.) Muell. } \\
\text { Arg. }\end{array}$ & 1 & 1 & 0,07 & 0,07 & 0,03 & 0,04 & 0,1 & 0,1 & 0,2 & 0,21 \\
\hline Aspidosperma cylindrocarpon Muell. Arg. & 1 & 1 & 0,07 & 0,07 & 0,02 & 0,03 & 0,1 & 0,1 & 0,19 & 0,2 \\
\hline Inga vera subsp.affinis (DC.) T.D. Penn. & 1 & 1 & 0,07 & 0,07 & 0,03 & 0,03 & 0,1 & 0,1 & 0,2 & 0,2 \\
\hline Nectandra rigida (H.B.K.) Nees & 1 & 1 & 0,07 & 0,07 & 0,01 & 0,03 & 0,1 & 0,1 & 0,19 & 0,2 \\
\hline Pilocarpus pauciflorus St. Hil. & 1 & 1 & 0,07 & 0,07 & 0,02 & 0,03 & 0,1 & 0,1 & 0,2 & 0,2 \\
\hline cf. Eugenia & 0 & 1 & 0 & 0,07 & 0 & 0,02 & 0 & 0,1 & 0 & 0,2 \\
\hline Erythroxylum buxus Peyr. & 1 & $i$ & 0,07 & 0,07 & 0,01 & 0,02 & 0,1 & 0,1 & 0,18 & 0,2 \\
\hline Alibertia concolor (Cham.) Schumm. & 1 & 1 & 0,07 & 0,07 & 0,01 & 0,02 & 0,1 & 0,1 & 0,19 & 0,19 \\
\hline Cariniana legalis (Mart.) Kuntze & 1 & 1 & 0,07 & 0,07 & 0,02 & 0,01 & 0,1 & 0,1 & 0,19 & 0,19 \\
\hline Indeterminada 3 & 0 & 1 & 0 & 0,07 & 0 & 0,02 & 0 & 0,1 & 0 & 0,19 \\
\hline Meliaceae 1 & 1 & 1 & 0,07 & 0,07 & 0,01 & 0,02 & 0,1 & 0,1 & 0,18 & 0,19 \\
\hline Pisidium sp. & 2 & 1 & 0,14 & 0,07 & 0,02 & 0,01 & 0,2 & 0,1 & 0,37 & 0,19 \\
\hline Pisonia ambigua Heimerl. & 1 & 1 & 0,07 & 0,07 & 0,01 & 0,02 & 0,1 & 0,1 & 0,18 & 0,19 \\
\hline Prockia crucis P. Browne ex L. & 0 & 1 & 0 & 0,07 & 0 & 0,01 & 0 & 0,1 & 0 & 0,19 \\
\hline Campomanesia guaviroba (DC.) Kiaersk. & 1 & 1 & 0,07 & 0,07 & 0,01 & 0,01 & 0,1 & 0,1 & 0,18 & 0,18 \\
\hline Inga marginata Willd. & 1 & 1 & 0,07 & 0,07 & 0,01 & 0,01 & 0,1 & 0,1 & 0,18 & 0,18 \\
\hline Ixora venulosa Benth. & 0 & 1 & 0 & 0,07 & 0 & 0,01 & 0 & 0,1 & 0 & 0,18 \\
\hline
\end{tabular}


(Cont.) Anexo 2.1 - Resultado dos parâmetros fotossociológicos de 1989 e 1998 calculados para as espécies amostradas em um trecho de floresta ribeirinha do Rio Passa Cinco, Ipeúna, SP, em ordem decrescente de IVI para 1998. $\mathrm{n}^{0}$ - número de indivíduos; dens. r.- densidade relativa; dom. r. - dominância relativa; freq. $r$ - freqüência relativa; IVI - índice de valor de importância.

\begin{tabular}{|c|c|c|c|c|c|c|c|c|c|c|}
\hline \multirow{2}{*}{$\begin{array}{l}\text { espécie } \\
\text { ano }\end{array}$} & \multicolumn{2}{|c|}{$\mathrm{n}^{\mathrm{O}}$} & \multicolumn{2}{|c|}{ dens. $r$} & \multicolumn{2}{|c|}{ dom. $\mathbf{r}$} & \multicolumn{2}{|c|}{ freq. $r$} & \multicolumn{2}{|c|}{ ivi } \\
\hline & 1989 & 1998 & 1989 & 1998 & 1989 & 1998 & 1989 & 1998 & 1989 & 1998 \\
\hline $\begin{array}{l}\text { Myrciaria floribunda (West \& Willd.) } \\
\text { Berg. }\end{array}$ & 0 & 1 & 0 & 0,07 & 0 & 0,01 & 0 & 0,1 & 0 & 0,18 \\
\hline Randia armata (Sw.) DC. & 1 & 1 & 0,07 & 0,07 & 0,01 & 0,01 & 0,1 & 0,1 & 0,18 & 0,18 \\
\hline Enthrina crista-galli L. & 1 & 0 & 0,07 & 0 & 0,36 & 0 & 0,1 & 0 & 0,53 & 0 \\
\hline Patagonula americana $\mathrm{L}$. & 1 & 0 & 0,07 & 0 & 0,09 & 0 & 0,1 & 0 & 0,27 & 0 \\
\hline Eugenia aff. pluriflora DC. & 1 & 0 & 0,07 & 0 & 0,01 & 0 & 0,1 & 0 & 0,18 & 0 \\
\hline Ocotea sp. & 1 & 0 & 0,07 & 0 & 0,01 & 0 & 0,1 & 0 & 0,18 & 0 \\
\hline
\end{tabular}


Anexo 2.2 - Lista das espécies que ocorrem em cada grupo vegetacional identificado nas Figuras 2 e 3 e distribuídas na área conforme Figura 1, do trecho de floresta ribeirinha estudada num fragmento do Rio Passa Cinco, SP. ++ Espécies amostradas apenas em 1989. + Espécies amostradas apenas em 1998.

\begin{tabular}{|c|c|c|}
\hline $\begin{array}{l}\text { Faixa ribeirinha } \\
\text { (Solo aluvial) }\end{array}$ & $\begin{array}{l}\text { Porção central e canto sudoeste } \\
\text { (Solo } \mathrm{AQ} / \mathrm{Cb} \text { ) }\end{array}$ & $\begin{array}{l}\text { Canto sudeste } \\
\text { (Solo PV) } \\
\end{array}$ \\
\hline Acacia polyphylla ++ & Acacia polyphylla & Acacia polypbylla \\
\hline Actinostemon klotzchii & Actinostemon klotzchii & Actinostemon klotzchii \\
\hline Allophylus edulis & Allopbylus edulis & Allophylus edulis \\
\hline Calliandra twveediei & Calliandra tweediei & Calliandra tweediei. \\
\hline Callisthene minor & Callisthene minor & Callisthene minor \\
\hline Campomanesia xanthocarpa & Campomanesia xanthocarpa & Campomanesia xanthocarpa \\
\hline Cariniana estrellensis & Cariniana estrellensis & Cariniana estrellensis \\
\hline Casearia sylvestris & Casearia sylvestris & Casearia syluestris \\
\hline Centrolobium tomentosum & Centrolobium tomentosum & Centrolobium tomentosum \\
\hline Chomelia ribesiodes ++ & Chometia ribesioides & Chomelia ribesioides \\
\hline Chrysopbyllum gonocarpum & Chrysopbyllum gonocarpum & Chrysopbyllum gonocarpum \\
\hline Copaifera langsdorfii & Copaifera langsdorfii & Copaifera langsdorfii \\
\hline Couratea bexandra & Couratea bexandra & Couratea hexandra \\
\hline Cryptocaria aschersoniana & Cryptocaria aschersoniana & Coyptocaria aschersoniana \\
\hline Cupania vernalis & Cupania vernalis & Cupania vernalis \\
\hline Dalbergia brasiliensis & Dalbergia brasiliensis & Dalbergia brasiliensis \\
\hline Diatenopteryx sorbifolia & Diatenopteryx sorbifolia & Diatenopteryx sorbifolia \\
\hline Dyospirus sp. & Dyospirus sp. & Dyospirus sp. ++ \\
\hline Esenbeckia frebifuga & Esenbeckia frebifuga & Esenbeckia frebifuga \\
\hline Eugenia blastantha & Eugenia blastantha & Eugenia blastantha \\
\hline Eugenia racemulasa ++ & Eugenia racemulosa & Eugenia racemulosa \\
\hline Eugenia uniflora & Eugenia uniflara & Eugenia uniflora ++ \\
\hline Galipea multiflora & Galipea multiflora + & Galipea multiflora \\
\hline Jacaranda macrantha & Jacaranda macrantha & Jacaranda macrantha \\
\hline Luebea divaricata & Luebea divaricata & Luebea divaricata \\
\hline Machaerium nictitans & Machaerium nictitans & Machaerium nictitans \\
\hline Machaerium stipitatum & Machaerium stipitatum & Machaerium stipitatum \\
\hline Matayba elaeagnoides & Matayba elaeagnoides & Matayba elaeagnoides \\
\hline Maytenus robusta & Maytenus robusta & Maytenus robusta \\
\hline Metrodorea nigra & Metrodorea nigra & Metrodorea nigra \\
\hline Myrcia rostrata & Myrcia nostrata & Myrcia rostrata \\
\hline Neomitranthes glomerata & Neomitranthes glomerata & Neomitranthes glomerata + \\
\hline Prunus sellowii & Prunus sellowii ++ & Prunus sellowii \\
\hline Rollinia sylvatica & Rollinia sylvatica & Rollinia sylvatica \\
\hline Rudgea jasminoides & Rudgea jasminoides & Rudgea jasminoides \\
\hline Sebastiania semata & Sebastiania serrata & Sebastiania serrata \\
\hline Syagrus romanzoffiana & Syagrus romanzoffiana & Syagrus romanzoffiana \\
\hline Tricbilia catigua & Tricbilia catigua & Trichilia catigua \\
\hline
\end{tabular}


(Cont.) Anexo 2.2 - Lista das espécies que ocorrem em cada grupo vegetacional identificado nas Figuras 2 e 3 e distribuídas na área conforme Figura 1, do trecho de floresta ribeirinha estudada num fragmento do Rio Passa Cinco, SP. ++ Espécies amostradas apenas em 1989. + Espécies amostradas apenas em 1998.

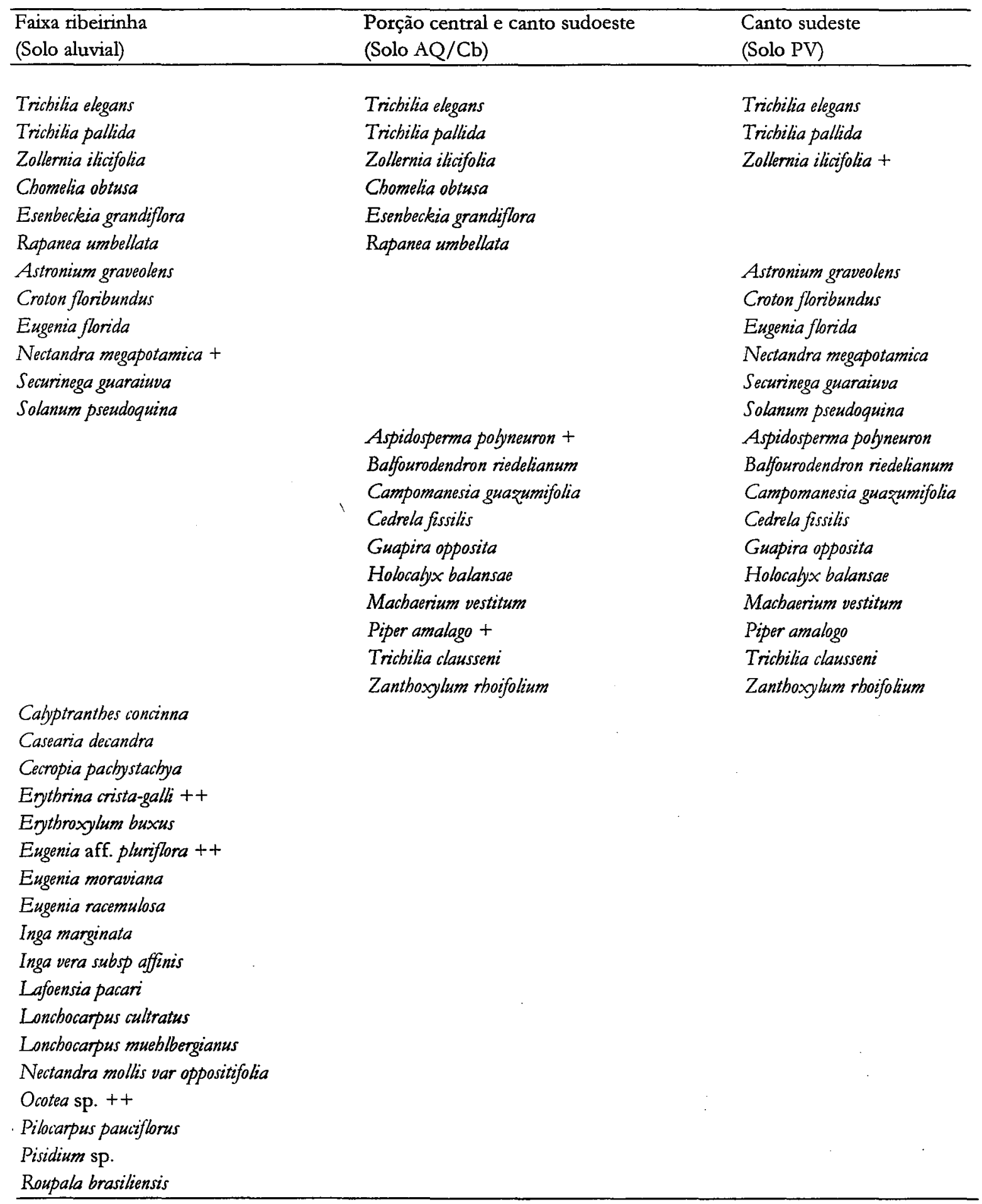


(Cont.) Anexo 2.2 - Lista das espécies que ocorrem em cada grupo vegetacional identificado nas Figuras 2 e 3 e distribuídas na área conforme Figura 1, do trecho de floresta ribeirinha estudada num fragmento do Rio Passa Cinco, SP. ++ Espécies amostradas apenas em 1989. + Espécies amostradas apenas em 1998.

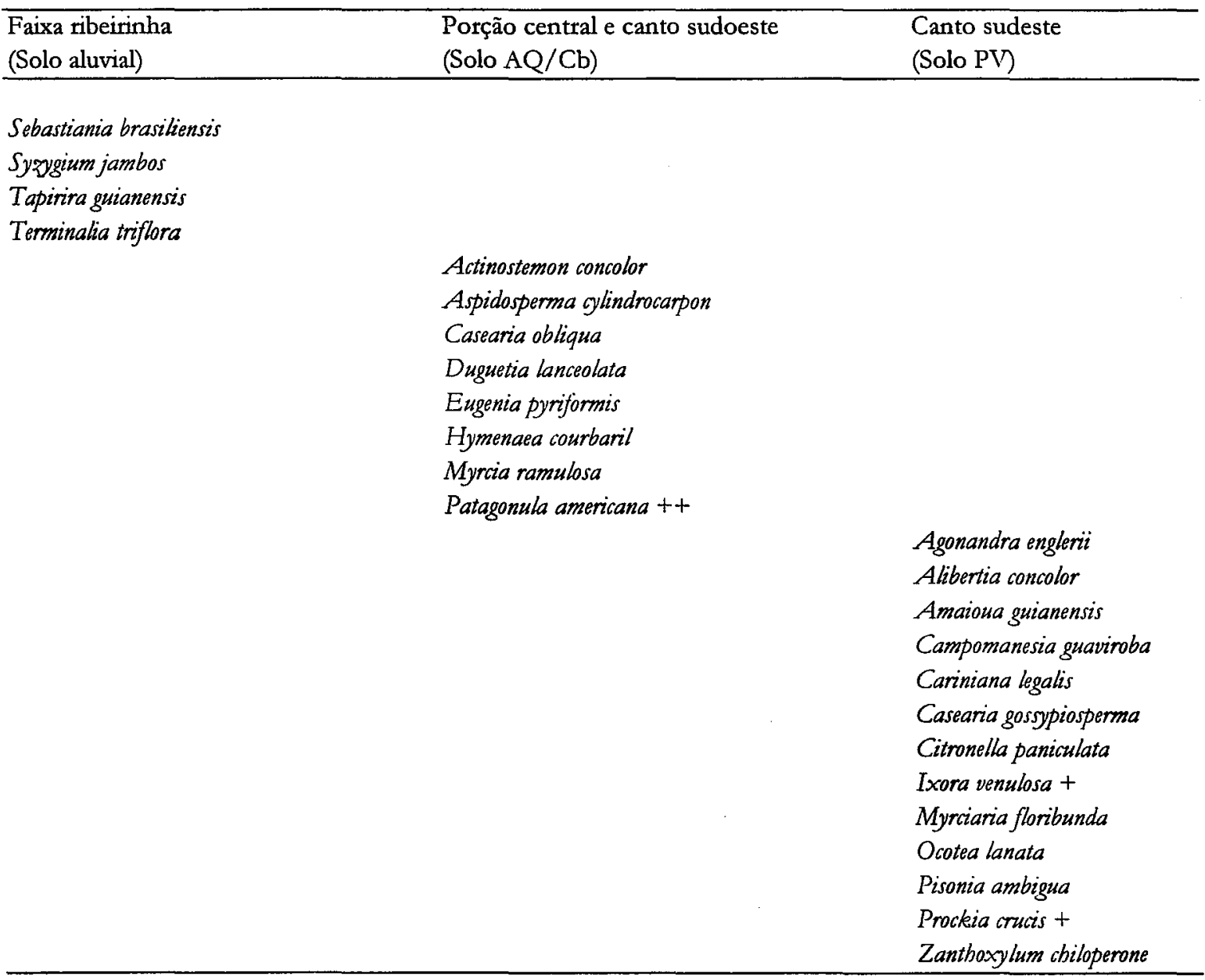




\section{CAPÍTULO 3}

\section{DINÂMICA, CRESCIMENTO E DISTRIBUIÇÃO ESPACIAL DOS INDIVÍDUOS ARBÓREOS DE UMA FLORESTA RIBEIRINHA EM IPEÚNA, SP: CARACTERIZAÇÃO EM TRÊS SUBSTRATOS}

\subsection{RESUMO}

Foram analisados aspectos da dinâmica e crescimento de uma comunidade em um trecho de floresta ribeirinha do Rio Passa Cinco, Ipeúna, SP. O trecho é caracterizado por um mosaico florestal constituido de três grupos vegetacionais correlacionados com as características edáficas da área. Foram medidos e mapeados em 1989 e 1998 todos os indivíduos arbustivo- arbóreos com DAP $\geq 5 \mathrm{~cm}$ em um trecho ao longo do rio, de 0,785 ha formado por 157 parcelas contínuas de $5 \times 10 \mathrm{~m}$. A taxa de mortalidade se igualou a taxa de ingresso, indicando estabilidade na comunidade. O padrão de distribuição espacial foi aleatório para as árvores mortas e agrupado para as árvores ingressantes. Houve diferenças consistentes nos componentes da dinâmica entre os três grupos vegetacionais do mosaico ribeirinho. O grupo vegetacional imediatamente paralelo ao curso d'água apresentou diferenças mais pronunciadas, com taxas de mortalidade e crescimento elevadas, e padrão de distribuição agrupado entre os indivíduos. Estas características devem estar relacionadas diretamente à influência das cheias do rio. Os grupos vegetacionais não sujeitos à 
interferência direta do rio apresentaram distribuição espacial aleatória de seus individuos, tendendo à regularidade, o que poderia indicar algumas restrições ambientais nestas áreas, relacionadas às características edáficas e topográficas.

\subsection{INTRODUÇÃO}

O estudo de dinâmica de populações vegetais em florestas tropicais tem grande importância não só como instrumento de compreensão de populações, como também de comunidades, caracterizadas pela grande diversidade e complexidade (Armesto, 1986). Esta complexidade está relacionada à grande heterogeneidade de condições ambientais encontradas no interior destas florestas, muitas vezes geradas pela heterogeneidade das características do ambiente (Rodrigues 1992, Felfili, 1995) ou abertura de clareiras (Whitmore, 1989).

As florestas tropicais são dinâmicas e mudanças ocorrem continuamente nos indivíduos e nas populaçòes ao longo do tempo (Felfili, 1994). De acordo com processos locais de mortalidade, crescimento e regeneração, árvores são perdidas e repostas continuamente, num balanço dado pelo ingresso de novos indivíduos e pela mortalidade. Estas mudanças são o maior foco de estudo de dinâmica de vegetação (Swaine, 1987a).

Trabalhos de acompanhamento de médio e longo prazo da vegetação em florestas tropicais vem sendo desenvolvidos, no sentido de estabelecer padrões de mortalidade, crescimento e ingresso para espécies e para a comunidade como um todo (Hartshorn, 1980; Lang \&Knight, 1983; Lieberman \& Lieberman, 1987; Swaine, 1987b; Lieberman et al., 1990; Hubbell \& Foster, 1990; Gentry \& Terborgh, 1990; Foster, 1990; Rankin-de-Merona, 1990; Primack, 1991; Condict, 1995; Felfili, 1995; Santos, 1996; Martini, 199; Toriola, 1998). Estes componentes da dinâmica variam muito entre as áreas, dentro destas áreas e no tempo (Dallmeier et al., 1996).

A inclusão de informações espaciais em estudos de dinâmica possibilita a detecção de importantes fatores que determinam os padrões encontrados nos componentes da dinâmica, como o efeito de densidade (Hubbell et al., 1990), predaçào (herbivoria), dispersão, alelopatia, competiçào intra e/ou interespecífica (Duncan, 1991a), e fatores 
físicos como condições do microambiente favoráveis ou não para o estabelecimento de determinada espécie, facilitando a compreensão da dinâmica das diversas populações envolvidas (Szwagrzyk, 1990; Stewart \& Rose, 1990; Moeur, 1993; Maguire et al., 1993; Batista, 1994).

Variações no ambiente podem ser as principais responsáveis por diferenças no padrão de crescimento de espécies, além de terem papel importante na alteração de taxas de mortalidade e ingresso (Swaine et al., 1987b). São poucos os estudos que abordam comparaçòes da dinâmica e crescimento de espécies em diferentes condições ambientais, numa mesma área. Dentre estes, podemos citar os estudos da ecologia de populações de duas espécies, em sítios esporadicamente alagáveis e não alagáveis na bacia do rio Tibagi, estado do Paraná (Bianchini, 1998; Pimenta, 1998). Um estudo comparando a dinâmica, composição florística e diversidade, em áreas com diferentes características edáficas, foi realizado em Pakitza, no rio Manu, Peru (Dallmeier et al., 1996). Outro trabalho realizado em La selva, Costa Rica, apresenta comparações da dinâmica e crescimento, entre áreas com diferentes características topográficas e edáficas (Lieberman \& Lieberman, 1987).

Neste estudo foram analisados aspectos da dinâmica de uma comunidade vegetal de florestas ribeirinha, caracterizada por apresentar um mosaico vegetacional com grande correlação às características edáficas da área (Rodrigues, 1992). Os objetivos específicos foram:

- determinar as taxas de mortalidade, ingresso e crescimento; descrever a estrutura espacial de uma florestas ribeirinha, após 9 anos;

- e fazer uma comparação da dinâmica e taxa de crescimento da vegetação sob três substratos diferentes encontrados na área, para verificar se estes parâmetros populacionais estão relacionados com a heterogeneidade ambiental. 


\subsection{MATERIAL E MÉTODOS}

\subsection{1 Área de Estudo}

Este estudo foi realizado em um fragmento de floresta ribeirinha do Rio Passa Cinco, localizado no Município de Ipeúna (22 $26^{\prime} 08^{\prime \prime}$ S e $47^{\circ} 43^{\prime} 05^{\prime \prime}$ O), Estado de São Paulo, que faz parte da APA de Corumbataí. Apresentando uma área de aproximadamente 60 ha, tem como atividade principal do entorno a cultura de cana de açúcar. Apesar da bacia do Rio Passa Cinco se caracterizar como altamente perturbada, tendo como principal causa práticas agrícolas inadequadas, restaram alguns fragmentos florestais remanescentes, como a área de estudo, que foi mantida em bom estado de conservação por estar confinada em um fundo de vale. Ainda assim, podem ser observados alguns sinais de degradação neste trecho de floresta ribeirinha, principalmente nas bordas, pela extração seletiva de madeira e pelo fogo originado da cultura de cana-de-açúcar. Os limites deste fragmento florestal estão definidos por encostas íngremes, com declividade superior a $30^{\circ}$. Nesta região, o rio tem cerca de $12 \mathrm{~m}$ de largura média, o fundo é irregular com grandes depósitos de material oriundo de assoreamento à montante, e alcança profundidade média de $1,5 \mathrm{~m}$ em época de chuvas.

O clima da região de Ipeúna caracteriza-se como quente úmido, com inverno seco (maio a setembro) e verão chuvoso (outubro a fevereiro) (Rodrigues, 1992).

\subsubsection{Métodos}

Em 1989 foi feito o estudo fitossociológico e o mapeamento de todos os indivíduos arbóreos com diâmetro à altura do peito, $(\mathrm{DAP}) \geq 5 \mathrm{~cm}$, em aproximadamente 0,8 ha (200 $\mathrm{m}$ de comprimento e $40 \mathrm{~m}$ de largura) em um trecho de floresta ribeirinha do Rio Passa Cinco, Ipeúna, SP (Rodrigues, 1992, Bertani et al. não publicado). Foi demarcada uma parcela de $200 \mathrm{~m}$ ao longo do rio e $40 \mathrm{~m}$ perpendicular a este, subdividida em 157 parcelas menores, de $5 \times 10 \mathrm{~m}$ (Figura 3.1). O levantamento indicou a existência de três grupos vegetacionais correlacionados com as características edáficas da área. Os tipos principais de 
solo encontrados neste trecho de floresta (Rodrigues 1992), foram: solo Aluvial (AL), solo Podzólico Vermelho Amarelo (PV) e solo Areia Quartzosa Intermediário para Cambissolo (AQ/Cb), conforme Figura 3.1.

Para o presente estudo foram feitas novas medidas de diâmetro de todas as árvores amostradas por Rodrigues (1992), sendo as árvores ingressantes, com DAP $\geq 5 \mathrm{~cm}$, coletadas para posterior identificação, numeradas com plaquetas de alumínio galvanizado, e medidos seus diâmetros. As árvores mortas que permaneciam em pé também foram medidas e plaqueadas. As árvores amostradas no estudo anterior que desapareceram foram consideradas mortas.

O material coletado foi identificado através de observações de campo, por auxilio de especialistas, e quando possivel por comparações com material do Herbário ESA, do Departamento de Ciências Biológicas da ESALQ/USP.

\subsubsection{Análise de dados}

\subsubsection{Mortalidade}

Para análise de mortalidade utilizou-se a taxa de mortalidade (me) proposta por Swaine \& Lieberman (1987):

$$
\mathrm{me}=[\ln (\mathrm{N} 0)-\ln (\mathrm{N} 1)] / \mathrm{t}
$$

Onde: N0 - número de indivíduos da população ou comunidade vivos iniciais, isto é, amostrados no primeiro levantamento (1989);

N1 - número de indivíduos da população ou comunidade encontrados no segundo levantamento (1998);

$\mathrm{t}$ - tempo entre os levantamentos (9 anos).

Esta taxa é uma aproximação da taxa instantânea de mortalidade (Condict, 1995). 


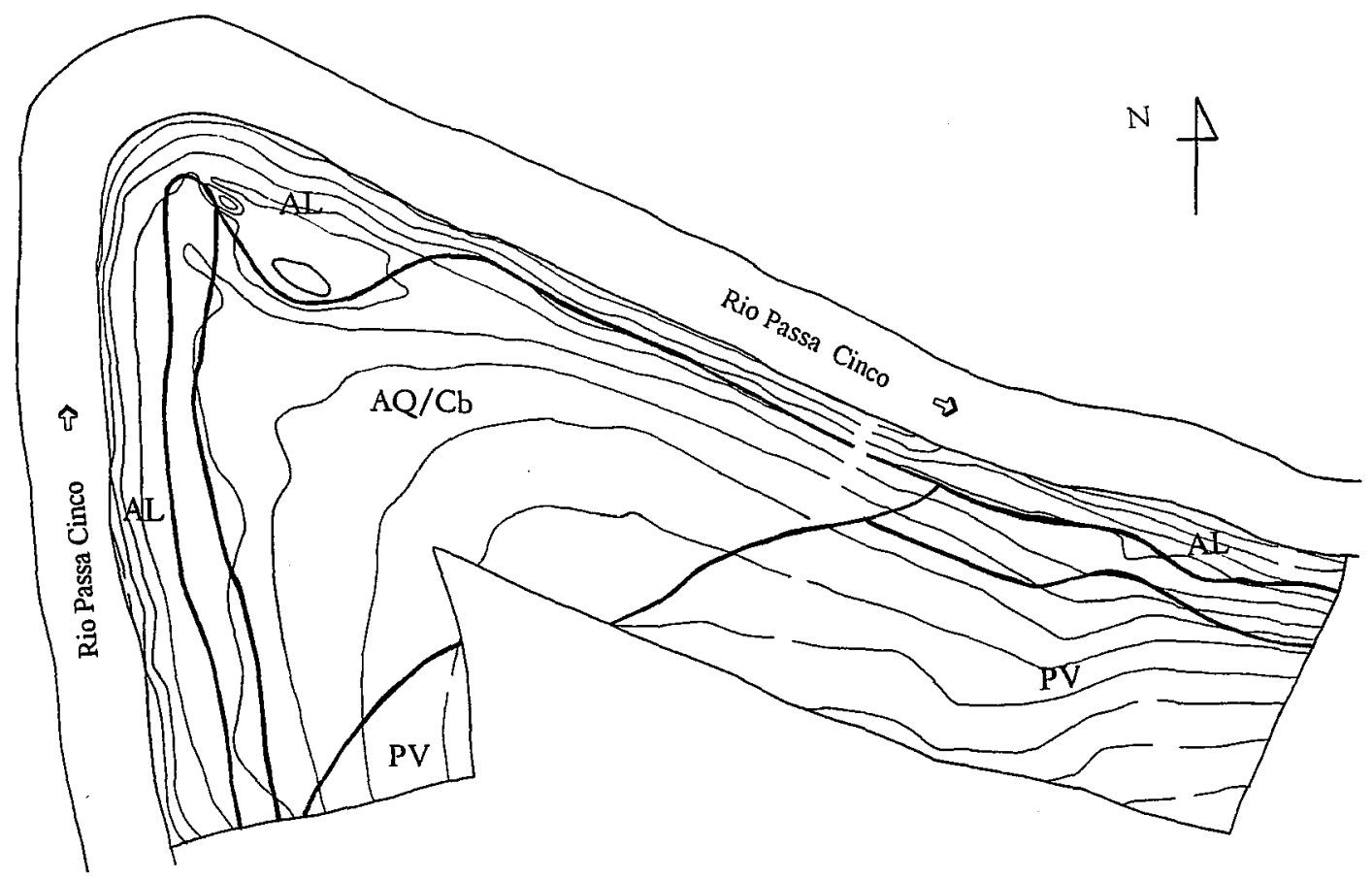

esc. aprox. : 1:1000

Figura 3.1 - Mapa topográfico e dos principais tipos de solo da área amostrada num trecho de floresta ribeirinha do rio Passa Cinco Ipeúna, SP. AQ/Cb - areia Quartzosa intermediário para cambissolo; $\mathrm{Al}$ - solo aluvial distrófico; $\mathrm{PV}$ - podzólico vermelho amarelo. 
Para verificar se existiram diferenças nas taxas de mortalidade entre os grupos vegetacionais sobre os solos $\mathrm{AL}, \mathrm{PV}$ e $\mathrm{AQ} / \mathrm{Cb}$, foi feito um teste de Qui-quadrado para testar homogeneidade entre as áreas (Zar, 1984).

Para verificar se a mortalidade foi dependente do tamanho dos indivíduos, foi feito um teste de Qui-quadrado para testar homogeneidade entre as taxas de mortalidade por classe de diâmetro (Zar, 1984), tanto para a comunidade como um todo como para os grupos vegetacionais sobre os solos $\mathrm{AL}, \mathrm{PV}$ e AQ/Cb.

Foram também calculadas as taxas de mortalidade para individuos maiores que 10 $\mathrm{cm}$ de diâmetro, para serem possíveis as comparaçōes com outros estudos presentes na literatura. A meia vida $\left(t_{(1,5)}\right)$, que representa o tempo necessário para que metade dos indivíduos de uma população tenha morrido, foi calculada a partir da taxa de mortalidade, da seguinte forma:

$$
t_{(1,5)}=\ln 0,5 / \mathrm{me}
$$

\subsubsection{Ingresso}

Para análise dos indivíduos que ingressaram após 9 anos, atingindo DAP $\geq 5 \mathrm{~cm}$, foi utilizada a taxa de ingresso anual (i), calculada desta forma:

$$
\mathrm{i}=\ln [(\mathrm{N} 0+\mathrm{I}) / \mathrm{N} 0] / \mathrm{t}
$$

Onde: N0 - número de indivíduos da população ou comunidade vivos iniciais, isto é, amostrados no primeiro levantamento (1989);

I - número de indivíduos nào amostrados no levantamento de 1989 , que atingiram DAP $\geq 5 \mathrm{~cm}$ em 1998 .

$\mathrm{t}$ - tempo entre os levantamentos ( 9 anos). 
Para verificar se as taxas de ingresso (i) entre os três grupos vegetacionais diferiram entre si, foi feito um teste de Qui-quadrado para testar a homogeneidade entre estes grupos (Zar, 1984).

\subsubsection{Crescimento}

A taxa média de crescimento em diâmetro foi calculada pela diferença entre os diâmetros amostrados em 1989 e 1998, dividido pelo tempo ( 9 anos), usando como unidade $\mathrm{cm} / \mathrm{ano}$. Os indivíduos que por motivo de quebra de ramos, senescência ou até de erros de medição tiveram suas medidas de diâmetro diminuídas à um valor inferior a $5 \mathrm{~cm}$, foram desconsideradas da análise.

A partir das taxas individuais de crescimento foram calculadas as taxas médias e o desvio padrão para cada grupo vegetacional e para a comunidade. As médias destas áreas foram comparadas através de uma análise de variância (ANOVA), e se encontradas diferenças significativas, foi utilizado o teste Tukey (Zar, 1984).

Para verificar se as taxas de crescimento foram dependentes das classes de tamanho do indivíduo, foi utilizados o mesmo procedimento estatístico do parágrafo anterior.

\subsubsection{Distribuição espacial}

Devido às dimensòes e formato da área amostrada, esta foi reduzida à uma área retangular de 30 × $50 \mathrm{~m}$, para possibilitar a análise espacial da distribuição dos indivíduos, devido a limitações do método (Figura 3.2). Tentou-se amostrar a porção mais representativa de cada grupo vegetacional, em relação aos tipos de solo mapeados por Rodrigues (1992).

Os padrões espaciais determinados pelo mapa dos dados foram analisados pela função K de Ripley (Ripley, 1977), que considera as distâncias entre todos os pares de árvores na área de estudo, sendo uma função de distribuição cumulativa das distâncias entre todas as árvores (Penttinen et al., 1992, Moeur, 1993). Assim, tem-se: 
$K(r)=$ sua interpretação é proporcional ao número esperado de pares de árvores cuja distância é no máximo i.

Onde K (r) é o valor da função K para uma dada distância r.

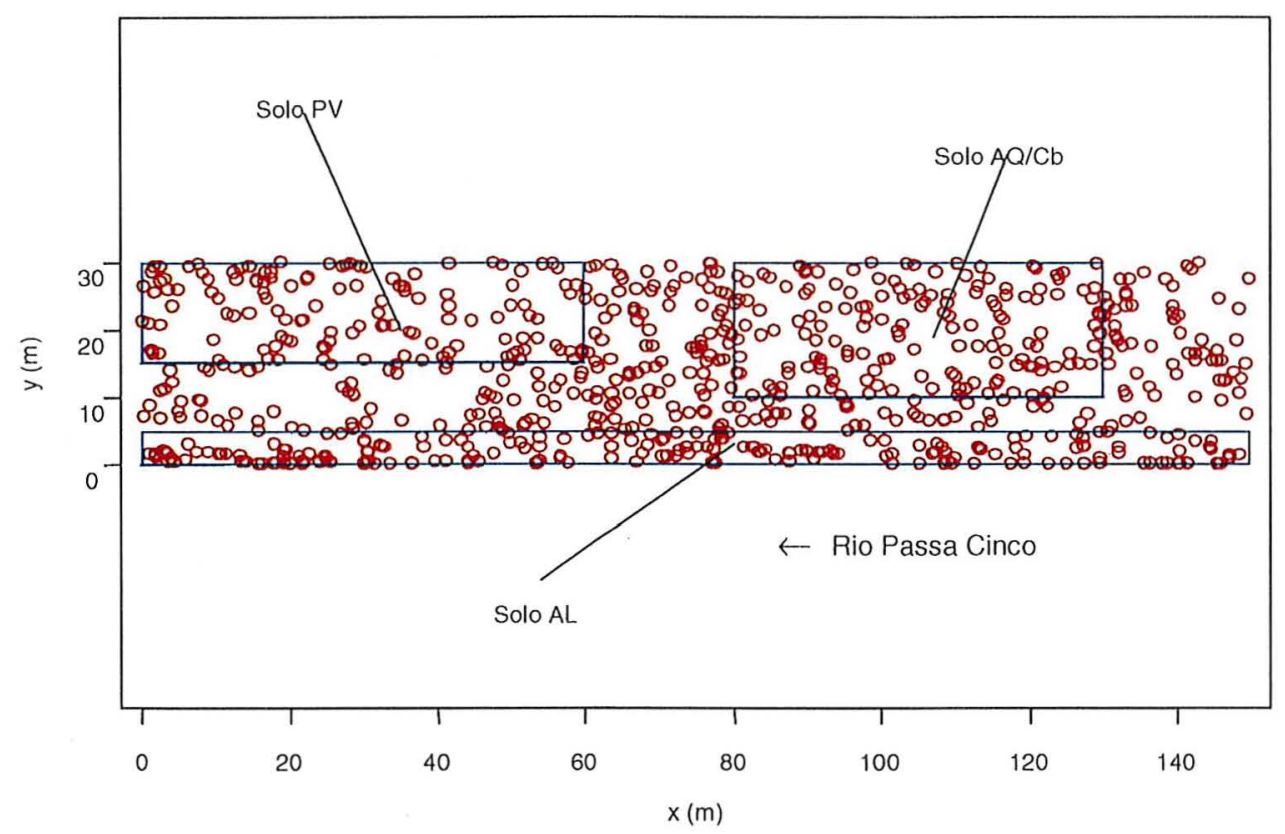

Fígura 3.2 - Mapa da distribuição espacial dos indivíduos amostrados por Rodrigues (1992) cm 1989, representando a área utilizada para o estudo da distribuição espacial, na floresta ribeirinha do Rio Passa Cinco, Ipeúna, SP. As áreas delimitadas pelos solos característicos de cada grupo vegetacional estão indicados por: Solo AJ; Solo PV e Solo AQ/Cb.

Isto possibilita uma análise mais detalhada do padrão espacial de uma população e também a independência entre dois padròes espaciais (Noeur, 1993; Batista, 1994)

Para processos espaciais completamente aleatórios, K (r) é igual à área do círculo de raio $\mathrm{r}\left(\mathrm{K}(\mathrm{r})=\pi \mathrm{r}^{2}\right)$, tornando fácil a detecção dos desrios da aleatoriedade espacial em 
diferentes escalas. Para facilitar a visualização dos desvios da aleatoriedade, constroe-se um gráfico colocando-se nas abcissas a distância $r$ e nas ordenadas a seguinte transformação da função $K$ :

$$
L(r)=[K(r) / \pi]^{1 / 2}-r
$$

Onde: L ( $\mathrm{r}$ - desvio da completa aleatoriedade espacial;

$K(r)$ - valor da função $K$;

r - distância entre pares de árvores.

Desta forma a linha horizontal passando pela origem representa no gráfico a completa aleatoriedade espacial, desvios positivos desta linha indicam agrupamento enquanto desvios negativos desta linha indicam regularidade no padrão de distribuição dos indivíduos.

Alguns trabalhos apresentam os detalhes da construção dos envelopes de confiança e testes relativos à função K ( Ripley, 1977; Penttinen et al., 1992; Moeur, 1993; Batista, 1994; Haase, 1995). 


\subsection{RESULTADOS}

\subsubsection{Mortalidade}

A taxa de mortalidade calculada para a comunidade estudada foi de 1,46\% ao ano, e a meia vida foi de 47 anos (Tabela 3.1).

Tabela 3.1 - Taxas anuais de mortalidade e meia vida calculadas para a comunidade como um todo e para cada sub-grupo vegetacional identificado no mosaico ribeirinho: trecho com vegetação sobre solo $\mathrm{AL}$ (Solo $\mathrm{AL}$ ), trecho com vegetação sobre solo $\mathrm{AQ} / \mathrm{Cb}$ (Solo $\mathrm{AQ} / \mathrm{Cb}$ ) e trecho com vegetação sobre solo PV (Solo PV); $\mathrm{M}$ - número de indivíduos mortos entre 1989 e 1998, N0 - número de indivíduos amostrados em 1989, me - taxa anual de mortalidade, $\mathrm{t}_{(1,5)}$ - meia vida.

\begin{tabular}{lccccc}
\hline & $\mathrm{M}$ & $\mathrm{N} 0$ & $\mathrm{me}$ & $\%$ & $\mathrm{t}_{(1,5)}$ \\
\hline Comunidade & 168 & 1363 & 0,0146 & 1,46 & 47 \\
Solo AL & 55 & 391 & 0,0168 & 1,68 & 41 \\
Solo AQ/Cb & 33 & 434 & 0,0088 & 0,88 & 78 \\
Solo PV & 43 & 301 & 0,0171 & 1,71 & 40 \\
\hline
\end{tabular}

O Anexo 3.1 apresenta as taxas de mortalidade e meia vida para as espécies com número inicial de indivíduos acima de 10. As espécies que apresentaram maiores valores de mortalidade, acima de 5\% ao ano, foram: Allopbylus edulis, com 8,59\% (e meia vida de 8 anos); Calliandra tweediei, com 5,47\% (e meia vida de 12 anos); e Lafoensia pacari, com taxa de mortalidade de 5,39\% ao ano (e 12 anos de meia vida).

As taxas de mortalidade das espécies mais abundantes na área, que foram como Actinostemon klotzchii, Callisthene minor, Matayba elaeagnoides, Metrodorea nigra e Dyatenopterix sorbifolia, variaram de $0,18 \%$ à $2,30 \%$ ao ano. 
Em relação aos sub-grupos vegetacionais identificados no mosaico vegetacional ribeirinho da área de estudo, as taxas de mortalidade diferiram estatisticamente $\left(\chi_{0,05,2}^{2}=\right.$ 9,222; $\mathrm{p}=0,01$ ), sendo que a menor taxa ocorreu na vegetação sobre solo AQ/Cb (Tabela 1) e foi de $0,88 \%$ ao ano. Nos trechos vegetacionais sobre solo PV e AL as taxas foram de 1,71 e 1,68 respectivamente. As espécies que apresentaram maiores valores de mortalidade variaram bastante entre os sub-grupos.

Não ocorreram diferenças significativas nas taxas de mortalidade para as árvores entre diferentes classes de diâmetros, tanto na comunidade e em cada um dos grupos vegetacionais identificados (Tabela 3.2).

Tabela 3.2 Taxa de mortalidade (me) por classes de diâmetro (d) para a comunidade como um todo e para cada sub-grupo vegetacional identificado no mosaico ribeirinho: trecho com vegetaçào sobre solo $\mathrm{AL}$ (Solo $\mathrm{AL}$ ), trecho com vegetação sobre solo $\mathrm{AQ} / \mathrm{Cb}$ (Solo $\mathrm{AQ} / \mathrm{Cb}$ ) e trecho com vegetaçào sobre solo (Solo PV).

\begin{tabular}{crrlrllllllllll}
\hline $\mathrm{d}(\mathrm{cm})$ & \multicolumn{1}{c}{ Comunidade } & \multicolumn{3}{c}{ Solo Al } & \multicolumn{3}{c}{ Solo AQ/Cq } & \multicolumn{3}{c}{ Solo PV } \\
\hline & No & M & me & No & M & me & No & M & me & No & M & me \\
$5-10$ & 789 & 104 & 1,57 & 216 & 34 & 1,90 & 258 & 20 & 0,90 & 179 & 26 & 1,74 \\
$10-15$ & 245 & 34 & 1,66 & 79 & 9 & 1,34 & 63 & 6 & 1,11 & 62 & 11 & 2,17 \\
$15-20$ & 133 & 15 & 1,33 & 39 & 6 & 1,86 & 38 & 4 & 1,24 & 24 & 2 & 0,97 \\
$20-25$ & 93 & 7 & 0,87 & 25 & 2 & 0,93 & 35 & 2 & 0,65 & 16 & 3 & 2,31 \\
$25-30$ & 41 & 5 & 1,45 & 10 & 3 & 3,96 & 19 & 1 & 0,60 & 5 & 0 & 0,00 \\
$>30$ & 62 & 3 & 0,55 & 22 & 1 & 0,52 & 14 & 0 & 0,00 & 15 & 1 & 0,77 \\
\hline
\end{tabular}

Teste de qui-quadrado para homogeneidade da mortalidade na Comunidade $\left(\chi^{2}=5,623\right.$; $\mathrm{p}=0,345)$; vegetação sobre Solo Al $\left(\chi^{2}=4,757 ; \mathrm{p}=0,446\right)$; vegetação sobre Solo AQ/Cb $\left(\chi^{2}\right.$ $=2,063 ; \mathrm{P}=0,840)$ e vegetaçào sobre Solo $\mathrm{PV}\left(\chi^{2}=2,668 ; \mathrm{p}=0,751\right)$.

Apesar da mortalidade não diferir estatisticamente entre as classes de diâmetro, a Figura 3.3 sugere uma reduçào na taxa de mortalidade com o aumento de diamétrico. Tanto na comunidade como na regetação sobre solo $\mathrm{AQ} / \mathrm{Cb}$ as maiores taxas de mortalidade 
foram observadas nas classes menores de diâmetro e as menores taxas nas classes maiores (Figura 3.3). Na vegetação sobre solo PV estes valores variaram muito entre as classes, e na vegetação sobre solo $\mathrm{AL}$ notam-se altas taxas de mortalidade para indivíduos entre 25 e 35 cm de diâmetro.

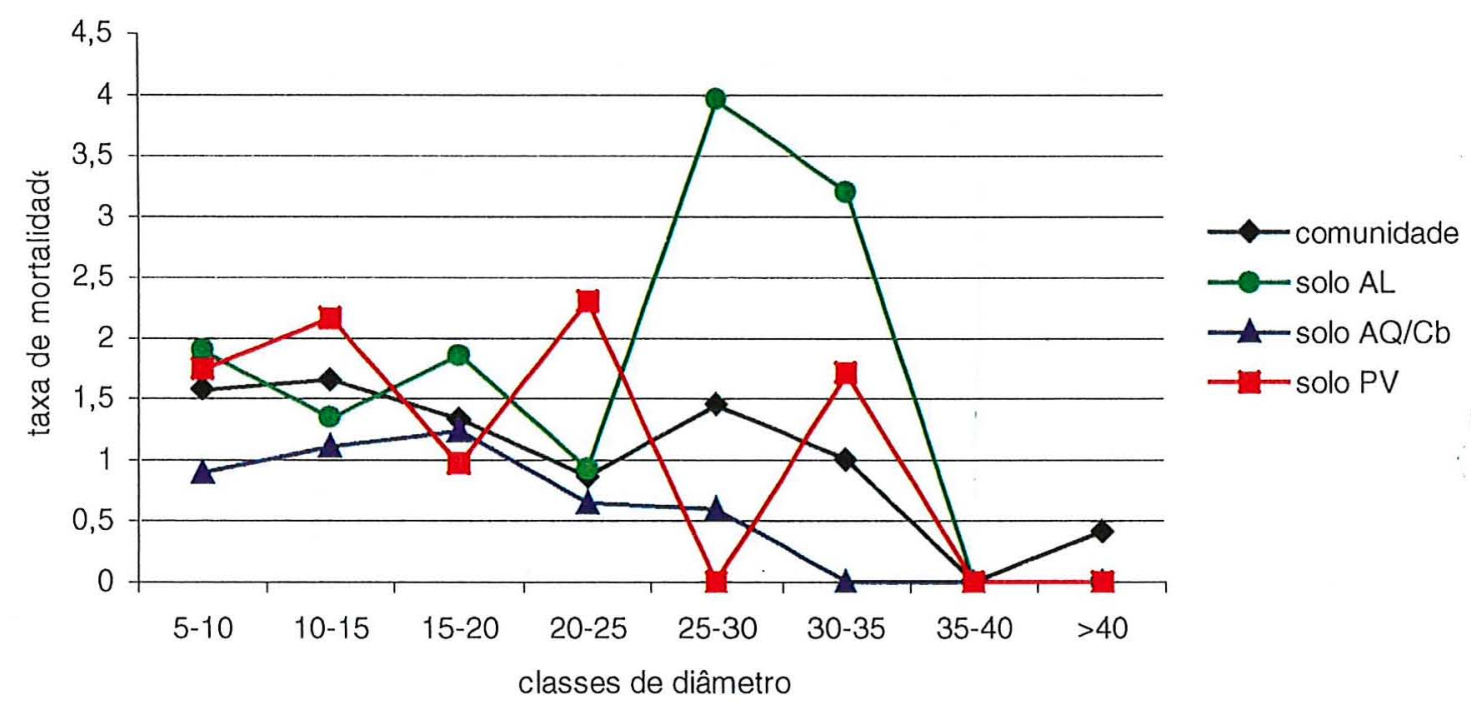

Figura 3.3 - Distribuição das taxas de mortalidade por classes de diâmetro na comunidade e nas três sub-áreas, sobre o solo $\mathrm{AL}$, solo $\mathrm{AQ} / \mathrm{Cb}$ e solo $\mathrm{PV}$.

\subsubsection{Ingresso}

Após nove anos foram amostrados 219 indivíduos ingressantes, isto é, que atingiram $D A P \geq 5 \mathrm{~cm}$ no segundo senso. Assim, a taxa de ingresso calculada para a comunidade foi de 1,66\% ao ano (Tabela 3.3). As espécies que apresentaram os maiores valores foram Actinostemon kelot zichï (4,30\% ao ano), Galipea multiflora $(2,92 \%)$ e Sebastiania serrata $(2,60 \%)$. Entre as espécies mais abundantes (Callisthene minor, Matayba elaeagnoides, Metrodorea nigra, Dyatenopterix sorbifolia), as taxas variaram de $0,29 \%$ a $4,30 \%$ ao ano (Anexo 3.1 ). 
Em relação aos sub-grupos vegetacionais identificados no mosaico ribeirinho, as taxas de ingresso diferiram estatisticamente $\left(\chi_{0,05,2}^{2}=15,946 ; p=0,001\right)$. A vegetação sob solo $\mathrm{AQ} / \mathrm{Cb}$ apresentou maior taxa de ingresso, $2,26 \%$ ao ano (Tabela 3.3). Tanto para a comunidade como para os sub-grupos vegetacionais, Actinostemon klotzchii e Sebastiania serrata foram as espécies com maiores taxas.

Tabela 3.3 - Taxas anuais de ingresso para a comunidade e para os três sub-grupos vegetacionais do mosaico ribeirinho: trecho com vegetação sobre solo AL (Solo AL), trecho com vegetação sobre solo $\mathrm{AQ} / \mathrm{Cb}$ (Solo $\mathrm{AQ} / \mathrm{Cb}$ ) e trecho com vegetação sobre solo (Solo PV); I - número de indivíduos ingressantes, $\mathrm{N} 0$ - número de indivíduos amostrados em $1989, i$ - taxa anual de ingresso.

\begin{tabular}{lcccc}
\hline & I & N0 & $i$ & $\%$ \\
\hline Comunidade & 219 & 1363 & 0,0166 & 1,66 \\
Solo AL & 49 & 391 & 0,0131 & 1,31 \\
Solo AQ/Cb & 98 & 434 & 0,0226 & 2,26 \\
Solo PV & 40 & 301 & 0,0139 & 1,39 \\
\hline
\end{tabular}

Fazendo-se um balanço entre as taxas de mortalidade e ingresso, observa-se um saldo positivo na comunidade e no grupo vegetacional sobre solo $\mathrm{AQ} / \mathrm{Cb}$, indicando estabilidade. Nos sub-grupos sobre os solos PV e AL, a vegetação amostrada apresentou um ligeiro declínio na densidade de indivíduos, causado pelo desequilibrio entre as taxas de mortalidade e ingresso, em favor da mortalidade.

A Figura 3.4 ilustra a relação entre as taxas de mortalidade e ingresso para as espécies da comunidade que apresentaram número inicial de indivíduos maior do que 10.

Nota-se que $A$. klotzcbii se destaca pelo balanço positivo entre as duas taxas $\mathrm{e}$ Allopbylus edulis e Lafoensia pacari pelo balanço negativo. Poucas espécies diferiram significativamente entre as duas taxas, indicando equilibrio na comunidade. 


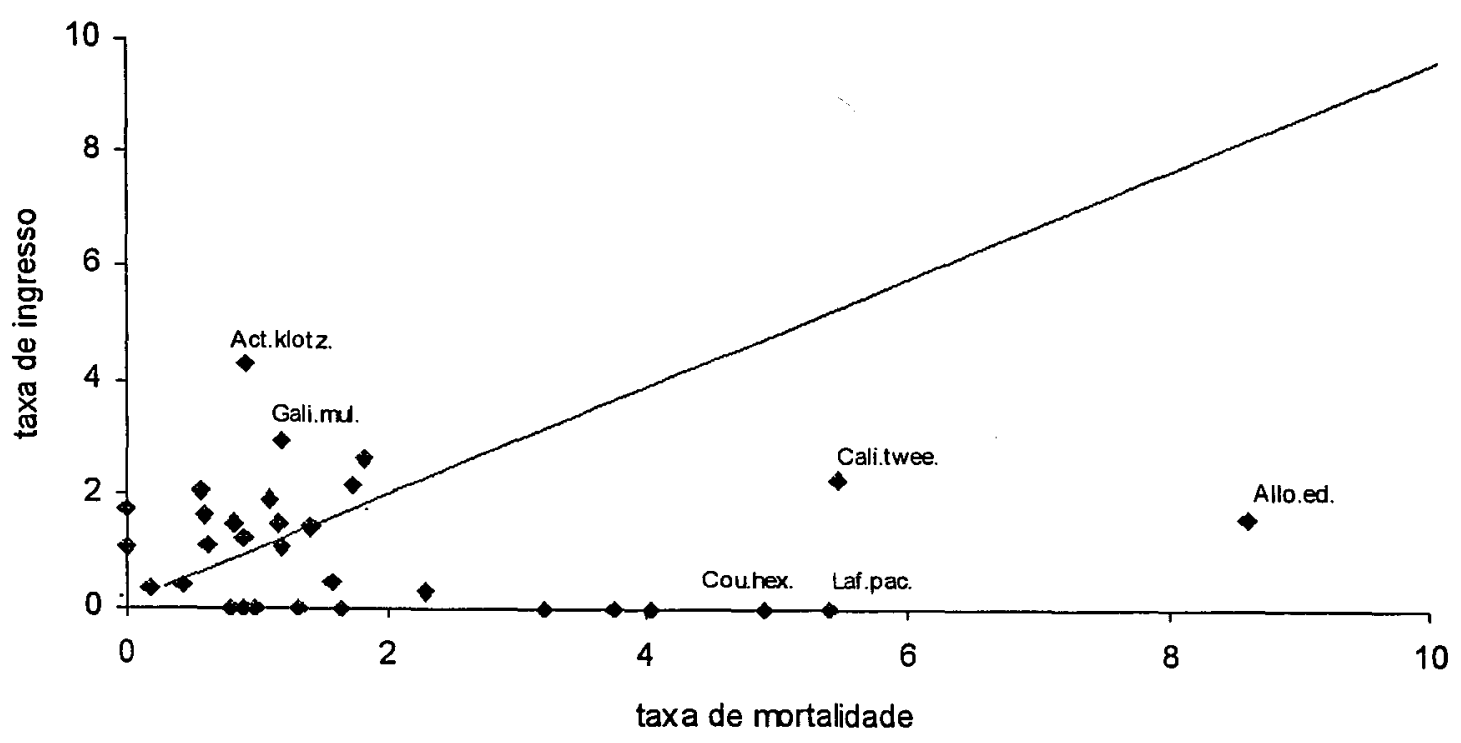

Figura 3.4 - Relação entre as taxas de mortalidade e de ingresso na comunidade por espécie; com número inicial de indivíduos maior que 10. Act. klotz. - Actinostemon klotzchiiz; Gali. mul. - Galipea multiflora, Cali. twee. - Calliandra tweediei; Allo. ed. - Allophylus edulis, Laf.pac. - Lafoensia pacari; e Cou.hex. - Couratea bexandra.

\subsubsection{Crescimento}

A taxa de crescimento para a comunidade foi de $0,14 \mathrm{~cm} /$ ano $\pm 0,18$ (Tabela 3.4). As espécies que apresentaram o maior crescimento foram Eugenia uniflora, Copaifera langsdorfii, Trichilia palida, Diatenopteryx sorbifolia e Centrolobium tomentosum, com taxas de crescimento entre 0,22 a $0,27 \mathrm{~cm} /$ ano (Anexo 3.1).

A análise de variância mostrou diferença significativa para a média do crescimento entre os três sub-grupos vegetacionais do mosaico ribeirinho e a comunidade como um todo, porém o teste Tukey indicou que as diferenças ocorrem em função da média da vegetação sobre solo $\mathrm{AL}$ (Tabela 3.4). Assim, a taxa de crescimento médio para a vegetação sobre solo AL foi maior do que para a comunidade como um todo e nos trechos de vegetação sobre os outros tipos de solo. 
Tabela 3.4 - Taxa anual de crescimento para a comunidade e para os três sub-grupos vegetacionais do mosaico ribeirinho: trecho com vegetação sobre solo $A L$ (Solo $A L$ ), trecho com vegetação sobre solo $\mathrm{AQ} / \mathrm{Cb}$ (Solo $\mathrm{AQ} / \mathrm{Cb}$ ) e trecho com vegetação sobre solo (Solo PV); (N - número de indivíduos amostrados, Tx. de cresc.- taxa anual de crescimento ( $\mathrm{cm} / \mathrm{ano}$ ), $s$-desvio padrão). Médias com diferentes letras diferem significativamente a $5 \%$ (teste de Tukey; $\mathrm{p}<0,05)$. ANOVA: $\mathrm{F}_{(3,1944)}=9,65 ; \mathrm{p}<0,001$.

\begin{tabular}{lccc}
\hline & $\mathrm{N}$ & Tx de cresc. & $s$ \\
\hline Solo AL & 296 & $0,19^{\mathrm{a}}$ & 0,25 \\
Solo AQ/Cb & 347 & $0,14^{\mathrm{b}}$ & 0,19 \\
Solo PV & 228 & $0,12^{\mathrm{b}}$ & 0,12 \\
Comunidade & 1077 & $0,14^{\mathrm{b}}$ & 0,18 \\
\hline
\end{tabular}

Entre os três sub-grupos vegetacionais do mosaico ribeirinho, a vegetação sobre solo AL apresentou taxa média de crescimento significativamente maior do que os subgrupos sobre os solos AQ/Cb e PV, e a taxa geral para a comunidade.

As taxas médias de crescimento diferiram significativamente entre as classes de diâmetro, tanto para a comunidade como para os três sub-grupos vegetacionais (Tabela 3.5).

$\mathrm{Na}$ comunidade variaram de $0,11 \mathrm{~cm} /$ ano $\pm 0,11$ para indivíduos de menor porte (entre 5 e $10 \mathrm{~cm}$ ), à $0,28 \mathrm{~cm} /$ ano $\pm 0,23$ em indivíduos maiores que $30 \mathrm{~cm}$ de diâmetro. No sub-grupo vegetacional de solo $\mathrm{AL}$, observa-se o mesmo padrão de crescimento encontrado para a comunidade, com maiores taxas em classes de diâmetro acima de $30 \mathrm{~cm}$ (Tabela 3.5). Tanto no sub-grupo sobre solo PV como no sub-grupo sobre solo AQ/Cb, o teste Tukey não identificou as classes onde ocorreram diferenças entre as taxas de crescimento. Porém, pela figura 3 nota-se que no sub-grupo sobre solo PV as menores taxas foram encontradas entre 25 e $30 \mathrm{~cm}$ de diâmetro e as maiores entre 20 e $25 \mathrm{~cm}$, e no solo AQ/Cb ocorreram na menor casse de diâmetro. 
Tabela 3.5 - Taxas de crescimento médio ( $\mathrm{cm} / \mathrm{ano}$ ) por classes de diâmetro para a comunidade e para os três sub-grupos vegetacionais do mosaico ribeirinho: trecho com vegetação sobre solo $\mathrm{AL}$ (Solo $\mathrm{AL}$ ), trecho com vegetação sobre solo $\mathrm{AQ} / \mathrm{Cb}$ (Solo $\mathrm{AQ} / \mathrm{Cb}$ ) e trecho com vegetação sobre solo (Solo PV); As médias que apresentam diferentes letras diferem significativamente (Teste de Tukey, $\mathrm{p}<0,05$ ), para cada tipo de solo e comunidade. ANOVA - Comunidade: $F_{(5,1071)}=16,79(\mathrm{p}<0,001)$; Solo Al: $F_{(5,200)}=$ $6,45(\mathrm{p}<0,001)$; Solo AQ/Cq: $F_{(5,341)}=6,17(\mathrm{p}<0,001)$ e Solo PV: $F_{(5,222)}=2,86(\mathrm{p}<$ $0,016)$.

\begin{tabular}{ccccc}
\hline & Comunidade & Solo AL & Solo AQ/Cb & Solo PV \\
\hline $5-10$ & $0,11^{\mathrm{a}}$ & $0,14^{\mathrm{a}}$ & 0,09 & 0,11 \\
$10-15$ & $0,19^{\mathrm{b}}$ & $0,26^{\mathrm{b}}$ & 0,14 & 0,21 \\
$15-20$ & $0,15^{\mathrm{a}, \mathrm{b}}$ & $0,17^{\mathrm{a}, \mathrm{b}}$ & 0,16 & 0,12 \\
$20-25$ & $0,21^{\mathrm{b}, \mathrm{c}}$ & $0,27^{\mathrm{a}, \mathrm{b}}$ & 0,17 & 0,23 \\
$25-30$ & $0,15^{\mathrm{a}, \mathrm{b}}$ & $0,27^{\mathrm{a}, \mathrm{b}}$ & 0,16 & 0,05 \\
$>30$ & $0,28^{\mathrm{c}}$ & $0,36^{\mathrm{b}, \mathrm{c}}$ & 0,18 & 0,21 \\
\hline
\end{tabular}

Foi observada uma grande variação nas taxas de crescimento entre as classes de diâmetro na comunidade, assim como para os sub-grupos vegetacionais sobre os solos AL e PV (Figura 3.5). No sub-grupo sobre solo AQ/Cb houve pouca variação.

Para todas as classes de diâmetro o grupo vegetacional sobre solo $\mathrm{AL}$ apresentou maiores taxas de crescimento. A menor taxa foi observada na vegetação sob solo PV, entre 25 e $30 \mathrm{~cm}$ de diâmetro. 


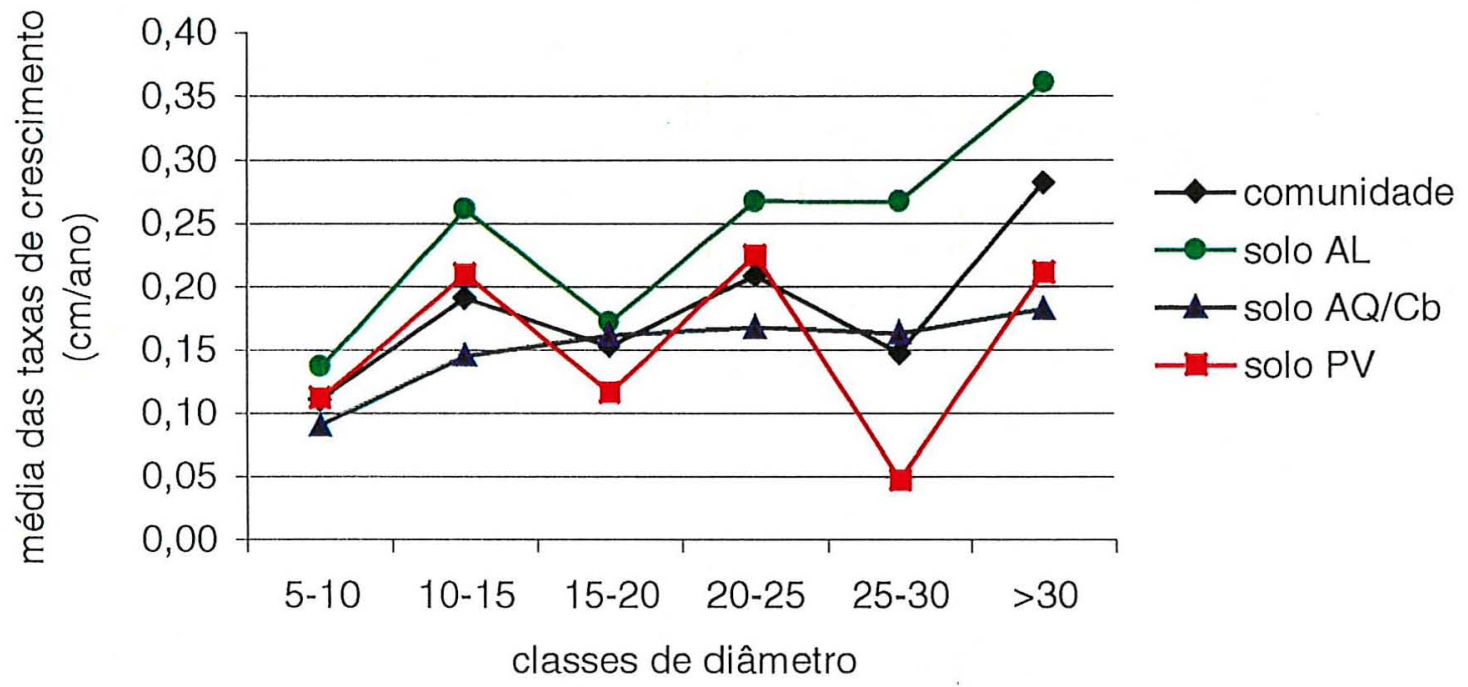

Figura 3.5 - Distribuição das taxas de crescimento médio por classes de diâmetro na comunidade e nos três sub-grupos vegetacionais, sobre solo $\mathrm{AL}$, solo $\mathrm{AQ} / \mathrm{Cb}$ e solo PV.

\subsubsection{Distribuição espacial}

Poucas alterações ocorreram em nove anos no padrão de distribuição espacial, entre os indivíduos maiores que $5 \mathrm{~cm}$ de DAP no trecho de floresta ribeirinha amostrado (Figura 3.6). Em 1989 observa-se um agrupamento para distâncias de 0 a $7 \mathrm{~m}$ entre os indivíduos, e um padrão regular em distâncias de 20 à 25 m. Em 1998 este agrupamento se restringiu à até $5 \mathrm{~m}$, e acima desta distância o padrão de distribuição foi aleatório, não se notando mais o padrão regular.

A figura 3.7 ilustra a distribuição das árvores que morreram no período de 9 anos (1989 à 1998) no trecho de floresta ribeirinha amostrado. Analisando-se o padrão de distribuição das árvores mortas em nove anos, comparadas às vivas (Figura 3.8), observa-se um padrão aleatório para estas últimas, e um padrão regular para distâncias entre as árvores mortas entre 21 e $29 \mathrm{~m}$ (aproximadamente). 


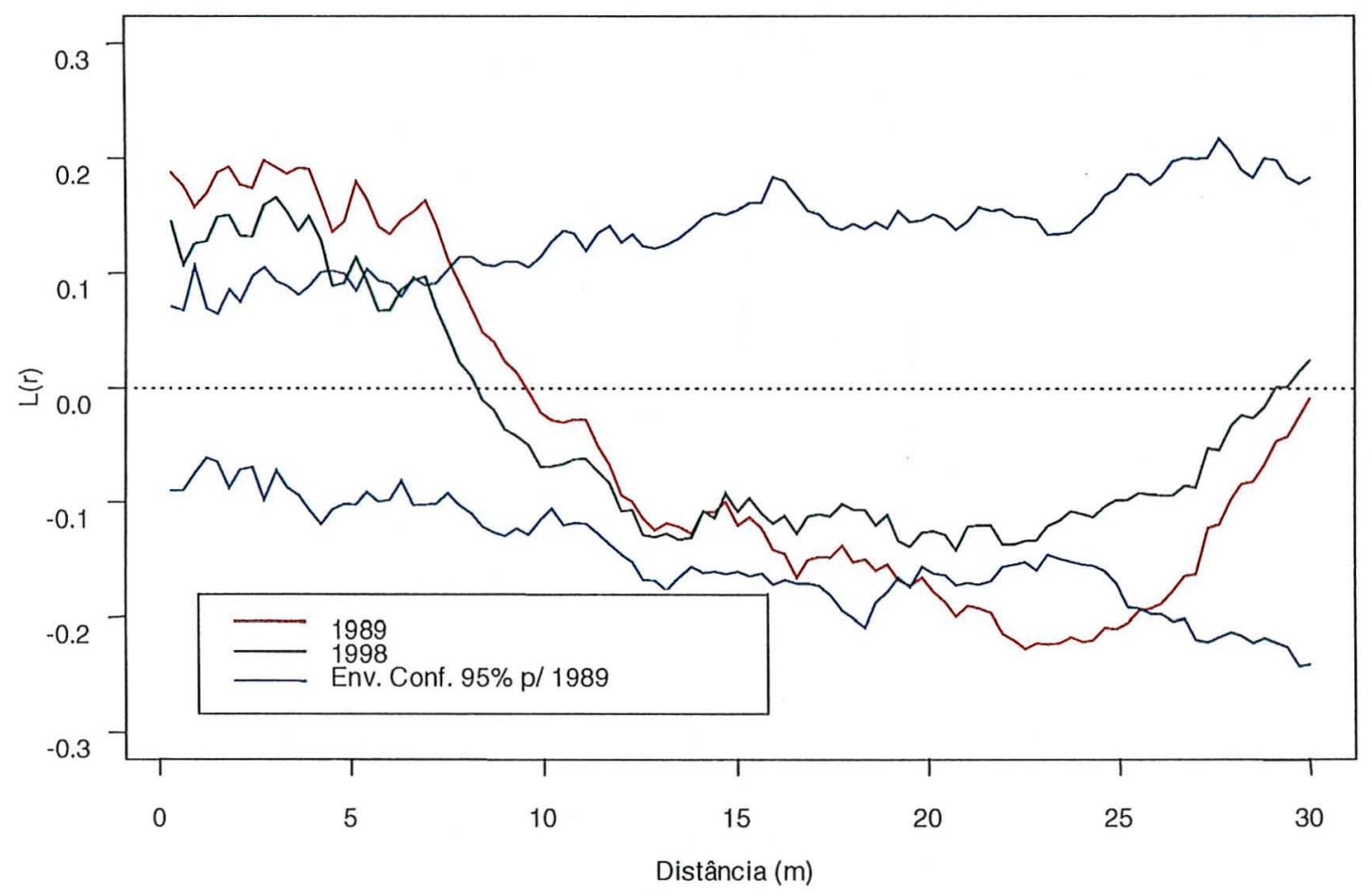

Figura 3.6 - Resultado da função K-Ripley, através da função derivada L (d) que mede o padrão espacial em várias distâncias. As linhas azuis representam envelopes à 95\% de confiança para completa aleatoriedade espacial. Os valores de L (d) acima da linha superior do envelope de confiança indicam padrão de distribuição agrupado, e os valores abaixo da linha inferior do intervalo indicam padrão regular de distribuição, para os indivíduos arbustivo- arbóreos amostrados em 1989 e 1998. 


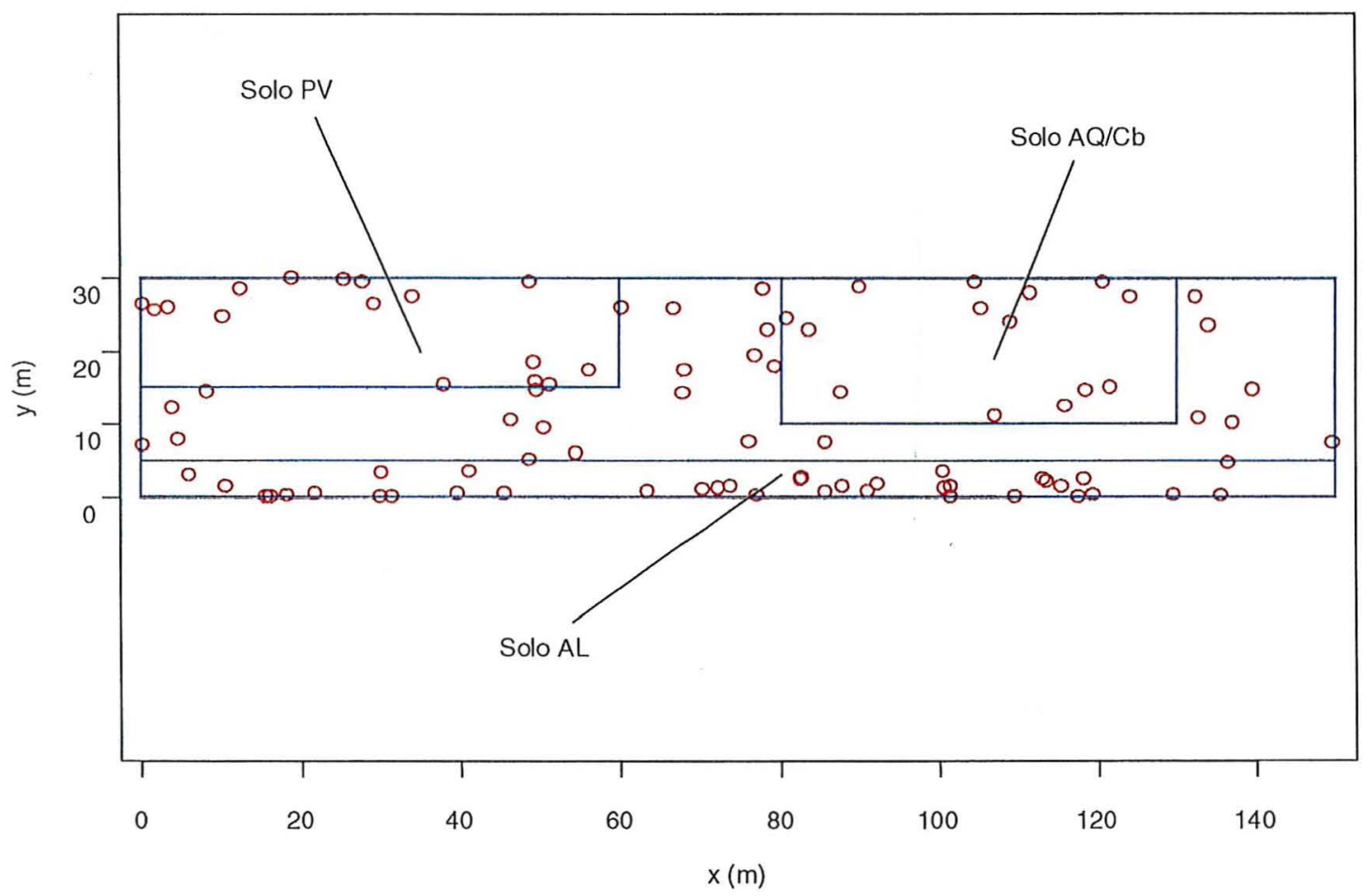

Figura 3.7 - Mapa da distribuição da árvores que morreram no período de 1989 à 1998, na área amostrada para análise espacial da floresta ribeirinha do rio Passa Cinco, Ipeúna, SP. 


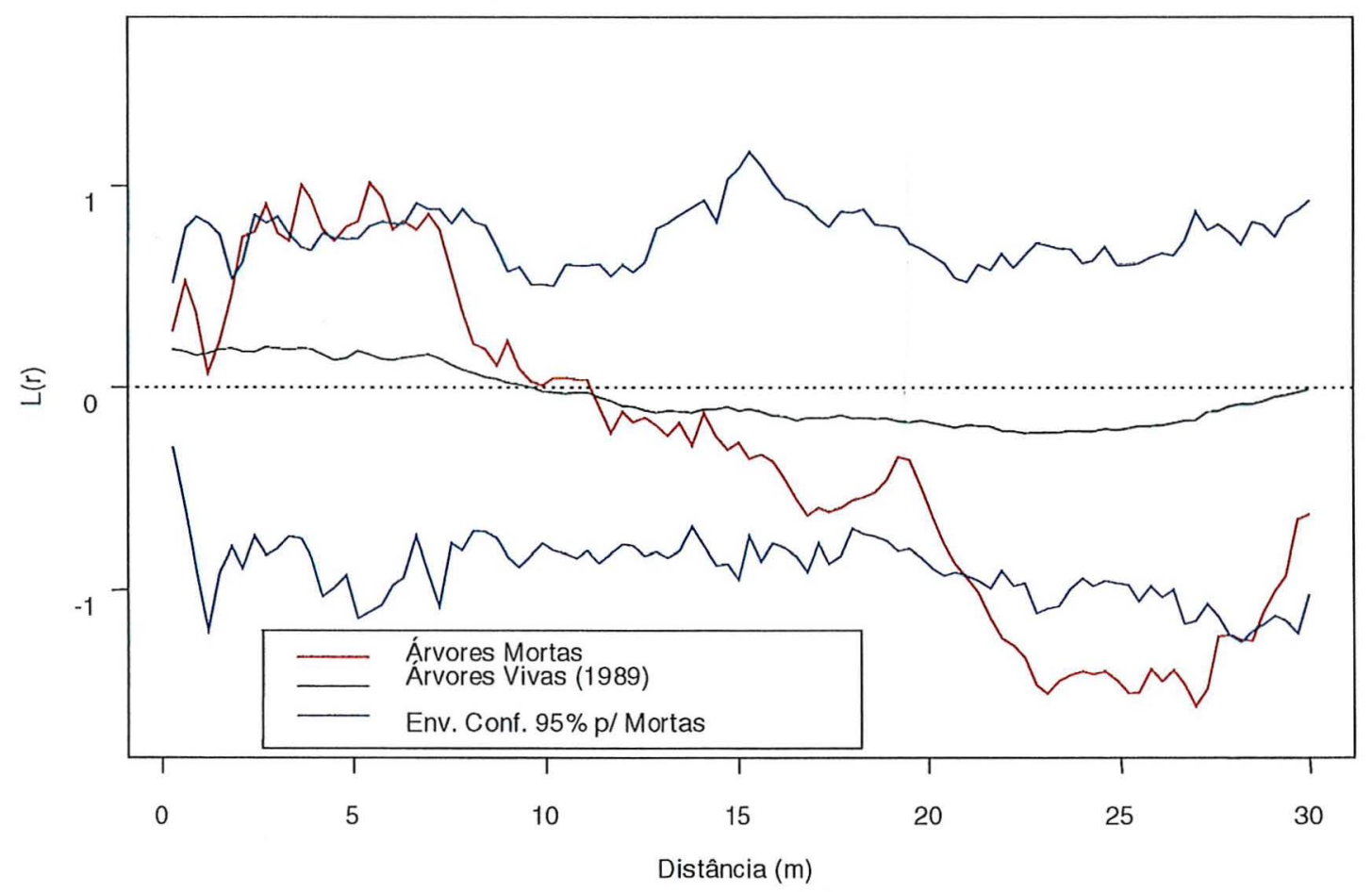

Figura 3.8 - Representação gráfica dos resultados das análises do padrão espacial das árvores que morreram entre 1989 e 1998, através da função K-Ripley . 
A distribuição das árvores ingressantes entre 1989 e 1998, está representada na Figura 3.9. A análise do padrão espacial para as árvores ingressantes apresenta distribuição agrupada em distâncias de 2 `a $4 \mathrm{~m}$ entre os indivíduos (aproximadamente), e distribuição aleatória para distâncias acima de $4 \mathrm{~m}$ entre estes indivíduos (Figura 3.10).

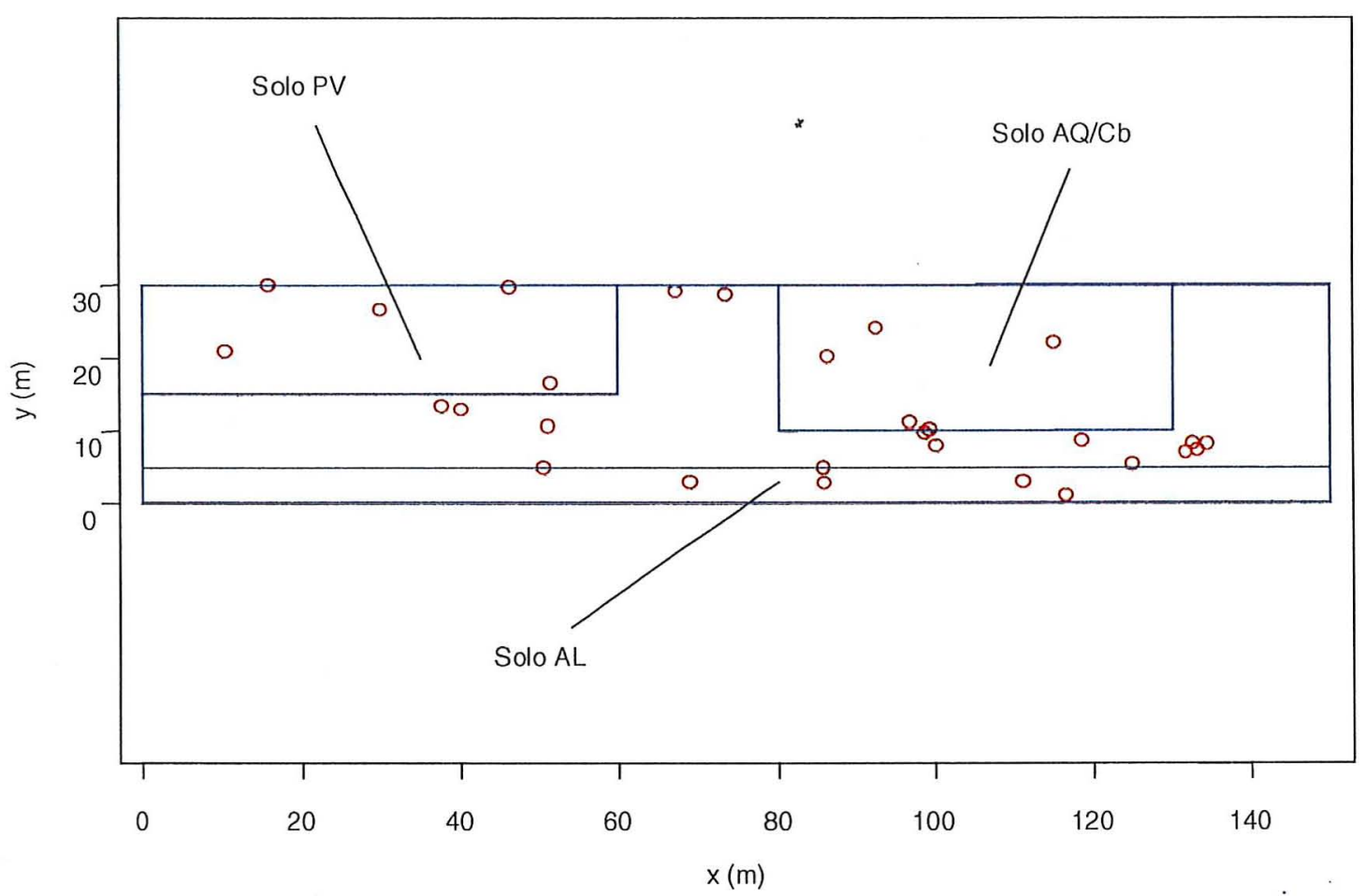

Figura 3.9 - Mapa da distribuição da árvores ingressantes no período de 1989 à 1998, na área amostrada para análise espacial da floresta ribeirinha do rio Passa Cinco, Ipeúna, SP. 


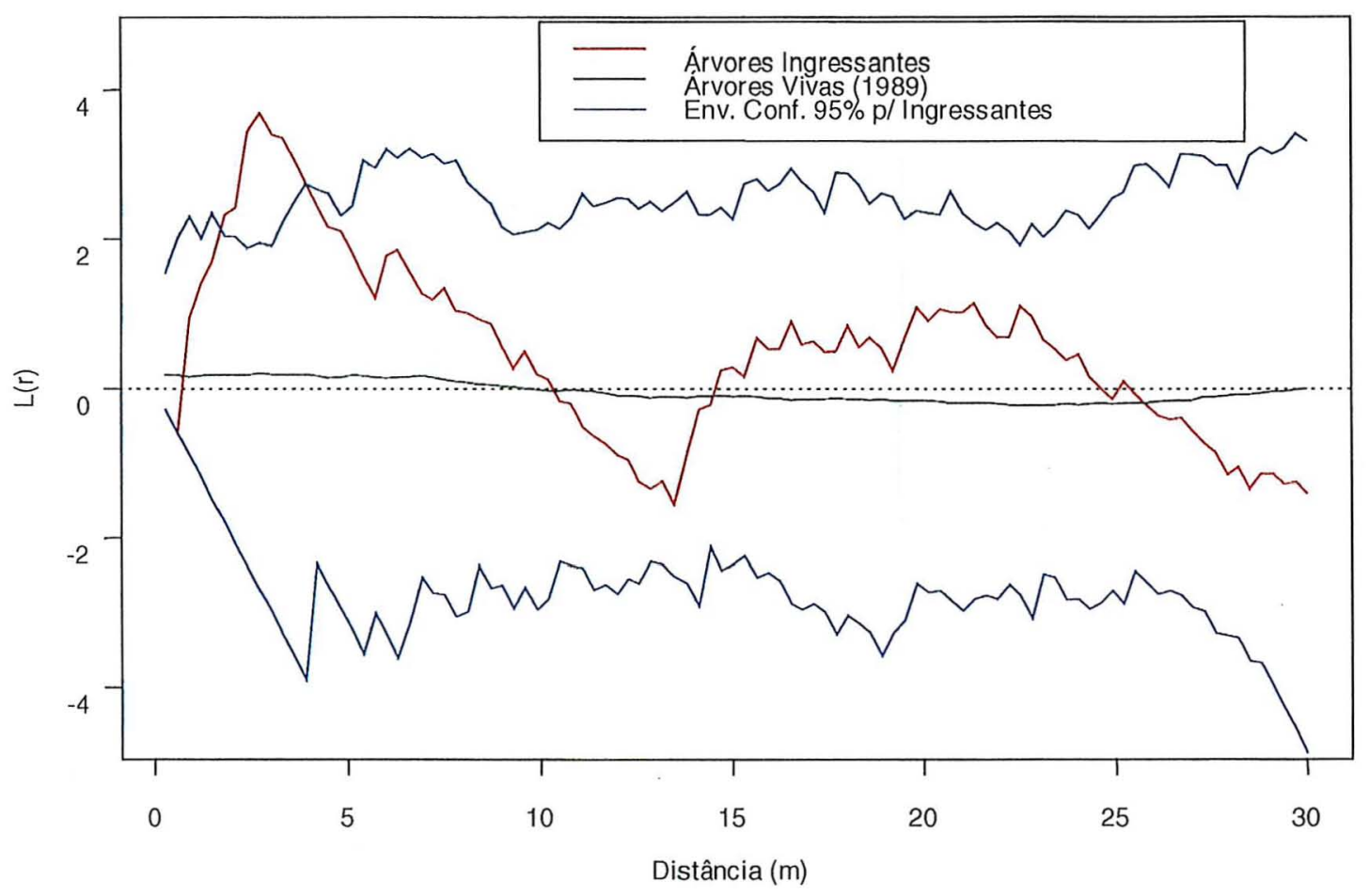

Figura 3.10 - Representação gráfica dos resultados das análises do padrão espacial das árvores ingressantes entre 1989 e 1998, através da função K-Ripley 
Observando-se o padrão de distribuição espacial dos indivíduos em 1989 e 1998 nos sub-grupos vegetacionais do mosaico ribeirinho sobre os solos $\mathrm{AL}, \mathrm{AQ} / \mathrm{Cb}$ e PV, nota-se particularidades claras quando comparamos os três sub-grupos (Figura 3.11).

A

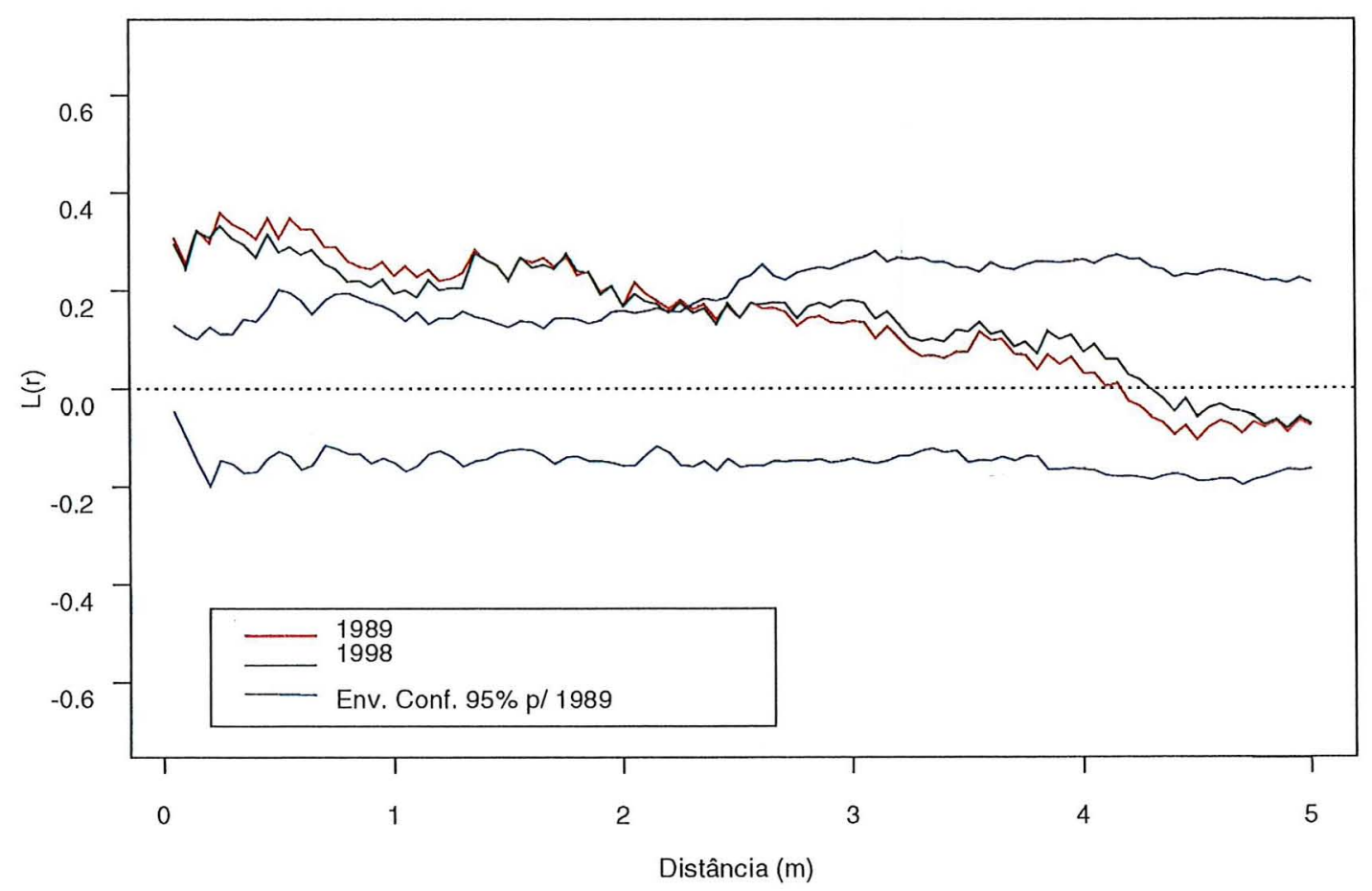

Figura 3.11 - Representação gráfica dos resultados das análises do padrão espacial das árvores em 1989 e 1998, através da função K-Ripley, para os três sub-grupos vegetacionais: A) Vegetação sobre o solo AL; B) Vegetação sobre o solo AQ/Cb; e C) Vegetação sobre o solo PV 
B

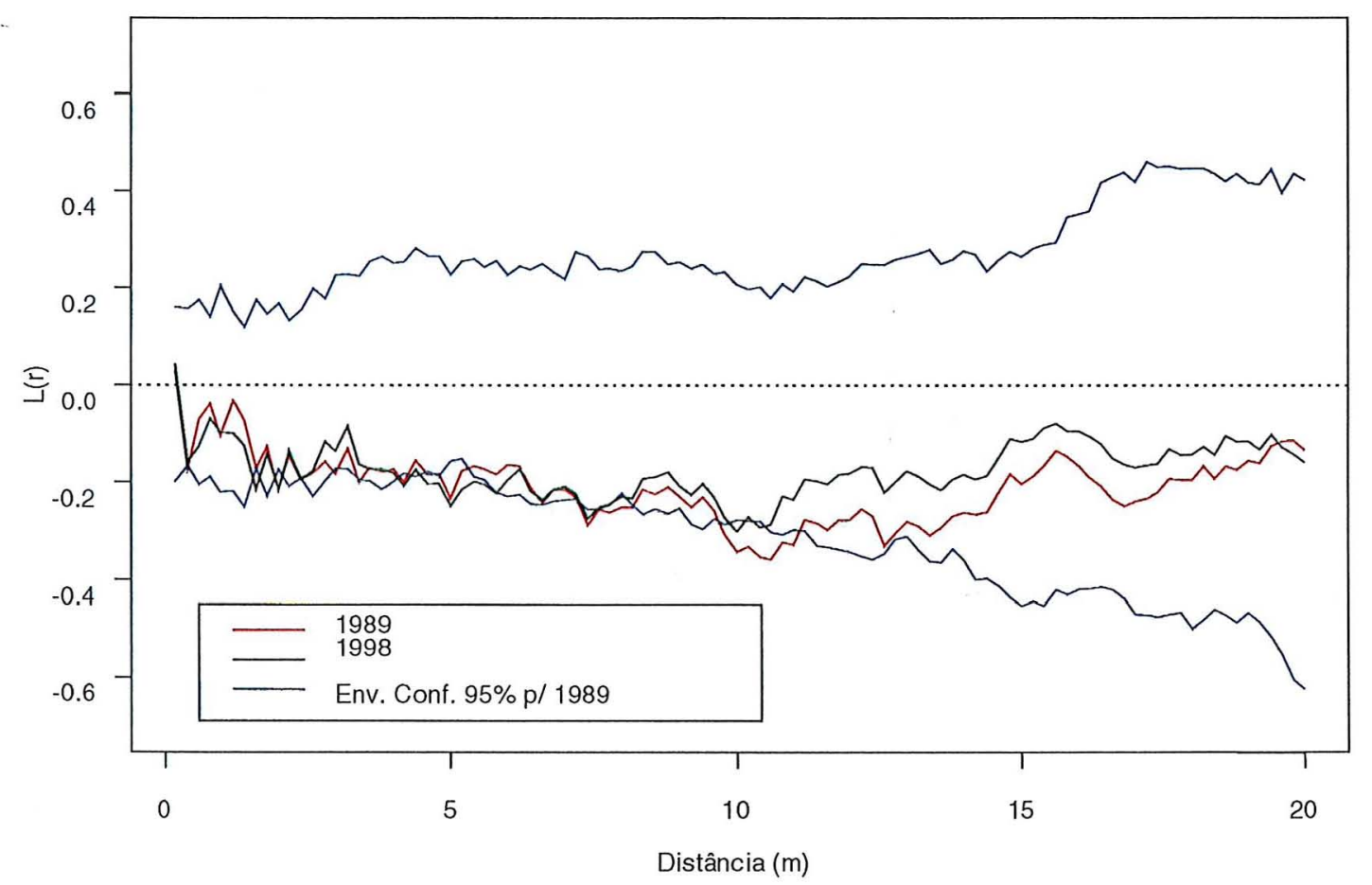

(Cont.) Figura 3.11 - Representação gráfica dos resultados das análises do padrão espacial das árvores em 1989 e 1998, através da função K-Ripley, para os três sub-grupos vegetacionais:

A) Vegetação sobre o solo AL; B) Vegetação sobre o solo AQ/Cb; e C) Vegetação sobre o solo PV 
C

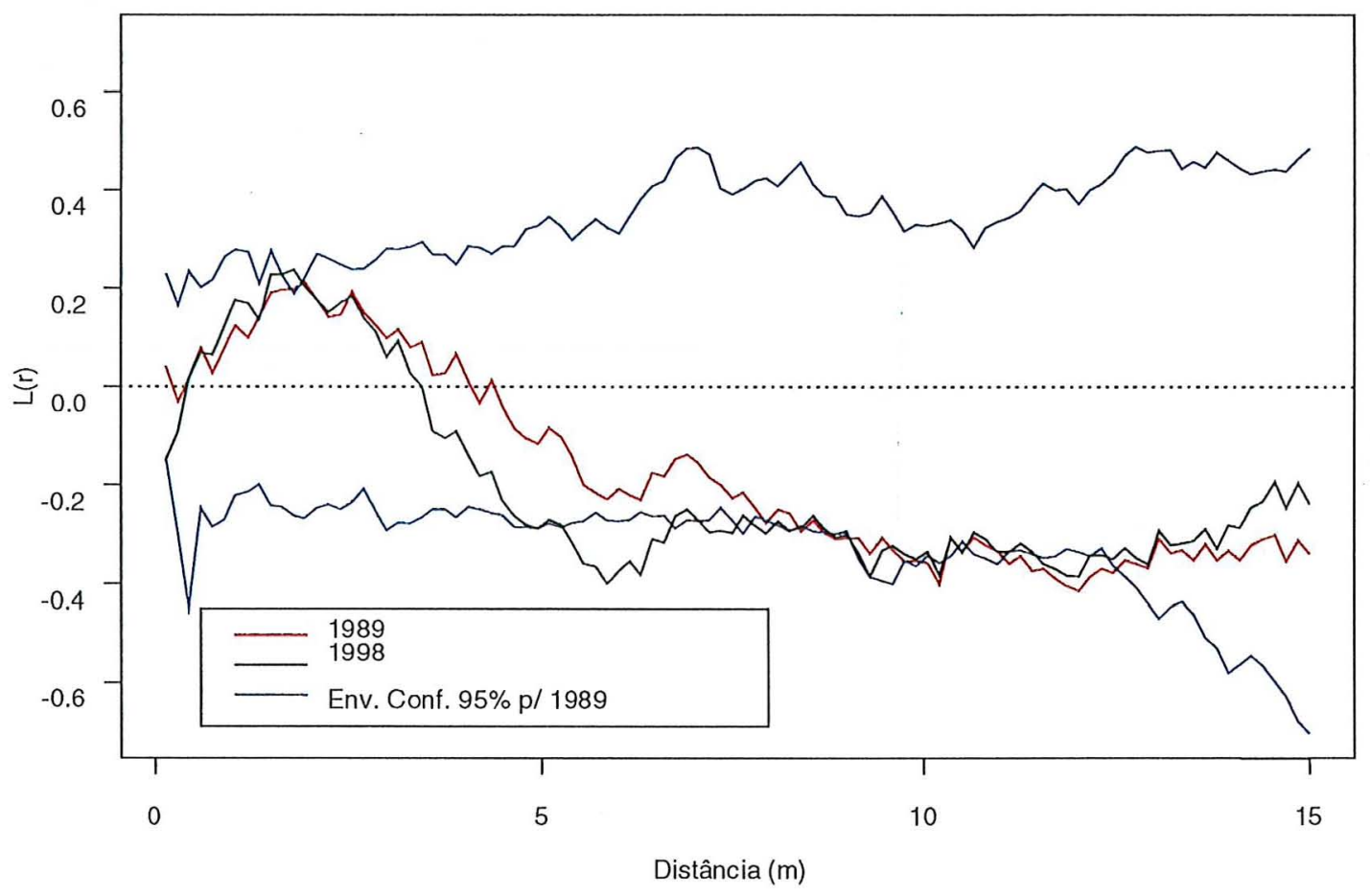

(Cont.) Figura 3.11 - Representação gráfica dos resultados das análises do padrão espacial das árvores em 1989 e 1998, através da função K-Ripley, para os três sub-grupos vegetacionais:

A) Vegetação sobre o solo AL; B) Vegetação sobre o solo AQ/Cb; e C) Vegetação sobre o solo PV 
No solo AL (Figura 3.11A) as árvores apresentam-se agrupadas para distâncias entre os individuos em até $2 \mathrm{~m}$, e padrão aleatório entre 2 e $5 \mathrm{~m}$. Em distâncias acima de 5 $\mathrm{m}$ não foi possível estabelecer padrões, devido às dimensões do trecho de floresta ribeirinha amostrado $(5 \times 150 \mathrm{~m})$. Não ocorreram alterações neste padrão em nove anos.

No solo $\mathrm{AQ} / \mathrm{Cb}$ (Figura 3.11B) o padrão de distribuição espacial foi aleatório, ocorrendo padrão regular apenas em 1989 para distâncias entre os indivíduos de 10 à $11 \mathrm{~m}$ (aproximadamente). Observa-se uma tendência à regularidade entre os indivíduos com distâncias de até $10 \mathrm{~m}$, tanto em 1989 como em 1998, porém não chega a ser significativa.

No solo PV (Figura 3.11C) ocorreu padrão de distribuição aleatório em todas as distâncias entre os indivíduos em 1989, e em 1998 este padrão se manteve, porém passou a ser regular entre 5 e $7 \mathrm{~m}$ de distância. Assim como no solo AQ/Cb, observa-se uma tendência à regualaridade, para distâncias de 5 à $13 \mathrm{~m}$ entre os indivíduos. 


\subsection{DISCUSSÃO}

\subsubsection{Mortalidade}

A taxa de mortalidade dos indivíduos arbóreos (DAP $\geq 5 \mathrm{~cm}$ ) calculada para todo o trecho da floresta ribeirinha estudada, de 1,46\% ao ano, foi baixa comparada à encontrada por Santos et al. (1996) em um trecho de Floresta Estacional Semidecidual não ribeirinha. Santos et al. (1996), em 11 anos de estudo, encontraram a taxa de 3,79\% ao ano na reserva municipal de Santa Genebra, Campinas, SP, distanciada aproximadamente $70 \mathrm{~km}$ em linha reta da área de estudo. Taxa de 3,50\% ao ano, também mais alta do que a encontrada neste estudo, foi encontrada por Felfili (1995), em 6 anos de estudo em uma floresta de galeria no Distrito Federal.

Porém, este valor está dentro da faixa de variação das taxas de mortalidade frequentemente encontradas em florestas tropicais, entre 1 e $2 \%$ (Swaine 1987 a e b). Como exemplo, tem-se que na Amazônia Central (em 5 anos de estudo) a taxa foi de 1,13\% ao ano (Rankin de Merona et al. 1992); no Peru, em Cosha Casu (em 10 anos de estudo) a taxa foi de 1,58\% ao ano (Gentry \& Terborg, 1990) ; em Pakitza (4 anos) a taxa foi de 2,7\% (Dallmeier et al., 1996) e na Costa Rica, em 13 anos de estudo foi de 2,03\% ao ano (Lieberman \& Lieberman, 1987).

Entre os três sub-grupos regetacionais do mosaico ribeirinho, no trecho sobre solo $\mathrm{AQ} / \mathrm{Cb}$ a taxa foi bem inferior à encontrada em outros estudos, menor que $0,1 \%$ ao ano, se mantendo baixa para todas as classes de diâmetro.

As taxas mais elevadas de mortalidade, superiores à $3 \%$ ao ano, ocorreram no trecho de vegetação imediatamente paralelo ao curso d'água (Figura 3.1), sobre solo AL, para indivíduos entre 25 e $35 \mathrm{~cm}$ de diâmetro. A alta mortalidade para indivíduos maiores pode estar relacionada com distúrbios provocados pelas cheias periódicas nesta faixa ribeirinha, às vezes de grande intensidade e duração (10-15 dias). A instabilidade gerada pelas características topográficas desta área e as características físicas deste tipo de solo (maiores proporçōes de areia fina) poderiam ser responsáveis pela mortalidade elevada, devido a queda de individuos maiores com as cheias do rio. 
$\mathrm{O}$ grupo vegetacional sobre o solo PV também apresentou altas taxas de mortalidade, o que poderia estar ocorrendo em função da maior declividade neste trecho, o que será melhor discutido adiante.

\subsubsection{Ingresso}

A taxa de ingresso calculada para a comunidade foi baixa, se comparada com aquela obtida por Felfili (1995) na floresta de galeria do Distrito Federal, 2,7\% ao ano, e a encontrada por Santos et al. (1996), na reserva municipal de Santa genebra, Campinas, SP., de 2,66\% ao ano. Mas está muito próxima a taxa de 1,76\% encontrada por Swaine et al. (1987 a) para uma floresta semidecidual em Ghana. Gentry \& Terborgh (1990) observaram em Cosha Casu (Peru), uma taxa de ingresso de 0,96\% ao ano, que foi inferior à amostrada neste estudo.

Para a maioria dos estudos em florestas tropicais, as diferenças obtidas entre as taxas de mortalidade e as taxas de ingresso nào são tão expressivas, indicando um certo equilíbrio destas formações (Swaine et al., 1987 a; Lieberman et al., 1996). O desequilíbrio entre estas duas taxas é atribuído à flutuações populacionais aleatórias, sendo que o equilibrio deve ser restabelecido com o tempo (Gentry \& Terborgh, 1996). Segundo Felfili (1995), este desequilíbrio pode ser resultado de um processo inicial de mortalidade, que concomitantemente oferece um "espaço" para o recrutamento de novos indivíduos, isto ocorrendo durante um curto espaço de tempo. No caso do presente estudo, houve um pequeno desequilíbrio positivo no período entre 1989 e 1998 ( 9 anos), em favor do ingresso para a comunidade. Mas, se forem considerados os três sub-grupos vegetacionais separadamente, os grupos sobre os solos AL e PV apresentaram um pequeno desequilibrio, em favor da mortalidade. Isto pode ser reflexo da atuação de fatores como a lavagem do solo pelas cheias do rio na área imediatamente paralela a este (grupo vegetacional sobre solo $\mathrm{AL})$, e pela área do grupo vegetacional sobre solo PV ser mais íngreme. 


\subsubsection{Crescimento}

A taxa de crescimento dos indivíduos arbóreos (DAP $\geq 5 \mathrm{~cm}$ ) calculada para a comunidade ribeirinha em questão, $0,14 \mathrm{~cm} /$ ano, foi similar a encontrada por Santos et al. (1996), 0,135 cm/ano, em uma floresta estacional semidecidual não ribeirinha, após um período de 11 anos, para os indivíduos com DAP acima de $5 \mathrm{~cm}$. Também foi mais baixa do que a encontrada por Felfili (1995) em estudo de 6 anos em uma floresta de geleria no Distrito Federal, cuja taxa foi de $0,25 \mathrm{~cm} /$ ano para indivíduos acima de $10 \mathrm{~cm}$ de DAP, sendo neste estudo de $0,19 \mathrm{~cm} /$ ano $(\mathrm{DAP} \geq 10 \mathrm{~cm}$ )

O crescimento em diâmetro foi muito variável entre espécies e entre classes de tamanho, como o encontrado em outras florestas (Lang \& Knight, 1983; Santos et al., 1996; Swaine et al., 1987a). Porém, concorda com o padrão encontrado em vários trabalhos em relação ao aumento do crescimento com o aumento das classes de diâmetro. Isto deve estar relacionado com a maior pressào competitiva entre individuos jovens.

Entre os três sub-grupos vegetacionais do mosaico ribeirinho, o trecho sobre solo AL apresentou maior taxa de crescimento. A condição de margeamento do rio pode causar maior luminosidade nesta faixa, maior disponibilidade hídrica e acréscimo de nutrientes em alguns locais devido às cheias do rio. Outro possivel fator gerador deste maior crescimento pode ter sido a grande mortalidade de individuos entre 25 e $35 \mathrm{~cm}$ de DAP (Tabela 3.1), o que aumentaria a luminosidade para estratos mais baixos, favorecendo o maior desenvolvimento de outros indivíduos.

Os valores baixos de crescimento encontrados para algumas classes de diâmetro no grupo vegetacional sobre o solo PV, pode estar sendo consequêencia da declividade neste trecho de floresta, sendo algumas espécies sensíveis a esta situaçào topográfica (Parresol, 1994 ). Observando-se as curvas das taxas de crescimento e mortalidade por classes de diâmetro, notamos o mesmo padrão, sendo os aumentos e diminuições correspondentes às mesmas classes de tamanho. Desta forma, para as classes de diâmetro entre 20 e $25 \mathrm{~cm}$ houve um grande aumento das taxas de mortalidade e crescimento, e entre 25 e $30 \mathrm{~cm}$, houve grande diminuiçào. Isto pode ser indício de forte competiçào entre indivíduos de mesma classe de diâmetro por algum recurso que não luminosidade, pois estariam no 
mesmo estrato, ou mais um indício da declividade atuando como fator de seletividade em todas as classes de diâmetro.

$\mathrm{O}$ trecho de vegetação sobre o solo $\mathrm{AQ} / \mathrm{Cb}$ apresentou taxas de ingresso que superaram as taxas de mortalidade. $O$ crescimento aparentemente não variou entre as classes de diâmetro, e com as baixas taxas de crescimento encontradas, pode-se supor que exista uma limitação em relação à disponibilidade de nutrientes no solo, sendo esta disponibilidade dependente da camada de serapilheira (Rodrigues, 1992), o que pode ser também indício de que a área está em fase de desenvolvimento.

\subsubsection{Distribuição espacial}

Tanto para a área total amostrada como os três sub-grupos vegetacionais não ocorreram alterações no padrão de distribuição espacial entre as árvores com DAP $\geq 5 \mathrm{~cm}$. Provavelmente mudanças no padrão espacial em um periodo curto de tempo como o estudado ( 9 anos) não seriam detectadas, à menos que ocorressem mudanças drásticas na área, causadas por grandes distúrbios. $\mathrm{Na}$ floresta ribeirinha do presente estudo, as enchentes periódicas não poderiam ser consideradas como agentes de distúrbios severos, mas de distúrbios naturais que fazem parte da dinâmica da área.

O padrão aleatório para os indivíduos mortos está dentro do encontrado em outros trabalhos (Sterner et al., 1986). Interpretando-se o padrão aleatório em termos de interações entre os indivíduos não significa necessariamente que não existam relações entre eles, ou que os processos que determinam a distribuição dos indivíduos seja altamente randômica.

O padrão agrupado das plantas ingressantes pode estar relacionado com a abertura de clareiras ou à heterogeneidade ambiental expressando a preferência de espécies à microhabitats específicos (Pielou, 1960; Armesto, 1986; Szwagrzyk, 1990). Como exemplo tem-se as áreas onde ocorre a deposição de sedimentos e nutrientes com as cheias do rio (Rodrigues, 1992).

Quando muitas espécies estão envolvidas torna-se difícil a interpretação de dados espaciais, e relações ecológicas tornam-se difíceis de serem comprovadas. 
$\mathrm{O}$ agrupamento à pequenas distâncias no trecho de vegetação sobre o solo $\mathrm{AL}$ e a aleatoriedade destes grupos pode estar relacionada com o mosaico de condiçòes ambientais encontrado na margem do rio, como variação na quantidade de luz incidente, deposição diferenciada de sedimentos pelas cheias do rio, etc. $\mathrm{O}$ rio parece ser um fator de distúrbio periódico na área, o qual torna peculiar a dinâmica da faixa sob influência direta deste.

Tanto no trecho de vegetação sobre o solo $\mathrm{AQ} / \mathrm{Cb}$ como no trecho sobre o solo PV observou-se um padrão bem diferente do encontrado para o trecho sobre o solo AL, sendo aleatório para os indivíduos arbóreos com $\mathrm{DAP} \geq 5 \mathrm{~cm}$, com uma tendência à regularidade. Kenkel (1998) sugere que quando a competição é forte o suficiente para produzir a mortalidade de indivíduos suprimidos, o padrào espacial deve mudar de agregado ou aleatório para um padrão mais regular. No trecho sobre o solo $\mathrm{AL}$ esta tendência não poderia ser esperada, pois os distúrbios causados pelas cheias do rio sempre iriam promover o agrupamento devido a heterogeneidade de microhabitats presentes nesta área. Porém, não se pode concluir sobre a ocorrência de competição e a influência desta no padrão de distribuição dos indivíduos, jả que a tendência à distribuição regular nào foi significativa. 


\subsection{REFERÊNCIAS BIBLIOGRÁFICAS}

ARMESTO, J.J.; MITCHELL, J.D. \& VILLAGRAN, C. A comparison of spatial patterns of trees in some tropical and temperate forests. Biotropica, v.18, n.1, p.1-11, 1986.

BATISTA, J.L.F. Spatial Dynamics of Trees in a Brazilian Atlantic Tropical Forest under Natural and Managed Conditions. Tese de Doutorado. University of Washington, 1994.

BIANCHINI, E. Ecologia de população de Chrysophyllum gonocarpum (Mart. \& Eichler) Engl. no Parque Estadual Mata dos Godoy, Londrina, PR. Tese de Doutorado. Universidade Estadual de Campinas. Instituto de Biologia, 1998.

CONDICT, R., HUBBELL, S.P. \& R.B. FOSTER.. Mortality rates of 205 Neotropical tree and shrub species and the impact of a severe drought. Ecological Monographs, v.65, n.4, p.419-439, 1995.

DALLMEIER , F. KADEL, M. \& FOSTER, R.B. Floristic Composition, Diversity, Mortality and Recruitment of different substrates: lowland Tropical Forest, Pakitza, Rio Manu, Peru. In: WILSON, D.E. \& SANDOVAL, A. (Ed.). Manu/ The biodiversity of southeastern Peru. Washington D.C: Smithsonian Institution., 1996. p. 89-125.

DUNCAN, R.P. Competition and the coexistence of species in a mixed podocarp stand. Journal of Ecology, v.79, p.1073-1084, 1991.

FELFILI, M.F. Growth, recruitment and mortality in the Gama gallery forest in central Brazil over a six-year period (1985-1991). Journal of Tropical Ecology, v.11, p. 67-83, 1995.

FOSTER, F.B. Long -term change in the successional forest community of the rio Manu foodplain. In: GENTRY, A.H. (Ed). Four Neotropical Rainforests. New Haven: Yale University Press, 1990. p.565-572.

GENTRY, A.H. \& TERBORG, J. Composition and dynamics of the Cocha Cashu "mature" floodplain forest. In: GENTRY, A.H. (Ed). Four Neotropical Rainforests. New Haven: Yale University Press, 1990. p. 542-564.

HAASE, P. Spacial pattern analysis in ecology based on Ripley's $\mathrm{k}$ function:introduction and methods of edge correction. Journal of Vegetation Science, v.6, n.4, p. 575-582, 1995.

HARTSHORN, G.S. Neotropical forest dynamics. Biotropica, v. 12, p. 23-30, 1980. Supplement, 7.

HUBBELL, S.P. \& FOSTER, S.B. Structure, dynamics. and equilibrium status of oldgrowth forest on Barro Colorado Island. In: GENTRY, A.H. (Ed). Four Neotropical Rainforests. New Haven: Yale University Press, 1990. p. 522-541. 
HUBBELL, S.P., CONDICT, R. \& FOSTER, R.B. Presence and absence of diversity dependence in a neotropical tree community. Philosophical Transections of Royal Society of London. Série B, v.330, p. 269-281, 1990b.

KENKEL, N.C. Pattern of self-thinning in jack pine: testing the random mortality hypothesis. Ecology, v.69, n.4, p. 1017-1024, 1988.

LANG, G.E. \& D.H. KNIGHT. Tree growth, mortality, recruitment, and canopy gap formation during a 10-year period in a tropical moist forest. Ecology, v.64, p.1075-1080, 1983.

LIEBERMAN, D. E LIEBERMAN, M. Forest tree growth and dynamics at La Selva, Costa Rica (1969-1982). Journal of Tropical Ecology, v.3, p.347-358, 1987.

LIEBERMAN, D., HARTSHORN, G.S., LIEBERMAN, M \& PERALTA, R.. Forest dynamics in La Selva Biological Station, 1969-1985. . In: GENTRY, A.H. (Ed). Four Neotropical Rainforests. New Haven: Yale University Press, 1990. p. 509-521.

MAGUIRE, D.A., BATISTA, J.L.F., MACKENZIE, D.. Horizontal structure of unevenaged mixed-species forests modelled as an Inhomogeneous Poisson Process. In: Meeting of IUFRO S 4 .11: Stochastic Spatial Models in Forestry, Thessaloniki. IUFRO. 1993.

MARTINI, A.M.Z. Estrutura e dinâmica populacional de três espécies arbóreas tropicais. 1996. Tese de Mestrado. Universidade Estadual de Campinas. Instituto de Biologia.

MOEUR, M.,. Characterising spatial patterns of trees using stem-mapped data. Forest Science, v.39, n. 4, p. 756-775, 1993.

PARRESOL, B.R. Basal area growth for 15 tropical tree species in Puerto Rico. Forest Ecology and Management, v.73, p. 211-219, 1995.

PENTTINEN, A., STOYAN, D., HENTTONEN, H.M. Marked point process in forest statistcs. Forest Science, v.38, p. 806-824, 1992.

PIELOU, E.C., 1960. A single mechanism to account for regular, random and aggregated populations. Journal of Ecology, v.48, p. 575-584, 1992.

PIMENTA, A.J.. Estudo populacional de Campomanesia xanthocarpa O. Berg (Myrtaceae) no Parque Estadual Mata dos Godoy, Londrina, PR. 1998. Tese de Doutorado. Universidade Estadual de Campinas. Instituto de Biologia.

PRIMACK, R.B. E H.S. LEE. Population dynamics of pioneer (Macaranga) trees and understorey (Mallotus) trees (Euphorbiaceae) in primary and selectively logged Bornean rain forests. Journal of Tropical Ecology, v.7, p. 439-458, 1991. 
RANKIN-DE MERONA, M.J., HUTCHINGS, R.W. E T.E. LOVEJOY. Tree mortality and recruitment over a five-year period in undisturbed upland rainforest of Central Amazon.. In: GENTRY, A.H. (Ed). Four Neotropical Rainforests. New Haven: Yale University Press, 1990. p. 573-584.

RIPLEY, B.D. Modelling spacial pattern. Journal of the Royal Statistical Society, v. 39, p. $172-212,1977$.

RODRIGUES, R.R.. Análise de um remanescente de vegetação natural as margens do rio Passa Cinco, Ipeúna. SP. 1992. Tese de Doutorado. Universidade Estadual de Campinas. Instituto de Biologia.

SANTOS, F.A.M., TAMASHIRO, J.Y., RODRIGUES, R.R. E SHEPHERD, G.J. The dynamics of tree population in a semideciduous forest at Santa Genebra reserve, Campinas, Se, Brazil. Bulletin of the Ecology Society America. Providence: Rhode Island, 1996. Supplement.

STERNER, R.W., RIBIC, C.A., SCHATZ, G.E. Testing for life historical changes in spatial patterns of four tropical tree species. Journal of Ecology, v.74, p. 621-633, 1986.

STEWART, G.H. \& ROSE, A.B. The significance of life history strategies in the developmental history of mixed beech (Nothofagus) forests, New Zealand. Vegetatio, v. 87, p. 101-114, 1990.

SWAINE, M.D.,D. LIEBERMAN E F.E. PUTZ. The dynamics of tree populations in tropical forests: a review. Journal of Tropical Ecology, v. 3, p.359-366, 1987a.

SWAINE, M.D., HALL, J.B. E ALEXANDER, I.J. Tree population dynamics at Kade, Ghana (1968-1982). Journal of Tropical Ecology, v. 3, p. 331-345, $1987 \mathrm{~b}$.

SWAINE, M.D.E D. LIEBERMAN. Note on the calculation of mortality rates. Journal of Tropical Ecology v.3, p. ii-iii, 1987.

SZWAGRZYK, J. Natural regeneration of forest related to the spatial structure of trees: A study of two forest communities in Western Carpathians, southern Poland. Vegetatio, v. 89 , p. $11-22,1990$.

TORIOLA, D., CHAREYRE, P. E A. BUTTLER. Distribution of primary forest plant species in a 19-year old secondary forest in French Guiana. Journal of Tropical Ecology, v. 14, p. 323- 340, 1998.

WHITMORE, T.C. Gaps in the forest canopy. In: TOMLINSON, P.B. \& ZIMMERMAN H.M. (Ed.). Tropical trees as a living systems. Cambridge: Cambridge Univ. Press. 1978. p. 639-655.

ZAR, J.H. 1984. Bioestatistical analysis. New Jetsey:Prentice Hall, 1984. 
Anexo 3.1 - Taxa de mortalidade (me), meia vida $\left(t_{(0,5)}\right)$, taxa de ingresso (i) e taxa de crescimento (Tx. cresc.) para as espécies mais comuns no trecho de floresta ribeirinha amostrado (que apresentaram 10 ou mais indivíduos nas duas amostragens).

\begin{tabular}{|c|c|c|c|c|}
\hline nome & $\%$ me & $t_{(0.5)}($ anos $)$ & $\% \mathrm{i}$ & Tx cresc. (cm/ano) \\
\hline Acacia polyphylla & 3,74 & 18,54 & 0 & - \\
\hline Actinostemon klotzchii & 0,91 & 76,10 & 4,30 & 0,07 \\
\hline Allophylus edulis & 8,59 & 8,07 & 1,59 & - \\
\hline Calliandra tweediei & 5,47 & 12,67 & 2,23 & - \\
\hline Callisthene minor & 1,56 & 44,31 & 0,44 & 0,19 \\
\hline Calyptrantbes concinna & 0,60 & 115,38 & 1,63 & 0,11 \\
\hline Campomanesia gua zumifolia & 0,89 & 77,94 & 0 & - \\
\hline Campomanesia xanthocarpa & 3,20 & 21,68 & 0 & 0,06 \\
\hline Cariniana estrellensis & 1,17 & 59,21 & 1,06 & - \\
\hline Casearia sylvestris & 0,89 & 77,94 & 0,00 & 0,15 \\
\hline Centrolobium tomentosum & 0,79 & 87,30 & 0,00 & 0,22 \\
\hline Chrysopbyllum gonocarpum & 0,89 & 77,94 & 1,21 & 0,13 \\
\hline Copaifera langsdorfii & 0,97 & 71,70 & 0 & 0,26 \\
\hline Couratea bexandra & 4,91 & 14,12 & 0 & - \\
\hline Dalbergia brasiliensis & 0,44 & 159,06 & 0,42 & 0,06 \\
\hline Diatenopteryx sorbifolia & 0,18 & 377,41 & 0,36 & 0,24 \\
\hline Eugenia blastantha & 1,40 & 49,40 & 1,41 & 0,10 \\
\hline Eugenia racemulosa & 0,82 & 84,18 & 1,48 & 0,08 \\
\hline Eugenia uniflora & 4,03 & 17,19 & 0 & 0,27 \\
\hline Eugenia pyriformis & 0 & - & 1,06 & 0,08 \\
\hline Galipea multiflora & 1,17 & 59,21 & 2,92 & - \\
\hline Lafoensia pacari & 5,39 & 12,85 & 0 & - \\
\hline Machaerium nictitans & 1,31 & 52,96 & 0 & 0,14 \\
\hline Macbaerium stipitatum & 1,63 & 42,55 & 0 & 0,12 \\
\hline Matayba elaeagnoides & 2,30 & 30,19 & 0,29 & 0,14 \\
\hline Maytenus robusta & 1,17 & 59,21 & 1,06 & - \\
\hline Metrodorea nigra & 1,15 & 60,10 & 1,46 & 0,15 \\
\hline Myrcia rostrata & 1,08 & 63,89 & 1,90 & 0,11 \\
\hline Neomitranthes glomerata & 0,57 & 121,62 & 2,03 & 0,08 \\
\hline Rudgea jasminoides & 1,71 & 40,47 & 2,16 & 0,11 \\
\hline Sebastiania serrata & 1,82 & 38,12 & 2,60 & 0,10 \\
\hline Terminalia triflora & 1,31 & 52,96 & 0 & - \\
\hline Trichilia catigua & 0,62 & 112,26 & 1,14 & 0,12 \\
\hline Trichilia pallida & 0 & - & 1,71 & 0,26 \\
\hline Syagrus romanzoffiana & 0 & - & 0 & 0,13 \\
\hline
\end{tabular}




\section{CAPÍTULO 4}

\section{CONCLUSÕES GERAIS}

Em nove anos houve um aumento da densidade de indivíduos na área amostrada, relacionado ao balanço positivo entre ingresso e mortalidade. A área basal total e riqueza também aumentaram. A diversidade diminuiu em função da diminuiçào da equidade, causada principalmente pelo aumento na dominância de Actinostemon klotzcchii.

Em relação às espécies mais importantes, $A$. klotz̨chii e Sebastiania serrata apresentaram aumento da maioria dos parâmetros fitossociológicos. Matayba elaeagnoides, Calisthene minor e Eugenia blastantha tiveram uma pequena diminuição na maioria dos parâmetros. Porém, estas variações não pareceram ser significativas, pois não representaram alterações na estrutura fitossociológica desta comunidade.

Os indivíduos apresentaram-se agrupados até $5 \mathrm{~m}$ de distância e estes grupos distribuídos de forma aleatória, o que pode indicar o desenvolvimento de indivíduos em sítios ou habitats mais favoráveis. As mortas apresentaram distribuição aleatória e as ingressantes agrupada.

Não houve alterações no padrão de distribuição espacial na área amostrada, indicando estabilidade para a comunidade em 9 anos.

Houve diferenças entre os grupos vegetacionais em cada tipo de solo, quanto à estrutura fitossociológica e os parâmetros de dinâmica, indicando que as diferenças ambientais encontradas entre estas áreas são determinantes para suas características vegetacionais. 
O grupo vegetacional sobre o solo Aluvial, localizado às margens do rio, foi o que apresentou os maiores valores de densidade, área basal, riqueza e diversidade. Em 9 anos a área basal aumentou bastante, em função das altas taxas de crescimento Pela alta taxa de mortalidade, a densidade e a riqueza diminuíram. Apresentou distribuição agrupada à distâncias de até $2 \mathrm{~m}$, sendo estes grupos distribuídos de forma aleatória. Estas caracteristicas estão diretamente relacionadas à influência do curso d'água, por ser uma área de maior luminosidade (crescimento), e que pode modificar a paisagem na época das cheias, provocando desde desbarrancamentos (mortalidade), até deposição de sedimentos (crescimento) e retirada da camada de serapilheira (agrupamento em função de áreas mais férteis).

O grupo vegetacional sobre o solo $\mathrm{AQ} / \mathrm{Cb}$ apresentou menores valores de diversidade, relacionado aos menores valores de equidade e riqueza. Houve aumento em 9 anos da densidade relacionado às baixas taxas de mortalidade e altas taxas de ingresso. A área basal também aumentou, em função do aumento de densidade, pois o crescimento foi baixo e constante entre as classes de diâmetro. Ocorreu um pequeno aumento na riqueza, mas a diversidade diminuiu em função da diminuição da equitatividade (causada pelo aumento na dominância da $A$. klotżchiz). A distribuição espacial dos indivíduos foi aleatória tendendo à regularidade, o que poderia ser indício de competição entre os indivíduos, no caso, por nutrientes (trata-se de um solo recente). Estes fatores podem estar indicando que esta vegetação ainda está em fase de desenvolvimento.

$\mathrm{Na}$ área do grupo vegetacional sobre o solo PV ocorreram os menores valores de densidade e área basal. A área basal diminuiu bastante, em função da baixa taxa de crescimento e do balanço negativo entre ingresso e mortalidade. Apenas a riqueza aumentou de valor. O padrão espacial foi aleatório tendendo para o regular, o que também pode indicar competição entre os indivíduos, que no caso seria por espaço. A declividade parece ser um fator restritivo nesta área.

Nos grupos vegetacionais identificados na área fora da interferência do curso d' água, sobre solos $\mathrm{AQ} / \mathrm{Cb}$ e $\mathrm{PV}$, percebe-se que tanto a topografia como as características edáficas são fatores determinantes do padrão de distribuição espacial, da estrutura e da dinâmica de seus indivíduos, na floresta ribeirinha do Rio Passa Cinco. 
O grupo vegetacional sobre o solo Aluvial, com interferências diretas do curso d'água, apresentou características que devem estar estritamente relacionadas com a dinâmica das cheias do rio, o que condiciona características ambientais diferenciadas no tempo e no espaço. $\mathrm{O}$ rio, considerado como um fator de perturbação nas faixas ribeirinhas, deve ser entendido como um elemento de manutenção da diversidade e heterogeneidade nestas áreas. 